\title{
RELATION OF AUXIN METABOLISM TO THE ROOTING OF TEA
}

By

RAUL H. FIGUEROA

\begin{abstract}
A DISSERTATION PRESENTED TO THE GRADUATE COUNCIL OF THE UNIVERSITY OF FLORIDA IN PARTIAL FULFILLMENT OF THE REQUIREMENTS FOR THE DEGREE OF DOCTOR OF PHILOSOPHY
\end{abstract}

\section{UNIVERSITY OF FLORIDA}

December, 1966 


\section{ACKNOWLEDGMENTS}

The author wishes to express his indebtedness and sincere appreciation to Dr. R. H. Biggs, Associate Biochemist, Department of Fruit Crops, for serving as Chairman of the Supervisory Committee and for his close and continuous supervision during the course of studies and guiding the research program and the preparation of this dissertation. Appreciation is also extended to Dr. A. H. Krezdorn, Professor and Head of Fruit Crops, Dr. J. Soule, Associate Professor of Fruit Crops, Dr. T. E. Humphreys, Associate Biochemist, Department of Botany, and Dr. H. L. Popenoe, Director of the Center for Tropical Agriculture, University of Florida, for serving as members of the Committee. The author is also grateful to Dr. H. S. Wolfe, retired Professor of Fruit Crops, and Dr. L. A. Garrard, Research Associate, Department of Botany, for their constructive criticism of the presentation of this material; to Dr. H. N. Miller, Plant Pathologist, Department of Plant Pathology, for his help in photomicrogr ahy; and Mrs. Celia Lescano, for her technical help in the experiments reported in this dissertation.

With deep gratitude he acknowledges the financial assistance given by AID Program through North Carolina State University at Raleigh, Mission to Peru, and Servicio de Investigación y Promoción Agropecuaria del Peru, to carry out the entire program of studies at the University of Florida. 
TABLE OF CONTENTS

\section{Page}

ACKNOWLEDGMENTS .................., i i

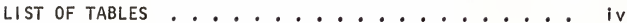

LIST OF FIGURES ................ vi vi

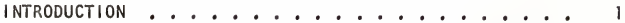

LITERATURE REVIEW ............... 3

MATERIALS AND METHODS ............. 23

EXPERIMENTAL RESULTS ........... 37

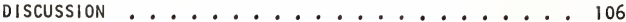

SUMMARY AND CONCLUSIONS ............. 112

LITERATURE CITED ..................... 115 


\section{LIST OF TABLES}

Table

Page

1. Comparison of rooting, number of roots, length of roots and callus formation on cuttings of Assam and Chinese types of tea as influenced by NAA and ethanol................... 38

2. Effect of NAA on rooting of Assam tea cuttings of different ages ..............

3. Distribution of $\mathrm{C}^{14}$ from alpha-labeled NAA in tea cuttings............... 54

4. Thin layer chromatography of pure $N A A-1-C^{14}$ and ethanolic extracts from NAA-1-C 14 treated tea stems

5. Radioactivity located in various tissue systems of tea 1 hour after treatment with $N A A=1-C^{14}$. . 57

6. Acropetal movement of $\mathrm{C}^{14}$ added to tea stems as NAA $-1-\mathrm{C}^{14} \ldots \ldots$

7. Basipetal movement of $C^{14}$ added to tea stems as $\mathrm{NAA}-\mathrm{I}-\mathrm{C} 4$....................... 60

8. Radioactivity in the respiratory $\mathrm{CO}_{2}$ from stem cuttings after treatment with $N A A-1=C^{14} . .$. .

9. A fomparison of trapping systems for respiratory $\mathrm{C}^{14} \mathrm{O}_{2}$ from cuttings after treatment with $\mathrm{NAA}-1-\mathrm{C}^{14}$

10. Recovery of $\mathrm{C}^{14}$ after the incubation of tea stem

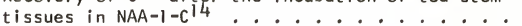

11. Radioactivity in the respiratory $\mathrm{CO}_{2}$ from intact $t$ issues and breis of tea treated with NAA-1-C 14 . 68 12. Radioactivity in the respiratgry $\mathrm{CO}_{2}$ of tea
tissues treated with $\mathrm{NAA}^{-1}-\mathrm{C} \mathrm{C}^{.} . .$.

13. Decarboxylation of $N A A-1-C^{14}$ by tissues of tea of different ages ............ 


\section{LIST OF TABLES (cont.)}

Table

Page

14. Effect of various concentrations of sucrose and casein hydrolyzate on the enzymatic destruction of NAA-1 $-\mathrm{C}^{14}$ by Assam tissue brei .......

15. Effect of dialysis and divalent cations on the evolution of $\mathrm{CH}_{4}$, from supernatant fraction of breis of tea treated with $\mathrm{NAA}^{-1-\mathrm{C}^{14}}$......

16. Amount of radioactivity leached from tea stems treated with NAA-1-C 14 during soaking in unlabeled NAA solution ...........

17. Influence of concentration of NAA on radioactivity in the ethanol extractable fraction and $\mathrm{C}^{14} \mathrm{O}_{2}$ fraction from tea-stems incubated in the solutions for 3 hours.............

18. Decarboxylating action on NAA-1-C 14 of acetonepowder extract from tea tissues at various times after preparing the extract .........

19. Effect of high temperature treatments on the capacity of the acetone powder extracts to decarboxyl ate NAA-1-C 14 ........

20. Effect of temperature and divalent cations on the evolution of $\mathrm{C}^{4} \mathrm{O}_{2}$ from dialyzed acetone powder extracts of Assam tea treated with NAA-

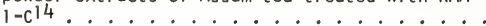

21. Decarboxylating activity on $N A A-1-C^{14}$ of the ammonium sulfate precipitable and nonprecipitable fractions of acetone powder extracts of tea............. 


\section{LIST OF FIGURES}

Figure

Page

1. Number of rooted cuttings of the Assam and Chinese types of tea at 4 and 8 weeks after treatment with NAA $(10,000 \mathrm{ppm})$, ethanol (50\%) and tap water ( 40 cuttings/treatment)..... 39

2. Average number of roots in cuttings of the Assam and Chinese types of tea at 4 and 8 weeks after treatment with NAA $(10,000 \mathrm{ppm})$, ethanol (50\%) and tap water (40 cuttings/treatment).... 40

3. Total length of roots $(\mathrm{mm})$ on cuttings of the Assam and Chinese types of tea at 4 and 8 weeks after treatment with NAA $(10,000 \mathrm{ppm})$, ethanol $(50 \%)$ and tap water (40 cuttings/treatment) . . 41

4. Rooting of Assam tea at 60 days after treatment . 4 ?

5. Rooting of the Chinese type of tea at 60 days after treatment........... 43

6. Effect of NAA on the rooting of Assam tea cuttings (200 cuttings per NAA treatment) ...... 46

7. Portions of cross-sectional $\left(C_{s}\right)$ views from the rooting zone at the base of stem cuttings of tea 48

8. Portions of cross-sectional $\left(C_{s}\right)$ views from the rooting zone at the base of stem cuttings of tea

9. Distribution of radioactivity in Assam and Chinese tea cuttings, treated as outlined in

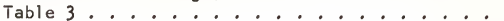

10. Radioactivity at the basal portion of Assam and Chinese tea cuttings, treated as outlined in

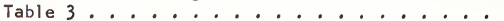

11. Thin-layer chromatography of NAA-1 $-\mathrm{C}^{14}$ and ethanolic extracts from NAA-1-C 14 treated tea stems.............. . 56

12. Transport of NAA-I-C $\mathrm{C}^{14}$ through stem tissues of Assam tea ................. 


\section{LIST OF FIGURES (cont.)}

Figure

Page

13. Transport of NAA-1-C $\mathrm{C}^{14}$ through stem tissues of the Chinese tea..............

14. Radioactivity in respiratory $\mathrm{CO}_{2}$ from tea stem cuttings treated with NAA-1 $-\mathrm{C}^{14^{2}} \ldots . . . .$.

64

15. The influence of $\mathrm{pH}$ on the activity of breis of Assam and Chinese tea cuttings as determined by the $\mathrm{C}^{14} \mathrm{O}_{2}$ evolved during the first 60 minutes

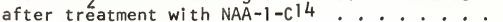

16. Rate of release of radioactivity by tea-stem explants, previously treated with various concentrations of NAA having a constant amount of NAA-1C 14 per concentration, by soaking in unlabeled NAA solutions .................

17. Autoradiogram of the TLC of fractions from an ethanolic extract of tea tissue treated with NAA$1-\mathrm{c}^{14} \ldots \ldots \ldots$

18. Autoradiogram of the TLC of an ethanolic extract of tea tissue treated with NAA-1-C 14 for varying lengths of time...............

19. Autoradiogram of the TLC of fractions from an ethanolic extract of tea tissue treated with NAA-

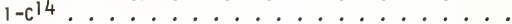

20. Autoradiogram of the TLC of fractions from an ethanolic extract of tea tissue treated with alanine-C ${ }^{14}$ plus cold NAA ..........

21. Autoradiogram of the TLC of fractions from an ethanolic extract of tea tissue treated with

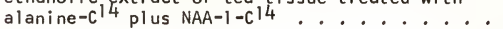

22. Autoradiogram of the TLC of fractions from an ethanolic extract of tea tissue treated with aspartic-c 14 plus cold NAA .........

23. Autoradiogram of the TLC of fractions from an ethanolic extract of tea $t$ issue treated with aspartic-c 14 plus NAA-1 $-\mathrm{C}^{14}$........ 100 


\section{LIST OF FIGURES (cont.)}

Figure

Page

24. Autoradiogram of the TLC of fractions from an ethanolic extract of tea tissue treated with glut ami $c-C^{14}$ plus cold NAA ........ 102

25. Autoradiogram of the TLC of fractions from an ethanolic extract of tea tjssue treated with

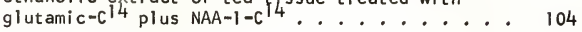




\section{NTRODUCTION}

of fundamental importance to an understanding of the auxin control of plant growth and morphogenesis is the promotion of root initiation in stems by these compounds. Since treatment of the basal portion of stemcuttings with auxin substantially increases the rooting of many plants $(25,36,37,96,107,153,159,175)$, it would seem that the physiological basis for the initiation of adventitious rooting may lie in the actual level of the auxin, native or applied, in the tissues $(25,32,36,37$, $47,55,71,73,78,156,159,171)$ or in a balance between auxin and certain other plant constituents $(27,33,68,76,77,92,136,142,144$, $158,167,176)$, particularly purine derivatives $(134,135,137)$.

The cellular site of action of axin is not known. Perhaps there is a direct effect of auxin at the site where rooting occurs $(27,32$, $78,96)$. Another possibility is that auxin stimulates mobilization of root-promoting substances from the leaves $(96,176)$. These substances would then presumably be translocated basipetally to the site of high cellular activity where the formation of adventitious roots takes place. In recent years evidence has accumulated that the uptake of auxins is a two-step process $(84,125)$. The first step is rapid and physical, probably simple adsorption. The second step is relatively slow, steady, more complicated, and appears to be of a metabolic nature. This information has bee: gleaned from uptake studies with intact plants, but data of this kind for cuttings are almost entirely absent. Moreover, although the effect of auxin on root formation is well defined $(32,73,91,96$, 
$107,119,153,179)$, very little is known of the relation between the fate of the auxin after it has entered plant tissues.and rooting. The present knowledge of the metabolism of some auxins, e.g., indoleacetic acid (IAA), shows that an oxidative degradation of this compound as well as conjugation with other compounds, occurred when it was administered to tissues which responded to its application $(3,4,5,6,7,21,50,64$, $87,101,102,115,117,118,123,124,129,154,170,185)$. Studies conducted to identify products of IAA oxidation and to investigate its pathways in metabolism, however, have yielded conflicting results (7, $87,102,115,151,185,186)$.

Considering the needs for research dealing with the physiological aspects of the effect of auxins on root initiation, and that a knowledge of the transport of auxins is essential to an understanding of the ways in which they serve to integrate the whole organism, the present study was designed to determine the relation between auxin uptake, accumulation, polar transport, and metabolism, and the rooting of tea (Camellia sinensis, (L.) 0. Kuntze. Tea was chosen as the experimental material because of the comparatively strong concentration of auxin needed to stimulate rooting and because of the differences in the rooting response of different types of tea to auxin. 


\section{LITERATURE REVIEW}

\section{Introduction}

This review is concerned primarily with the physiology of rooting. However, since structural features are of importance in understanding the physiology of rooting in cuttings, a brief review of the origin of adventitious roots in stems is included.

\section{Adventitious Root Formation on Stem Cuttings}

The origin of adventitious roots has been studied in many types of plants $(12,48,49,153)$. The results have shown that roots may occur on the hypocotyl of a seedling (73), at nodes and internodes of stems $(9,10,12,14,28,29,30,31,35,182)$, and on roots (10). It appears that they may arise either in connection with or independent of buds (10). They may be formed in young organs (embryos and intercalary meristems in Gramineae) (9) or in older tissues that have not lost their meristematic potentialities $(9,31,121,153)$.

Most adventitious roots arise endogenously, although examples of exogenous origin are also known (30). Adventitious roots may arise from pre-existing primordia which have remained.dormant until stimulated to growth (31), or they may be from new formations (153). The subject of adventitious root formation in cuttings has been explored most extensively in connection with the stimulation of rooting by growth-promoting substances $(31,153)$.

Adventitious roots usually are initiated in the vicinity of the differentiating vascular tissues of the organ which gives rise to them 
$(121,153)$. If the organ is young, the adventitious primordium is initiated by a group of cells near the periphery of the vascular system but in older organs, the seat of origin is often located near the vascular cambium (121). In young stems, the cells forming the root primordia are commonly derived from the interfasicular parenchyma while in older stems they are derived from a vascular ray (150). At other times, the adventitious roots appear to be initiated in the cambial zone (138). Often the seat of the first divisions forming a root primordium in the stem is identified in the literature as pericycle (49). In many stems the region formerly defined as pericycle is, by origin, partially primary phloem, and partially interfasicular parenchyma between two strands of primary phloem. Some authors specifically state that adventitious roots arise in the phloem region $(130,138)$. However, variations in the origin of adventitious roots may be found within the same plant (181)

The origin of adventitious roots in the interfasicular region, in vascular rays, and in the cambium places the young root close to both xylem and phloem of the parent axis and apparently facilitates the establishment of vascular connections between the two organs. Before the adventitious root emerges from the stem, it differentiates a root cap and the usual tissue systems found in the body of the root (49). This differentiation is similar to that observed in the formation of lateral roots but in neither case has the formation of the vascular connection with the parent axis been critically studied. When vascular elements differentiate in the adventitious root, the parenchyma cells, or other cells located at the proximal end of the primordium, 
differentiate into vascular elements and provide the vascular connection between the main axis and the initiating organ. Adventitious roots originating in relatively old stems may grow obliquely through the outer tissues of the stem, probably as a result of the resistance offered by sclerenchyma in the phloem or just external to it (12). Poor rooting capacity of certain kind of plants has been related to a high degree of sclerification (12). It is obvious that if a correlation exists between the degree of sclerification of the primary phloem and rooting capacity, the rooting of difficult subjects might be facilitated by using very young shoots, taken before the cells of the primary phloem system become lignified.

It has long been known that the formation of callus and the formation of roots are independent of each other. In 1898, Corbett, as quoted by Smith (138), presented evidence that callus tissue was not concerned with production of roots and further stated that "the root takes its origin in, and is an extension of, the active formative material of the cambium layer in woody materials such as grape and currant."

Callus growth (74), an irregular mass of parenchyma cells in various stages of proliferation, generally arises from cells in the region of the vascular cambium and adjacent phloem, although various cells of the cortex and pith may also contribute to its formation. Frequently, the first roots penetrate through callus, leading to the belief that callus formation is essential for rooting.

As will be discussed later, the relation of auxin and other factors to callus growth is different from the relation of these substances to root initiation and growth $(8,13,23,24,25,27,37,59,89,90,132$, 
$175,176,180)$. This lends support to the idea arising from histological $(32,62,73)$, morphological $(121,130,142,150,153)$, and gross observations $(74,79,113,153)$ on rooting that optimum conditions for good callusing may not be optimum conditions for good rooting.

\section{General Consideration of the \\ Physiology of Rooting}

The physiology of root formation in cuttings has been reviewed by Burstrom (25), Mitchell and Marth (107) and the importance of auxins has been recognized. These growth substances were originally shown to be involved in rooting by Went (175), using etiolated pea epicotyls.

The name rhizocaline was first suggested (74) for a rooting substance produced by the leaves in the presence of light and translocated to stems and roots. This substance, not considered a plant nutrient, was thermostable. Also, it was stored in cotyledons and buds and its transport was basipetally polar. The activity of this compound in forming roots followed auxin activity through all stages of chemical testing (179). It was concluded that the root-forming substance was either identical with, or closely related to, an auxin. Shortly after this report indole-3-acetic acid (IAA) was identified as a naturally occurring compound, having considerable auxin activity in cultures of Rhizopus (155). Thus, it was logical to assume that IAA was involved in rooting. Confirmation came with the proof (158) that synthetic IAA was as active in root formation as the natural auxin-containing Rhizopus preparation. In this way, it was shown that at least one of the substances causing root formation was an auxin. 
Synthetic IAA $(36,158)$ was tested further for its activity in promoting root initiation in cuttings, and in 1935, the practical use of this material in stimulating the rooting of stem cuttings was demonstrated. In this same year, it was shown that naphthaleneacetic acid (NAA), indolebutyric acid (IBA), and other aromatic acids were also active in promoting adventitious rooting in cuttings (190). Experience has since proved that NAA and IBA have been, in general, the most effective for stimulating rooting in cuttings of many plant species $(25,26,42$, $107,113,142,165,187)$, although other auxins do have activity in this regard $(23,25,36,75,96,159)$.

The physiological basis for the initiation of adventitious root primordia may lie in the actual level of the auxin in the tissues (57) or in a balance between auxin and certain other constituents. It has been shown $(134,135,137)$ that in segments of tobacco stems, when the auxin concentration is relatively high, formation of adventitious roots will be favored but bud formation prevented. When other plant constituents, such as adenine or kinetin (6-furfuryl adenine), are relatively high, bud formation is suppressed. When both auxin and adenine are present in nearly equal proportions, cell proliferation (callus) occurs but with little cellular organization (137). This does not mean that other factors do not influence rooting. It has been shown that the type of cutting or explant $(31,53,54,71,76,79$, $92,134,144,145,168)$; environmental conditions of light $(54,79,90$, $92,144,160,168,191)$, temperature $(44,54,71,76,79,90,92,144$, 191), moisture $(71,79,90,92,144,191)$, gases $(188,189)$, and rooting media $(71,79,90,92,144)$; vitamins (77); isolated chemical factors other than auxins $(167,176)$; and content of substrate materials in 
the tissues $(59,79,90,134,144,145,153,176)$ also affect root development. Many of these factors are thought to have only a secondary influence on rooting through an effect on auxin and cell division factors related to rooting (96).

In some cases $(100,137,179)$ it has been observed that very high concentrations of auxin are needed to hasten rooting. This could be due to poor uptake, translocation and accumulation, or a rapid rate of metabolic change of the compound to non-auxinic components, as has been found for other systems influenced by auxins (uptake: 2, 17, 40, 41, 52, $84,133,140,146,163,172,183,184$; translocation and accumulation: $22,38,39,52,61,63,70,72,81,95,99,103,104,109,139,146$, 152, 163, 166, 172, 173, 178, 183; metabolism: 3, 4, 5, 6, 7, 8, 18, 43, $50,51,52,56,57,58,60,64,65,67,78,93,101,102,108,112,115$, $117,118,123,129,143,149,151,154,161,170,174,185,186)$. Yet, a need for a higher than usual level of auxin might also be due to the higher content of certain compounds, such as phenols, in the cuttings which could interfere with oxidative phosphorylation and the related metabolism needed for cell division (120).

In other cases $(25,76,96)$, it has been observed that very low levels of auxin are needed to promote rooting. Here, active uptake, rapid polar translocation and stability of auxin in the system may contribute to this response (96). Moreover, the tissues may contain substances which act synergistically with auxin on rooting $(68,69)$, or they may contain auxin-sparing compounds $(20,85)$, or the metabolism of the tissue may be in a state in which only auxin is the limiting factor (25).

In plant cells, a multitude of chemical and physical changes have been observed following auxin treatment, none of which have yet been connected with the subsequent growth of the cell (58). Auxin apparently 
acts on the protoplasmic systems. This action leads to an altered arrangement of cell wall components $(23,25)$, which in turn leads to greater extensibility of cell walls (25). Among other effects noted are decreases in cytoplasmic viscosity (56), an increased oxygen consumption (18, 45), altered permeability patterns $(162,169)$, altered nucleic acid metabolism (137), and altered carbohydrate $(105,147)$ and organic acid metabolism $(114,141)$. It is also worthy of note that tissues of different ages respond differently to auxin (122).

\section{Uptake of Auxins by Cuttings}

The study of the uptake of auxins in cuttings is of great interest in connection with the established fact that these substances hasten and facilitate the formation of adventitious roots on various plants. It may also permit an approach to the clarification of certain physiological effects. It should be noted that much attention has been given to the absorption of auxins by intact plants, but few workers have investigated auxin uptake in detached parts of woody plants.

Preliminary experiments (53) with leaf-bud cuttings of tea in the summer of 1964 indicated relatively high concentrations of NAA are required.to obtain good rooting in tea. Additional preliminary experiments in the early spring of 1965 involving the treatment of softwood tea cuttings with NAA showed that root production was greatly increased with $5,000 \mathrm{ppm}$ of the auxin. A further desirable effect was the inhibition of bud growth during the root-production stage.

Skoog (133) reported that the uptake of auxin by the roots of tomato plants was proportional to the concentration supplied in the external solution over a wide range of concentrations. Various factors 
such as rate of transpiration, $\mathrm{pH}$, and concentrations of salts influenced the uptake of auxin from the external solutions. Albaum, Kaiser, and Nestler (2), who studied the effects of $\mathrm{H}$-ion concentration on the penetration of IAA into Nitella cells, found that the curve representing the velocity of penetration as a function of $\mathrm{pH}$ coincided with the dissociation curve for IAA. They concluded that this substance entered the cells in the form of undissociated molecules, and considered that diffusion fully accounted for their observations. Sutter, as quoted by Reinhold (125), conducted a study of the uptake of IAA by the tissues of a higher plant. Experiments with submerged Cucumis hypocotyls led her to conclude that the uptake of auxin from the medium was solely the result of diffusion into the tissue. Her evidence, however, was not entirely conclusive.

Cooper (37), using 'Eureka' lemon and 'Delicious' apple stem cuttings, some of which had been treated at the apex and some at the base with IAA, found large amounts of auxin in the bark immediately after treatment, but about 90 per cent of the auxin disappeared from the tissue during the first day. Very little auxin was recovered from the bark at the apex of cuttings which had been treated at the base with $0.001,0.005$, or 0.02 per cent solutions of IAA. Moderate amounts of auxin were recovered from the base when the cuttings were treated at the apex with these solutions; however, with the 0.02 per cent solution, the amount recovered at the base was small when compared to that at the apex. Also the 0.02 per cent solution applied at the base of lemon cuttings was the only treatment of those tested that gave a significant increase in root formation over the controls. There was little difference 
in the amount of auxin recovered from treated apple and lemon cuttings, yet the apple cuttings did not form roots with any of the solutions tested.

As shown by numerous workers $(11,17,84,125,133,166,172)$, the uptake of auxin may be quite complicated. Reinhold (125), studying the uptake of IAA by pea-epicotyl segments and carrot disks, concluded that uptake was not a simple diffusion process. She maintained that two processes, or groups of processes, appeared to be involved, one physical and the other metabolic. Johnson and Bonner (84) reported that the uptake of labeled 2,4-dichlorophenoxyacetic acid $(2,4-D)$ by Avena coleoptile tissues consists of three separate processes. The first, completed in 20-30 minutes, resembled a diffusion into the tissue in the sense that 2,4-D taken up by this process was readily leached to the outside solution. The second, also a rapid process, resembled a physical binding since 2,4-D could be removed by exchange with unlabeled 2,4-D. The third phase of $2,4-D$ uptake was a continuing adsorption, maintained at a steady rate for several hours, with accumulation by the tissue to a concentration higher than that in the external medium. Both the exchangeable binding and the continuing uptake of 2,4-D were inhibited by the presence of a high concentration of a second auxin, e.g., IAA. Uptake of 2,4-D was influenced less by this substance, however, than was growth of the coleoptile induced by 2,4-D.

Andreae and van Ysselstein (4) observed that the fate of IAA applied externally to pea epicotyls differed from that of IAA which was already in the tissues. When IAA was taken up from solution, only about 20 per cent of the IAA which disappeared from the solution could 
be accounted for as Salkowski-reactive material in the tissues. These substances were chiefly IAA and indoleacetylaspartic acid. Their relative amounts depended upon the concentration of applied IAA with very little or no free IAA detected when low concentrations were used. Turetskaya (163) reported that NAA was absorbed in cuttings of different plants to varying degrees. In cherry cuttings, which root with greater difficulty than those of black currant or balsam, absorption of NAA was relatively weak. Labeled NAA was absorbed in the cortical zone of cherry cuttings and only at the beginning of rooting was $c^{14}$ observed in other stem tissues. NAA penetrated into all stem tissues of black currant cuttings directly after treatment and persisted there up to a stage of good rooting. Fang and Butts (50), working with carboxyl- $-C^{14}-1$ abeled IAA in bean plants, showed that only 10 to 14 per cent of the $c^{14}$ activity was absorbed and transported to the other parts during a 14-day experimental period. Strydom and Hartmann (146) observed no difference in the amount of IAA taken up by leafy and leafless plum stem cuttings treated with IAA by dipping.

Auxin uptake from solution by whole plants or cuttings is increased by a high transpiration rate, which in turn is promoted indirectly by strong light. Thimann and Wardlaw (160) concluded that high-intensity light greatly promoted the accumulation of IAA in green tissues. Wetting agents, a low pH, and an oil/water partition coefflcient in the direction of oil are all influencing the uptake of auxins favorably (166). The effect of $\mathrm{pH}$ on uptake of auxin was similar to that found for other organic acids (131). 
Translocation and Site of Accumulation of Auxins

A principal factor molding the morphology and physiology of higher plants is the correlative influence of auxin. Inherent in the correlative effects of auxin is the mode of transport of auxin. The transport system for auxin not only establishes the distribution pattern of auxin throughout the plant, but provides a powerful vector in the forces establishing the polarity of plant growth and development (97).

As a feature of plant development, the active transport of auxin is especially interesting because it causes more or less polar distribution through plant organs, providing a basis for hormonal influences by one part of the plant on another part (96). Thus, in respect to the relation between root and shoot formation, the initial differentiation of meristematic tissue is determined, at least in part, by the local concentration of auxin; shoots developing at lower and roots at higher concentrations (113).

With the advent of isotopic tracer methodology $(19,46,152,157$, $163,166,183)$ and techniques for the fractionation of minute quantities of a compound from a mixture $(66,88,127,128,164)$ research on uptake, distribution, and utilization of auxins has taken on added significance.

It has been established by means of many experiments $(81,82,109$, 177) that the translocation of native auxins is strongly polar. The first investigation along this 1 ine was done by Went (178) . In subsequent experiments by others (190) it was shown that synthetic auxins were capable of translocation not only from top to bottom, but al so from bottom to top. Hitchcock and Zimmerman (80) observed that when indole and naphthol compounds in crystalline form were introduced 
into the soil, they entered the roots and were translocated throughout the entire plant. These substances caused a vigorous development of roots along the entire stem, curvature of stems, and epinasty of the leaves in tomato and tobacco plants.

Plant (119) observed the formation of roots on the top ends of root cuttings of ocean cabbage (Crambe maritima) when these were treated with a solution of IAA $(0.01 \%)$. Treatment of the apical ends of such cuttings with a high concentration of NAA $(0.02 \%)$ gave rise to root formation along the entire cutting and greatly retarded shoot formation. In order to decrease the content of auxins in the cuttings, a frequent decapitation was performed on the apex and the base. This resulted in the formation of roots first at the base, then at the apex.

The disruption of polarity in the formation of roots and shoots on cuttings with the aid of auxins was also demonstrated by Zimmerman and Hitchcock (189) and Went (177). In Zimmerman and Hitchcock's experiments, cuttings of marshmallow (Althaea), minus shoots and treated with vapors of indole and naphthol compounds, developed roots not only at the base of the cutting, but also in the middle and on the tip. Went (177) succeeded in getting roots on the tip, and side shoots at the base, of African marigold (Tagetes) stem cuttings by treating them with a solution of IAA (0.01\%). In this case, according to Went (177) a high concentration of auxin caused the appearance of roots, whereas a low concentration of these substances favored shoot development. Such an effect of auxins has been explained thus, that these substances, as Mitchell and Stuart (106) suggested, promote the influx of food materials to their places of use, and consequently roots develop more rapidly. Thus, it 
cipeors that one role of auxins in estabiishing a poiarity of rooting on cuttings depends upon the disturbance of the usual translocation of substances. As is weil known, girdling has a similar effect.

There is cumulative evidence that different auxins are metabolized differently by different cells and tissues of a plant $(1,47,86,142$, 184, 186). For example, phenoxy compounds seem to enter and move in the symplast, and they appear to be immobilized in living parenchyma tissues, as are food reserves (24). This may place a definite limitation on the extent of their movement from a given source. On the other hand, there is evidence that auxin transport is an active transport (96). It is specific for IAA and oniy a few synthetic auxins (97, 103, 173); it depends on metabolic forces, as evidenced by its sensitivity to metabolic inhibitors $(45,110)$; it is specifically inhibited by various sulhydryl-inactivating compounds, and reaches maximal inhibition with the trichlorinated phenoxyacetic acids. Nieciergang-Kamien and Leopold (111) mentioned in this respect that the transport-inhibition affects may be related to adsorptive or chemical interference at some transport site of attachment.

Turetskaya (163) followed the distribution of $1^{131}$ in softwood and hardwood cuttings of various species treated with $1^{131}$-labeled p-iodophenoxyacetic acid, In hordwood cuttings, the maximum accumulation of 131 eccurred in the base of the stem where the roots were formed. Decreasing amounts of $1^{131}$ were found in xylem, bark, and buds, in that order. Turetskaya (163) followed the movement of NAA labeled in the carboxyl position with $\mathrm{C}^{14}$ in leafy cuttings of balsam, cherry, and currant. In cherry cuttings, 15 hours after treatment, $\mathrm{C}^{14}$ appeared in 
the areas of treatment or else a bit higher on the stem, while at the same time in the easily rooted cuttings of currant and balsamine, NAA had entered not only the area of treatment, but had been transported a good distance along the stem and had even penetrated into the leaves. Also, Strydom and Hartmann (146), using IAA with labeled $C^{14}$ at 4,000 ppm in plum stem cuttings, found movement of the auxin in both acropetal and basipetal directions. In leafy cuttings the radioactivity was distributed throughout the entire cutting 24 hours after treatment.

Although the existence of polar auxin transport through plant tissues was established by Went (179), the mechanism of this movement remains unknown. If one could determine what physical conditions, metabolic states, and chemical reactions in plants are necessary for auxin transport, the problem would be well on its way to clarification.

Metabolism of Auxins in Stem Explants

Although the effects of application of auxins on morphological features of plants are well defined, very little is known of their fate after they have entered the plant tissues, especially as related to physiological responses. It can be said (94) that the plant has enzymes capable of disposing of native auxins by several means, but the relative importance of the formation of complexes, the formation of bound auxins, and the degradation of auxins in the plant are not well known.

The type and magnitude of responses obtained with auxins would depend upon the amount of the compound absorbed by the plant, the amount translocated within the plant, detoxification reactions, and the ability of the plant to respond to the amount of the particular 
chemical that becomes present at the site of action, a factor which is still unknown.

In 1934 Thimann (157) suggested that some plant tissues could cause the disappearance of natural auxins. Since then many mechanisms have been suggested to explain enzymatic oxidation of IAA by plant extracts or purified enzymes $(115,116,123)$. However, as noted by Briggs et al. (21), there are conflicting results between data from plant extracts and from partially purified enzyme preparations. Tang and Bonner (154) separated an enzyme system from peas which carried out the oxidative degradation of IAA. Andreae and Good (3), working with pea stems and roots, observed the exogenous IAA was largely converted in the tissue into an ether-insoluble substance which gave a characteristic stable color with Salkowski reagent and was not affected by the IAA oxidase of peas. This substance was identified as indoleacetylaspartic acid (IAAspA). The mechanism of formation of IAAspA appears to be Iinked to respiration, as its production ceased in absence of oxygen (4). It is possible that the reaction may require the intermediate formation of an indole-acetyl coenzyme-A thioester, which then reacts with aspartic acid to give IAAspA by a process analogus to the formation of hippuric acid. Andreae and co-workers $(3,4,5)$, based on their previous results and the results of others (129, 154), suggested that the toxic action of IAA may be related to the accumulation of free IAA in the tissues, which appeared in turn to be related to the rate of IAAspA formation. Both IAAspA formation and growth became maximal at the same concentration of applied IAA (about $\left.0.6 \times 10^{-4} \mathrm{M}\right)$. With loive concentrations almost all the IAA found in the tissues was present as IAAspA. Only with the higher, grouth-inhibitory 
concentrations did free IAA accumulate in the tissues to any extent.

Andreae and van Ysselstein (6), studying IAA metabolism by roots, found that whereas tips of intact roots accumulated IAAspA at a rate considerably greater than did epicotyl segments, excised root tips almost entirely lost this ability. The addition of $\mathrm{Ca}^{++}$or certain other divalent ions in combination with sucrose completely restored the ability of roots to accumulate IAAspA but had no effect on this process in epicotyls. The disappearance of IAA from the tissues appears to be related almost entirely to its conjugative activity. It was found that the degradative and conjugative activities are more active processes in roots than in epicotyls. The conjugative activity has been observed to occur only in intact tissues, while in homogenized tissue extracts the IAA molecule was degraded by oxidative decarboxylation, ring opening, or both (123).

With the use of IAA labeled with $\mathrm{C}^{14}$, new methods have been developed to study the metabolism of auxin per se. First, the presence of $\mathrm{C}^{14}$ in the side chains (carboxylic groups) allowed the study of IAA decarboxylation $(50)$. Use of IAA labeled with $\mathrm{C}^{14}$ in the $-\mathrm{CH}_{2}$ - of its side chain gave more convincing indications of auxin enzymatic destruction $(115,148)$. Then, the availability of IAA labeled in the ring by $c^{14}$ (alpha-position) gave rise to new methods of measurement of IAA-oxidase activity $(115,124)$ and ring opening. Fang (51) studied the effect of light on the destruction of $|A A-|-C^{14}$ in kidney bean, pea, and corn plants. The rate of destruction of $\mid A A-1-C^{14}$ in bean and pea plants was greatly reduced during the first 12-hour period in the dark as measured 
by the production of respiratory $\mathrm{C}^{14} \mathrm{O}_{2}$, while the destruction of IAA in the corn plants was completely light-dependent.

Experiments with IAA labeled in the two position (alpha or methylene carbon) of the side-chain $\left(1 A A-2-C^{14}\right)$ have yielded different results but the systems were different. Stutz (149), using a purified enzyme system from Lupinus albus (L.), obtained no $\mathrm{C}^{14} \mathrm{O}_{2}$ production but recovered several labeled products. Andreae, Robinson and van Ysselstein (7) studied the metabolism of IAA in pea roots using IAA labeled in the side chain $\left(\mid A A-1-C^{14}\right.$ or $\left.\mid A A-2-C^{14}\right)$ and/or in the indole nucleus $\left(\mid A A-7 a-C^{14}\right)$. They found that IAAsPA was the only metabolite which accumulated in the tissues and that the products of IAA degradation occurred entirely in the culture solution. Three decarboxylated products were recognized, none of which gave a positive reaction with Salkowski or Ehrlich reagents.

Strydom and Hartmann (146), using cuttings prepared from Marianna2624 plum that were treated with alpha-labeled IAA, showed detectable amounts of radioactivity in the respiratory $\mathrm{CO}_{2}$ within 12 hours after treatment. Within 60 hours the respiratory $\mathrm{CO}_{2}$, precipitated as $\mathrm{BaC}^{14} 0_{3}$, yielded 675 net counts per minute. By the 7 th day this value had decreased to 42 net counts per minute. The respiratory $\mathrm{CO}_{2}$ still showed some radioactivity 30 days after treatment. Tissue slices of the same material metabolized $\mid A A-2-C^{14}$ very readily since appreciable amounts of $\mathrm{C}^{14} \mathrm{O}_{2}$ were detected within one hour after treatment. Homogenates prepared from both intact and autoclaved plum tissue showed an apparent destruction of IAA as measured by the Salkowski reaction. Peroxidase activity could only be demonstrated with the intact tissue. They concluded that the apparent destruction with homogenates was due 
to an interference of endogenous phenolic substances with the Salkowski reaction.

Geronimo, Catiin, and Maxie (60), studying the metabolism of IAA-2$\mathrm{C}^{14}$ to plum stem tissues, reported that the maximum $\mathrm{C}^{14} 0_{2}$ production from $I A A-2-C^{14}$ occurred between two and five days after treatment and was not the result of increased respiration and did not necessarily represent a peak in auxin destruction. Considerable $1 A A-2-C^{14}$ was metabolized prior to appreciable appearance of $\mathrm{C}^{14} \mathrm{O}_{2}$. In extracted fractions, over 70 per cent of the non- $\mid A A-C^{14}$ was in aromatic compounds. The low $\mathrm{C}^{14}$ content of organic acid and sugar fractions could be accounted for largely by quinic acid and a non-sugar unknown. Extraction for indole compounds of cuttings treated with $I A A-2-C^{14}$ yielded only IAA and an unident ified complex.

Troxler and Hamilton (161) studied IAA metabolism in geranium stem-callus cultures. The IAA supplied in the culture medium could not be detected after about 30 days, at which time growth stopped. When $\mid A A-2-C^{14}$ was supplied, two ether-soluble radioactive metabolites in addition to IAA were found in the callus tissue. One of these was tentatively identified as IAAsPA, based on color reactions and chromatography. Four other $\mathrm{C}^{14}$ ether-soluble metabolites were detected in the culture medium. Water-soluble components that were radioactive also increased in both the callus tissue and the culture solution after seven to 14 days. The methylene carbon of $1 A A-2-C^{14}$ was completely metabolized by the cultures and radioactivity disappeared after 30 days. $\mathrm{C}^{14} \mathrm{O}_{2}$ was detected as evolving from 15 or 28-day-old culture solutions when $I A A-1-C^{14}$ was added which indicated that IAA was degraded by extracelliular enzymes. 
Studies with auxin oxidase in tissues from cultures (143) showed that an extra cellular IAA-oxidase was excreted into the nutrient medium by root callus of spruce and pea, as well as by callus tissues of Parthenocissus tricuspidata induced by crown-gall infection (102). An IAA-inactivating enzyme from Ephedra callus (143) was found in both the tissue and the culture medium.

Klambt (87), studying the metabolic products of labeled IAA and benzoic acid supplies to wheat coleoptile tissue, observed at least eight reaction products formed from labeled IAA with a major product being identified as the IAA-glucose ester. Following separation on paper chromatograms, two other spots containing radioactivity remained at the origin which also gave positive tests as esters of IAA. Corresponding reaction products were also obtained from the benzoic acid. Klambt regarded the sugar esterification reactions as a detoxification mechanism but suggests the possibility that these compounds might also play a key role in the synthesis of cellulose.

The use of IAA labeled with $\mathrm{C}^{14}$ has made it possible to complete the degradation schemes of IAA by enzymatic processes as suggested by Tang and Bonner (154), and by Galston (56).

The formation of amino acid conjugates with auxin has also been studied with acids which do not occur naturally in plant tissues but are physiologically active auxins, such as NAA and 2,4-D, and with inactive acids such as benzoic. When pea epicotyls were incubated with labeled NAA, Zenk (185) observed an active uptake (inhibited in an $\mathrm{N}_{2}$ atmosphere and by chloramphenicol) of the NAA with up to 95 per cent of the accumulated acid being converted to the acetylaspartic acid 
derivative. The rate of formation of this compound could be increased by preincubation of the $t$ issues not only with NAA, but also with IAA, 2,4-D, or benzoic acid. These results suggested the existence of an L-aspartic acid acylase whose adaptive formation could be induced by pretreatment with any of the acids tried.

Sudi (151) also studied the pretreatment induction effect of a large number of carboxylic acids on the stimulation of complex formation between aspartic acid and labeled IAA or NAA, using a wider range of concentrations. He found that IAA, NAA, 2,4-D, and 2,3,6-triidobenzoic acid, all active as auxins, were effective in reducing the lag period of indoleacetylaspartic acid formation, while 2,4-dichlorophenoxyiso-butyric acid, 3,5-dichlorophenoxyacetic acid, benzoic acid, and trans-cinnamic acid (non-auxinic) were all ineffective. Sudi pointed out that compounds effective in reducing the lag period of the aspartic acid complexes are all active as auxins, while those that were not effective are not active, even though in some cases they were very closely related structurally to the effective acids. Although these acids varied greatly with respect to their ability to induce more rapid formation of the IAA-or NAA-aspartic derivatives, none of them affected the rate of total radioactivity uptake of the labeled auxins. 
MATERIALS AND METHODS

\section{Plant Material}

Clonal material from Camellia sinensis (L.) 0 . Kuntze of the Assam and Chinese types of tea was used. The former was difficult to root and the latter easily rooted under the conditions of these tests. Both clones were vigorous growers.

Material for the various tests were stem cuttings prepared from nine-month-old plants. These cuttings were made by severing the apical portion of the shoot at the site of the first fully expanded leaf, followed by a second cut about four inches down the shoot. The cuttings, with two to three leaves, were used immediately and not more than ten minutes elapsed between preparation of the cuttings and treatments. These cuttings were used to determine the degree of stimulation of rooting caused by NAA, the site of adventitious root formation, and NAA uptake, translocation and accumulation. For the studies on the possible polarity of auxin movement, the stem of the primary cutting was subdivided into 0.5 to 1.5 inch pieces. For studies with breis and extracts, only cutting of the primary stem was used.

In the treatments where materials were applied to the cutting by dipping, the basal one-inch of the stem was placed in a solution with or without addendum for ten seconds. The solution adhering to the surface of the cutting was allowed to evaporate; this usually required about five minutes. Cuttings to be used in short-term experiments were wrapped in moist filter paper. Cuttings for long-term experiments were 
placed in the greenhouse in a propagating bed of $(3: 1)$ perlite and peat, and subjected to mist in a system of five seconds on and 55 seconds off. The tests were conducted so a statistical analysis of variance could be applied to the data (34). There were four replications and ten cuttings per treatment.

In the experiment where the effect of auxin concentrations and type of cutting were studied, NAA at $0.0,300,1,000,3,000,10,000$, and 30,000 ppm were used. The two-leaf cuttings were made up as described above and divided in five groups according to their original position on the shoot. The cutting, made up from the apical portion of the shoot starting at the site of the first fully expanded leaf, was named as segment 1; the second portion, going down along the shoot, as segment 2, and so on.

\section{Anatomical and Morphological Techniques}

Concurrent with the above experiments, additional cuttings were made for periodic anatomical studies. After five days from the start of the treatments, samples of cuttings were collected daily. Determinations of the origin of root initials and the initiation of cell division were made by procedures outlined by Johansen (83) and Sass (126). The killing and fixing of the tissues were done with standard FAA. Crosssections of the stem were obtained by free-hand sectioning. After parlodion infiltration, staining was carried out with a combination of safranin-fast green. Photomicrographs of the preparations were made with Kodachrome II, using a Spencer microscope equipped with a Kodak camera having a blue filter. 
Techniques for Uptake, Translocation and Accumulation Studies

$\alpha$-Naphthaleneacetic acid labeled with carbon-14 in the carboxyl position (NAA-1-C $\mathrm{C}^{14}$ ) was used. This compound was obtained from Nuclear Equipment Chemical Corp., Farmingdale, N.Y., and $3.6 \mathrm{mg}$ contained 0.3 millicuries of $\mathrm{C}^{14}$ (specific activity, 0.16 millicurie per millimole). This material, plus enough unlabeled NAA to make a $10^{-3} \mathrm{M}$ solution of the auxin, was dissolved in $17.7 \mathrm{ml}$ of distilled water.

To test for absorption, translocation, and site of accumulation of the labeled auxin in the cuttings by autoradiographic procedures, samples of four cuttings each of the Assam and Chinese types of tea were taken at time intervals of one, two, four, and eight days. In each case, the cuttings were divided into 1-inch segments. Each sub-sample was fixed in FAA; cross-sectioned and median, longitudinal sectioned. Sections were mounted on slides covered with a thin mylar film. The sections covered by the thin film were placed next to no-screen, X-ray film to obtain autoradiograms of the tissues. Similar tests for chromatographic separation and radioactive detection by GM counting were conducted using 12 cuttings of each type of tea. Samples were taken at the following time intervals: $1,4,8,16$, and 24 hours, 4 and 8 days. The samples from each time were grouped as follows: 1) four cuttings were extracted in 80 per cent ethanol for 30 minutes and the extracts fractionated on Eastman thin-layer chromatogram sheets (Type K-301R2), using as solvent systems benzene-acetic acid-methanol, 1:1:1, v/v/v, and isopropanol-water, 8.5:1.5, v/v; and 2) eight cuttings were dried, ground, and placed in planchets to be counted with a Tracer-lab counter, 
model TGC-14 equipped with a GM thin-window tube, and with an automatic sample changer.

In order to determine grossly the site of accumulation of the $N A A-1-C^{14}$ stem pieces treated with NAA-1-C $C^{14}$ were divided into three portions: 1) epidermis and parenchymatous layer, 2) vascular system except the primary xylem, and 3) primary xylem and pith. Each portion was uniformly ground, dried in planchets and the activity counted as previously described.

Auxin movement in both acropetal and basipetal directions was determined using tea stem pieces 1.5 inches long. All determinations were conducted at room temperature $\left(\sim 25^{\circ} \mathrm{C}\right)$ in complete darkness for a duration of four hours. Small agar discs were formed by placing 1 per cent liquified agar into small glass tubing of $10 \mathrm{~mm}$ diameter, extruding the agar after solidification, and cutting it into discs $2 \mathrm{~mm}$ thick. Each agar disc contained NAA-1 $-C^{14}$ yielding $10,200 \pm 200 \mathrm{cpm}$. The donor and receiver discs were placed at opposite ends of sets of four segments that were kept in an upright position. In some sets, the basal ends of the cuttings were next to the donor blocks containing auxin, and in other sets, the apical ends were next to the donor blocks. To prevent auxin movement along the surface of the stem pieces, Dow Corning stopcock grease (silicone lubricant) rings were applied around the middle of the stem sections before the diffusion period began. Three replicated determinations of four stem sections were used for each treatment. After four hours of diffusion time, the samples were divided into three segments of $0.5 \mathrm{~mm}$ in each (apical, middle, and basal third), then dried, ground, and counted, as described previously. The ratio of 
basipetal to acropetal movement was estimated from the radioactivity detected in the stem pieces.

\section{Determination of Decarboxylation of NAA by Tissues of Tea}

Techniques of trapping and counting $\mathrm{C}^{14} \mathrm{O}_{2}$ : Measurements of $\mathrm{C}^{14} \mathrm{O}_{2}$ by scintillation were conducted using an EKCO Electronics Liquid Scintillator counter. Four different methods of $\mathrm{C}^{14} 0_{2}$ trapping were tested.

1) Hydroxide of Hyamine 10-X [p-(di i sobutylcresoxyethoxyethyl) dimethylbenzyl ammonium hydroxidel

Six samples (stem pieces) of $1 \mathrm{~g}$ fresh weight of each of the Assam and the Chinese types of tea were treated with NAA-1-C 14. After five minutes the samples were washed three times with distilled water and placed in $10 \mathrm{ml}$ beakers that were placed in $50 \mathrm{ml}$ Erlenmeyer flasks, sealed in a flow-system and covered with black cloth. Carbon dioxidefree air was passed over the cuttings, and the liberated $\mathrm{CO}_{2}$ was trapped directly in counting vials using $1 \mathrm{ml}$ of hydroxide of hyamine $10-x$. Once the absorption time of one hour at intervals of $1,8,16$, and 24 hours were completed, $9 \mathrm{ml}$ of a solution of PPO (2,5-diphenyl oxazole) at $3 \mathrm{~g}$ per $1,000 \mathrm{ml}$ of toluene were added and the radioactivity of the samples determined by scintillation counting.

\section{2) Sodium hydroxide}

Ten grams of stem tissue from each type of tea were treated with NAA-I $-C^{14}$ as described above and placed in two $10 \mathrm{ml}$ beakers. The beakers were affixed with modeling clay to the inner wall near the top of a brown $500 \mathrm{ml}$ bottle. Then $20 \mathrm{ml}$ of 10 per cent $\mathrm{NaOH}$ was pipetted 
into the bottom of the bottle, the system sealed, and the chamber covered with a black cloth. After 24 hours at room temperature (approximately $25^{\circ} \mathrm{C}$ ), an aliquot of the $\mathrm{NaOH}$ solution was used to determine the $\mathrm{C}^{14} \mathrm{O}_{2}$ present by using Bray's mixture (19) for aqueous solutions $[60 \mathrm{~g}$ naphthalene, $4 \mathrm{~g}$ PPO, $200 \mathrm{mg}$ 1,4-bis-2-(5phenyloxazoly1)-benzene (Scintillation Grade (POPOP) $100 \mathrm{ml}$ methanol, $20 \mathrm{ml}$ ethylene glycol, and p-dioxane to make one 1$]$ and liquid scintillation detection techniques.

\section{3) Potassium hydroxide}

This procedure was essentially the same as that used with sodium hydroxide except for the following modifications: Three $1 \mathrm{~g}$ samples of stem tissues and breis of each type of tea were placed in small plastic cups that were suspended by a piece of wire from the top of a vial, and the systems sealed and covered with black cloth. After an absorption period of one hour the samples were counted as described in the previous method.

\section{4) Paper-strip counting}

Three $1 \mathrm{~g}$ pairs of samples of each type of tea, treated as before, were placed in $1 \mathrm{ml}$ beakers and affixed to the bottom of a $50 \mathrm{ml} \mathrm{Erlen-}$ meyer flask. A strip of Whatman No. 1 chromatographic paper, $2 \times 4 \mathrm{~cm}$ in size was suspended from the top of the flask and the system completely sealed. Then $0.2 \mathrm{ml}$ of 10 per cent $\mathrm{NaOH}$ was injected onto the strip of paper by means of a hypodermic syringe and the strip allowed to trap $\mathrm{C}^{14_{0}} \mathrm{O}_{2}$ for one hour. The strips of paper were then removed, dried, and placed in counting vials and the radioactivity determined using Bray's mixture and liquid scintillation counting. 
Relative Comparison of the Amount of NAA-1-C 14

Decarboxylated, and that Retained by the Tissue

To carry out an analysis of NAA metabolites, $10 \mathrm{~g}$ of stem tissues

from Assam tea were taken for each of two replications. These were incubated in a $10 \mathrm{ml}$ solution of NAA-1-C $14(13,545,600 \pm 4,000 \mathrm{cpm})$ which was placed onto the bottom of $500 \mathrm{ml}$ brown bottles. A counting vial containing $0.1 \mathrm{ml}$ of 10 per cent $\mathrm{KOH}$ was affixed with modeling clay to the inner wall near the top of the bottle and the system sealed. After three hours of incubation at room temperature, the trapped $\mathrm{CO}_{2}$ was analyzed for $\mathrm{c}^{14}$ activity as described previously. Then the stem pieces were washed three times with 5 per cent ethanol and the washings added to the incubated solution and the total volume made to $30 \mathrm{ml}$. Then the tissues were extracted with 80 per cent ethanol, washed three times, and the ethanolic solution made to a total volume of $10 \mathrm{ml}$. Aliquots of the incubation and ethanolic solutions were analyzed for total $c^{14}$ activity.

The Effects of Heat on Decarboxylation

To test for non-enzymatic vs enzymatic destruction of NAA-1 $-C^{14}$ by the plant tissues, six samples (stem pieces) of $1 \mathrm{~g}$ fresh weight from each type of tea were placed in small cups. One-half of each lot was autoclaved for one hour at a pressure of $15 \mathrm{psi}$, and then the samples were treated with $25 \lambda$ of $N A A-1-C^{14}(10,000 \mathrm{cpm}$, approximately). After adding the $N A A-1-C^{14}$, the small cups containing the reaction mixture were affixed directly into the counting vials, which contained $0.1 \mathrm{ml}$ of 10 per cent $\mathrm{KOH}$. After one hour with the system completely sealed, the 
reaction mixture was removed and the radioactivity in the $\mathrm{KOH}$ was determined following the techniques described above.

Using this same procedure, $1 \mathrm{~g}$ of tea tissue, ground in $1 \mathrm{ml}$ of phosphate buffer was used. Six samples from each Assam and Chinese types of tea were divided in two lots. One lot was boiled for ten minutes and the other kept at approximately $25^{\circ} \mathrm{C}$ until both were checked for the capacity to decarboxylate NAA-1-C 14 .

Influence of $\mathrm{pH}$ on the Rate of Decarboxylation

To test the $\mathrm{pH}$ sensitivity of the breis from both types of tea, a mixture of $\mathrm{Na}_{2} \mathrm{HPO}_{4}\left(11.876 \mathrm{~g}\right.$ in one 1 of solution) and $\mathrm{KH}_{2} \mathrm{PO}_{4}(9.078 \mathrm{~g}$ in one 1 of solution) was used. The bre $i$ solutions were adjusted to the following $\mathrm{pH}$ values: $4.5,5.0,5.5,6.0,6.5,7.0$, and 8.0 using a Beckman $\mathrm{pH}$ meter, model G. After the treated samples had been sealed for one hour and the $\mathrm{C}^{14} \mathrm{O}_{2}$ trapped in $\mathrm{KOH}$, the radioactivity in the alkali was determined by scintillation techniques.

\section{Influence of the Buffer System on the Rate of Decarboxylation}

The effect of buffer on enzymatic activity at $\mathrm{pH} 6.8$ was tested with three different buffer solutions: Mcllvaine buffer (mixture of

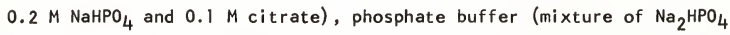
and $\mathrm{KH}_{2} \mathrm{PO}_{4}$ ), and $\mathrm{Trizma}-\mathrm{Tr}$ is buffer [(hydroxymethyl) aminomethane and hydrochloride, $7.925 \mathrm{~g} / 1$ liter ( $\pm 0.05 \mathrm{pH}$ units) ]. The first two buffers were adjusted using a Beckman $\mathrm{pH}$ meter and the latter controlled by temperature according to the specified directions of Sigma Chemical Co. 
Influence of Substrates on Decarboxylation

Two materials, sucrose and caseine hydrolyzate were tested as metabolites for enzymic action. Sucrose at $0.0,0.1,0.3,0.7,1.0$, and $2.0 \mathrm{M}$, and caseine hydrolyzate at 1,000, 3,000, 7,000, and 10,000 ppm were used. For these experiments, three $1 \mathrm{~g}$ lots of breis from each type of tea were used.

\section{Determination of Cellular Fractions with Decarboxylation Activity}

To study auxin decarboxylation of gross cellular fractions, breis of both types of tea were prepared using $60 \mathrm{ml}$ of phosphate buffer, $\mathrm{pH}$ 6.0 , containing $0.03 \mathrm{M}$ sucrose. The samples were centrifuged at 2,500 xg for ten minutes, using a Servall superspeed $\mathrm{R}-\mathrm{C}-2$ centrifuge. The supernatant fraction was centrifuged a second time at $10,000 \times \mathrm{xg}$ for 30 minutes and this supernatant fraction $\left(\mathrm{S}_{2}\right)$ was divided into three portions of $15 \mathrm{ml}$ each. A $15 \mathrm{ml}$ portion of the $\mathrm{S}_{2}$, and the precipitated pellet that was resuspended in $15 \mathrm{ml}$ of phosphate buffer and sucrose were treated with $100 \lambda N A A-1-C^{14}$. The $C^{14} 0_{2}$ evolution during an hour period was determined using $\mathrm{KOH}$ trapping and scintillation techniques.

The second and third 15-ml portions of the supernatant were kept under refrigeration and tested for the capacity to decarboxylate NAA after 48 and 96 hours, respectively.

\section{Influence of Dialysis on the Decarboxylation Activity}

Using $50 \mathrm{ml}$ of an $\mathrm{S}_{2}$ fraction of samples processed in the manner given above, the influence of dialysis at $4^{\circ} \mathrm{C}$ for 36 hours against three $100-\mathrm{ml}$ portions of phosphate buffer at $\mathrm{pH} 6.0$ and containing $0.03 \mathrm{M}$ 
sucrose was determined. The $\mathrm{pH}$ of the supernatant fraction was adjusted to 6.0 with phosphate buffer. Every 12 hours the liquid from the bath outside the membrane was replaced and the first lot saved. After 36 hours, the $50 \mathrm{ml}$ of $\mathrm{S}_{2}$ was divided into five $10-\mathrm{ml}$ portions and each portion was treated separately with $100 \lambda$ of NAA-1-C 14 . Then the following variations were introduced: (1) $10 \mathrm{ml}$ of the supernatant only, (2) 10 $\mathrm{ml}$ of the supernatant plus an aliquot $(10 \mathrm{ml})$ of the first dialyzate, (3) $10 \mathrm{ml}$ of the supernatant plus $24 \mathrm{ppm}$ of $\mathrm{Mg}$ as $\mathrm{MgSO}_{4}$, and (4) $10 \mathrm{ml}$ of the supernatant plus $0.55 \mathrm{ppm}$ of $\mathrm{Mn}$ as $\mathrm{MnSO}_{4}$, (5) $10 \mathrm{ml}$ of the supernat ant plus amounts of $\mathrm{Mg}$ and $\mathrm{Mn}$ as in (3) and (4).

The radioactivity of $\mathrm{C}^{14} \mathrm{O}_{2}$ evolved in one hour was determined by using the potassium hydroxide trapping method and liquid scintillation detection.

\section{Influence of NAA Concentration on Uptake of $N A A-1-C^{14}$}

To determine the rate and pattern of auxin uptake, an experiment under room temperature was conducted in which four $1 \mathrm{~g}$ samples of tea stem sections were allowed to take up labeled NAA from various molar concentrations $\left(10^{-6}, 10^{-5}, 10^{-4}\right.$, and $\left.10^{-3}\right)$ for three hours. Each treatment was replicated three times. After the three-hour incubation period, the stem pieces were transferred to unlabeled NAA solutions of corresponding molar concentrations for 24 hours. At the beginning, 0.1 $\mathrm{ml}$ aliquots were taken from the labeled NAA solutions and then similar volumes from the unlabeled NAA solutions at the following time intervals: $0.5,1.0,1.5,2.0,2.5,3.0,3.5,4.0,8.0,16.0$, and 24.0 hours. The 
$3.0 \mathrm{ml}$ of unlabeled NAA solutions were kept at constant volume by replacing the removed volume after each sampling.

\section{Preparation of Acetone Powders and \\ Extracts of the Acetone Powders}

The procedure for preparing acetone powder extracts was essentially that followed by Black and Humphreys (16). Pieces of tea stems $(10 \mathrm{~g})$ were chilled in water and ground with $30 \mathrm{ml}$ of phosphate buffer at pH 6.0 containing $0.03 \mathrm{M}$ EDTA. Then acetone $\left(125 \mathrm{ml},-15^{\circ} \mathrm{C}\right)$ was added slowly with stirring to the suspension. The resulting slurry was immediately filtered with suction through Whatman No. 1 filter paper on a Buchner funnel. The precipitate was washed three times with $75 \mathrm{ml}$ portions of acetone $\left(-15^{\circ} \mathrm{C}\right)$ and left under the conditions of filtration until the precipitate was free of acetone. The precipitate was then dried in vacue for 12 hours over $\mathrm{P}_{2} \mathrm{O}_{5}$. After the initial drying the acetone powders were stored in a dessicator at $0^{\circ} \mathrm{C}$ over $\mathrm{CaCl}_{2}$.

Extracts of the acetone powders were prepared by stirring the acetone powder for 15 minutes in $25 \mathrm{ml}$ of a solution of phosphate buffer at $\mathrm{pH} 6.0$, containing $0.03 \mathrm{M}$ EDTA. The slurry was filtered through glass wool and the filtrate was centrifuged at $10,000 \times g$ for five minutes at $-5^{\circ} \mathrm{C}$. Then it was filtered through Whatman No. 1 filter paper. This filtrate was designated as the acetone-powder extract. To check for decarboxylation of NAA-1-C 14 by the acetone-powder extract, $100 \lambda$ of NAA-1 $-C^{14}$ solution was added to $25 \mathrm{ml}$ of the extract and $\mathrm{C}^{14} \mathrm{O}_{2}$ collected at the following time intervals: $1,4,8,16$, and 24 hours. Carbon dioxide was trapped in sodium hydroxide and radioactivity determined as described previously. 


\section{Determination of NAA-1-C 14 Metabolites}

In order to determine the fate of NAA after it had entered the plant, samples of five cuttings were taken at the following time intervals: 1 and 24 hours; 2,4 , and 8 days after treatment with NAA-1-C 14 . The leaves were removed from the cuttings and the test was done on the stem pieces. These explants were washed three times with distilled water and extracted with 80 per cent ethanol and fractionated by TLC chromatography as described previously.

Radioactive areas on the chromatograms were determined by a Geiger-Muller counter (Nuclear Chicago Model 1619A). For more accurate determination, the radioactive areas of the chromatogram were divided into strips $0.5 \mathrm{~cm}$ wide and the silica gel plus fractions were scraped into planchets and radioactivity determined using a Tracer-1ab TGC-14, equipped with a thin-window G.M. tube.

Each radioactive spot was divided into two parts, lower and upper, and diluted separately with $15 \mathrm{ml}$ of ethyl ether. The ether solutions were filtered through glass-fiber filter paper with suction. The residue was rinsed with three small charges of ether and the total volume of solution was reduced to $0.5 \mathrm{ml}$ by a $\mathrm{N}_{2}$ gas stream. The samples were chromatographed as described above.

The residue left on the filter paper, following ether extraction, was redissolved in $30 \mathrm{ml}$ of 80 per cent ethanol and filtered through glass-fiber filter paper. Then the filtrate was reduced to dryness. The samples were redissolved in $0.5 \mathrm{ml}$ ethanol, spotted on thin layer sheets, and chromatographed as described previously. 
Using the original ethanolic extracts, alkali and acid hydrolysis were attempted. Aliquots of $0.1 \mathrm{ml}$ were treated with $0.1 \mathrm{ml}$ of $2 \mathrm{~N}$ $\mathrm{NH}_{4} \mathrm{OH}$ and $0.1 \mathrm{ml}$ of $2 \mathrm{~N}$ formic acid at $60^{\circ} \mathrm{C}$. After ten minutes of this combined treatment, the samples were reduced to dryness with a desiccator vacuum pump, redissolved in $0.1 \mathrm{ml}$ of 80 per cent ethanol, and chromatographed.

Subsequent to the above-mentioned test, an additional analysis was done as follows: $1 \mathrm{ml}$ of ethanolic extract was dried in vacuo and the residue adjusted to $\mathrm{pH} 8.3$ with sodium bicarbonate. This solution was partitioned with $1 \mathrm{ml}$ of ether. The ether phase was retained for thin-layer chromatography and the water phase adjusted to $\mathrm{pH} 2.0$ with tartaric acid. This second solution was partitioned with ether and the ether phase again retained for chromatography. The water phase was finally partitioned against hexane and the two fractions retained for chromatography and autoradiography.

A further attempt to isolate the radioactive products was carried out using $10 \mathrm{~g}$ of stem pieces of the Assam type of tea which were incubated with $1 \mathrm{ml}$ of $10^{-3} \mathrm{MNAA}-1-\mathrm{c}^{14}$ for three hours. $\mathrm{C}^{14} 0_{2}$ was collected during the entire period of incubation and the radioactivity determined by the sodium hydroxide trapping method and scintillation detection. At the end of the incubation period, the tissues were washed three times with $15 \mathrm{ml}$ of 5 per cent ethanol and the washings added to the incubated solution. An aliquot was taken for the determination of the radioactivity remaining in the external solution.

The $t$ issues were extracted in 80 per cent ethanol as described above and the final extract was made up to a total volume of $1 \mathrm{ml}$. 
One-half of this extract was used in a similar fractionation to that described previously to obtain ether-soluble neutral and acidic compounds, hexane soluble compounds and those retained in the aqueous phase.

To determine the possible nature of some of the NAA metabolites, seven $1 \mathrm{~g}$ samples of stem tissues were incubated for three hours with $2 \mathrm{ml}$ of the following $10^{-3} \mathrm{M}$ solutions of $\mathrm{C}^{14}$ labeled compound: NAA, L-alanine, L-aspartic acid, L-glutamic acid, NAA plus L-alanine, NAA plus L-aspartate, and NAA plus L-glutamate. The activity per mM of each amino acid was 8.5 microcuries. (The $c^{14}-1$ abeled amino acids were obtained from New England Nuclear Corp., Boston, Mass.) At the end of the incubation period, the tissues were washed briefly in 5 per cent ethanol solution, and then extracted in 80 per cent ethanol as described previously. The total ethanolic extracts were dried in yacuo and partitioned two times against ether and then against hexane as described before. The final four fractions from each of seven treatments were used in chromatography and autoradiography. 


\section{EXPERIMENTAL RESULTS}

Influence of NAA on the Rooting of Tea Cuttings

Auxin enhanced the capacity to root of both the Assam and Chinese type of tea. As shown in Table 1 and Figures 1, 2, and 3, the number of rooted cuttings, number of roots, and length of roots per treatment were greater in the NAA $(10,000 \mathrm{ppm})$ treatment than in the other two. With the Assam type of tea (Figures 1 and 4-b), 50 per cent ethanol treatment also increased the number of rooted cuttings. The response of the Chinese type of tea was more pronounced than that of the Assam type.

Axillary buds in both types of cuttings were inhibited by NAA treatment. As illustrated in photographs of Figures 4 and 5 , the axillary buds of the cuttings treated with water or 50 per cent ethanol reached a noticeable length in 60 days, but the growth of buds on NAAtreated cuttings was almost completely inhibited. However, the buds did resume growth when the cuttings were transplanted from the rooting bed.

Callus formation was inhibited also by the NAA treatment. As shown in Table 1 and illustrated in the photographs of Figures 4 and 5, callusing was appreciable on the control and ethanol-dipped cuttings but was only slight on the NAA-treated cuttings. 


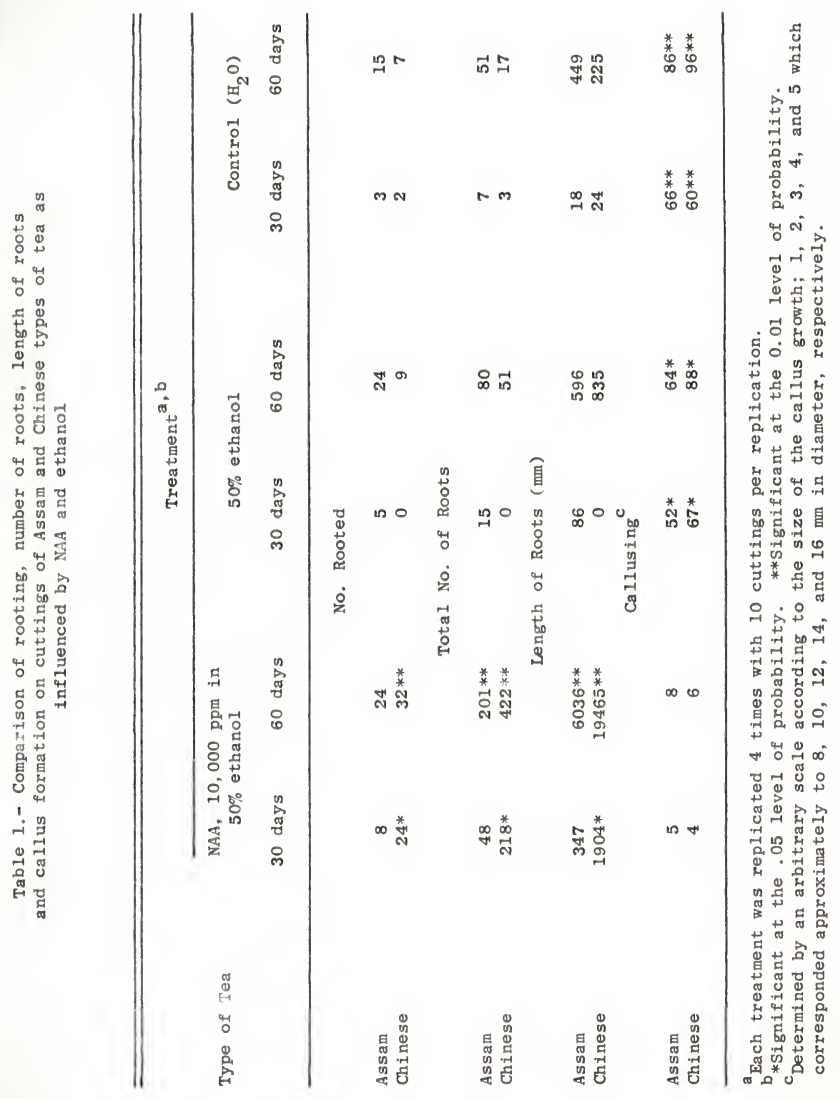




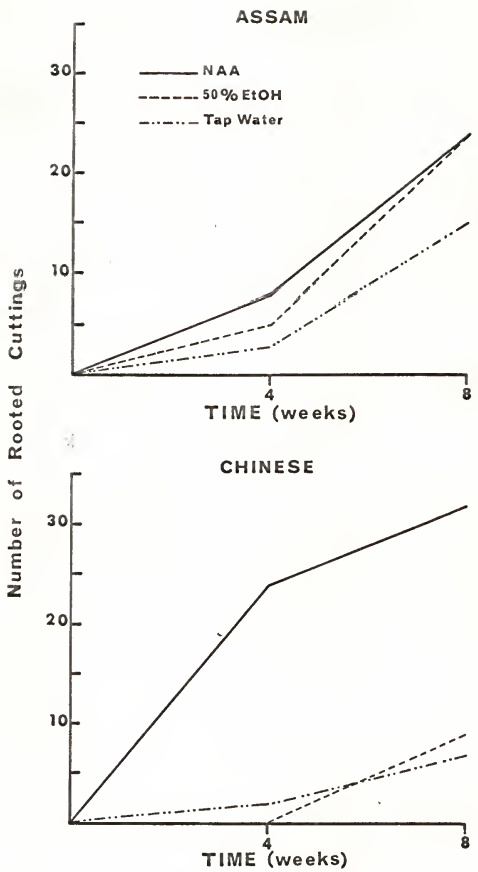

Fig. 1. Number of rooted cuttings of the Assam and Chinese types of tea at 4 and 8 weeks after treatment with NAA $(10,000 \mathrm{ppm})$, ethanol $(50 \%)$ and tap water $(40$ cuttings/treatment). 


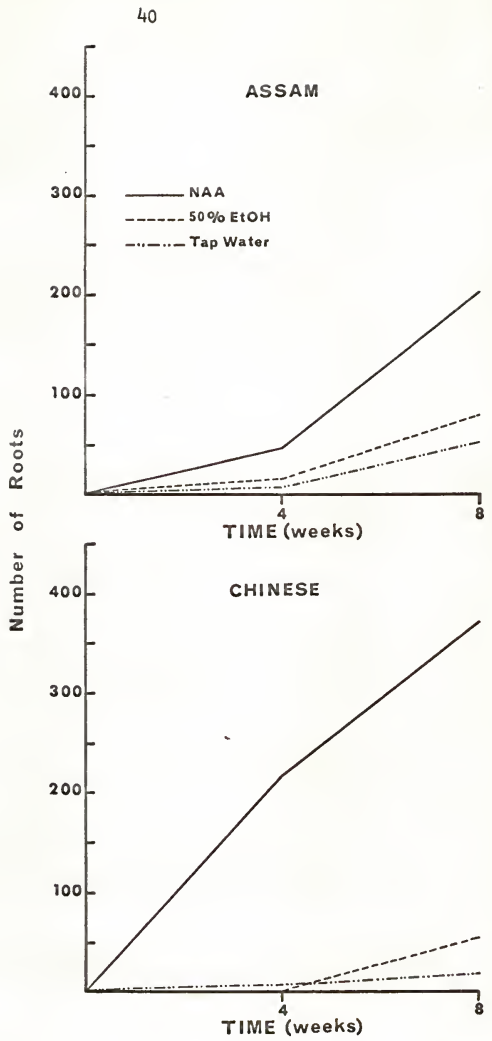

Fig. 2. Average number of roots in cuttings of the Assam and and Chinese types of tea at 4 and 8 weeks after treatment with NAA $(10,000 \mathrm{ppm})$, ethanol $(50 \%)$ and tap water (40 cuttings/treatment). 
41

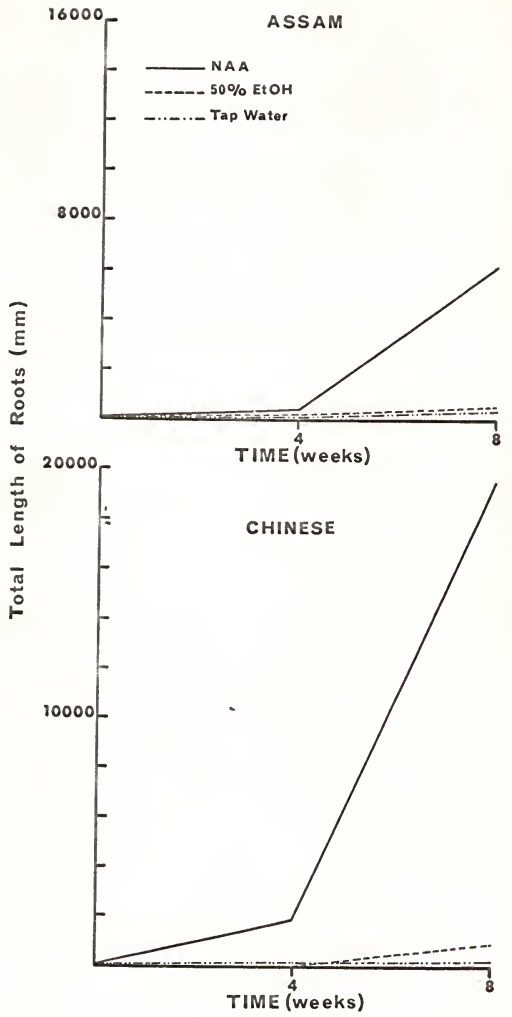

Fig. 3. Total length of roots (mm) on cuttings of the Assam and Chinese types of tea at 4 and 8 weeks after treatment with NAA $(10,000 \mathrm{ppm})$, ethanol $(50 \%)$ and tap water ( 40 cuttings/treatment). 


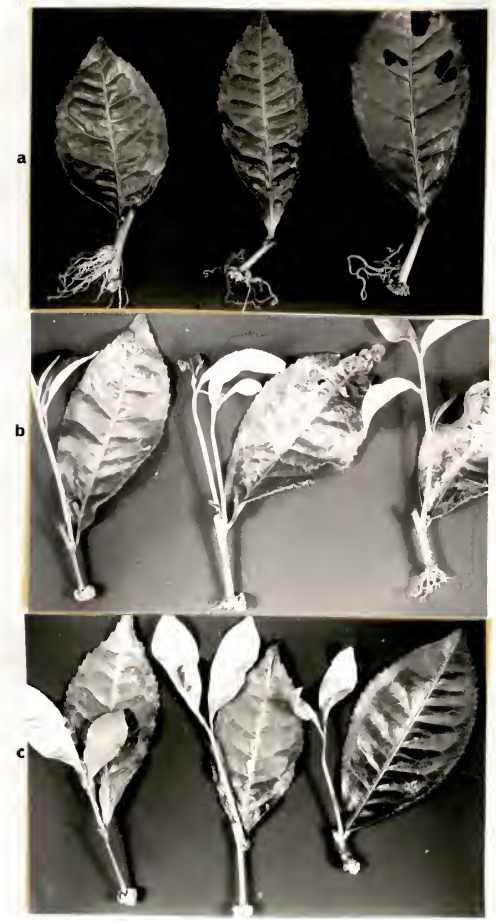

Fig. 4. Rooting of Assam tea at 60 days after treatment: a) Cuttings treated with NAA $(10,000 \mathrm{ppm})$. Noticeable inhibitory effect on growth of the axillary bud but good proliferation of adventitious roots; b) Cuttings treated with $50 \%$ ethanol in which there was considerable growth of the axillary bud; c) Cuttings treated with tap water. Note the growth of the axillary bud and development of callus at the base of the cuttings. 


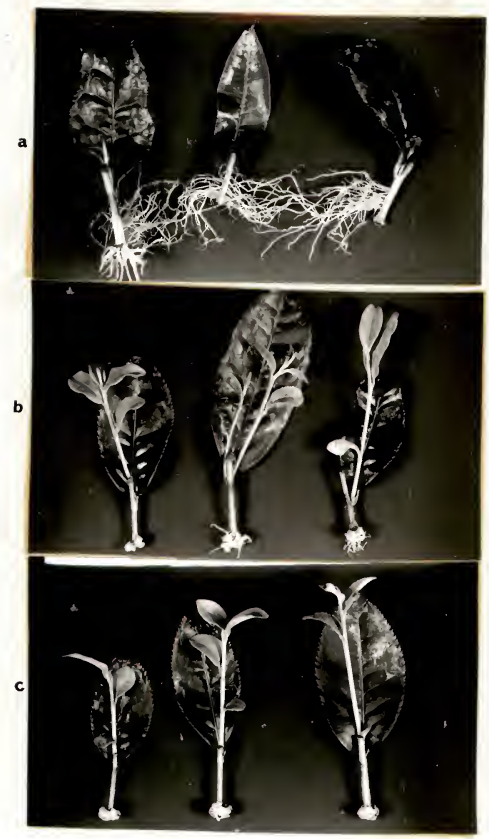

Fig. 5. Rooting of the Chinese type of tea at 60 days after treatment: a) Cuttings treated with NAA $(10,000 \mathrm{ppm})$. Almost complete inhibition on growth of the axillary bud but abundant proliferation of adventitious roots; b) Cuttings treated with $50 \%$ ethanol showing a considerable amount of growth of the axillary bud; c) Cuttings treated with tap water in which the axillary bud growth and callus development was considerable. 
Effect of NAA on the Rooting of Assam Tea Cuttings from Different Portions of the Stem

As shown in Table 2, the number of rooted cuttings increased almost linearly with NAA concentration up to $10,000 \mathrm{ppm}$ with the various types of cuttings. Figure 6 illustrates the influence of NAA on a combined total of the various types of cuttings. The stimulative effect due to NAA treatments, at concentrations above 1,000 ppm, reached a level that was highly significant. Yet, it would seem that there was no significant difference in rooting ability of the cuttings made up from stem segments of different ages.

\section{Anatomical Description of the Tea Stem}

For orientation, a brief description of the stem of tea is presented. The stem of Camellia sinensis, (L.) 0. Kuntze, at the physiological age used in this study for asexual propagation, had epidermal cells as the outermost layer. The cortex, mostly parenchymatous cells, was just internal to the epidermal cells and was well delimited from the phloem which had fibers in its peripheral part (primary phloem fibers). Just internal to these fibers was the primary phioem, which was usually crushed by secondary growth. Adjacent to this crushed phloem was the more recently formed secondary phloem. The secondary phloem had dilated rays and alternate bands of fibers and bands of sieve tubes, companion cells and parenchymatous cells. A conspicuous ergastic substance in the parenchyma cells, apparently tannins, was found in both types of tea but was especially prominent in the Assam type. The cambial zone appeared as a more or less wide stratum of periclinally dividing cells, organized into axial 
Table 2.- Effect of NAA on rooting of

Assam tea cuttings of different ages

\begin{tabular}{|c|c|c|c|c|c|c|c|}
\hline \multirow[t]{2}{*}{ Segment No. } & \multicolumn{6}{|c|}{$\begin{array}{ll}\text { NAA treatment: } \\
\text { Number of rooted cuttings } \\
\end{array}$} & \multirow{2}{*}{$\begin{array}{c}\text { Total } \\
\text { per } \\
\text { ppm segment }\end{array}$} \\
\hline & 0 & 300 & 1,000 & 3,000 & 10,000 & 30,000 & \\
\hline 1 & 2 & 4 & 6 & 7 & 12 & 11 & 42 \\
\hline 2 & 3 & 4 & 7 & 10 & 16 & 15 & 55 \\
\hline 3 & 2 & 3 & 5 & 11 & 15 & 14 & 50 \\
\hline 4 & 1 & 5 & 10 & 11 & 14 & 13 & 54 \\
\hline 5 & 2 & 3 & 8 & 12 & 17 & 16 & 58 \\
\hline $\begin{array}{l}\text { Total per } \\
\text { NAA conc. }\end{array}$ & 10 & 19 & $36 *$ & $51 * *$ & $74 * *$ & $69 * *$ & \\
\hline $\begin{array}{l}\text { Per cent } \\
\text { rooted }\end{array}$ & 5.0 & 9.5 & 18.0 & 25.5 & 37,0 & 33.0 & \\
\hline
\end{tabular}




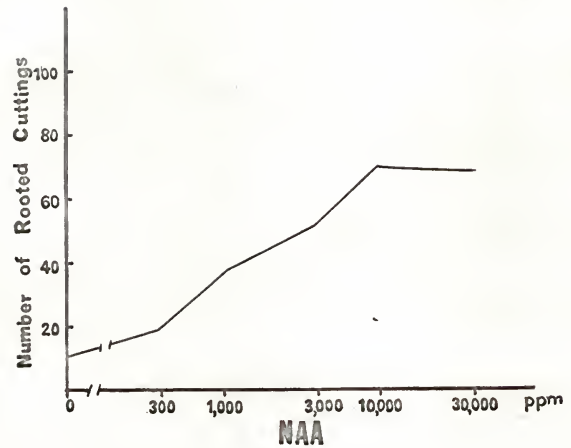

Fig. 6. Effect of NAA on the rooting of Assam tea cuttings (200 cuttings per NAA treatment). 
and ray systems. These cells had large nuclei. The secondary xylem had a somewhat denser appearance than the primary xylem system and contained, in the axial system, vessel elements, tracheids, fibers, and xylem parenchyma cells in a banded paratracheal arrangement. Wide and narrow rays were present.

On the inner edge of the continuous secondary xylem, the primary xylem had a slightly uneven outline around the pith and could be delimited from the secondary xylem only by approximation. The pith was parenchymatous and contained cavities. Large sclereids occurred both in the pith and cortex. These cells appear to be characteristic of the family Theaceae (120).

\section{Anatomical Origin of the Adventitious Root Meristem of Tea}

After five days under conditions favorable for rooting, portions of stems in the rooting zone at the base of the cuttings were sectioned and examined. Present in the sections in certain cambial region were cell initials in the prophase of mitosis (Fig. 7-b) with conspicuous and very dense nuclei. From a timed developmental sequence study, these cells appeared to divide rapidly, some radial and other tangential, without much enlargement of the daughter cells between mitoses (Fig. $7^{-c}$ and $d$ ), thus giving rise to a root primordium (Fig. 8-a). The root cap was formed very early (Fig. 8-b and $\mathrm{c}$ ), and just before it was distinguishable, dissolution of the cortical cells surrounding its apex was observed. Dissolving of the cells resulted in the formation of a cavity around the root, the cavity being enlarged as the root grew out ward and perpendicular to the stem axis. The parenchyma cells in the 
a
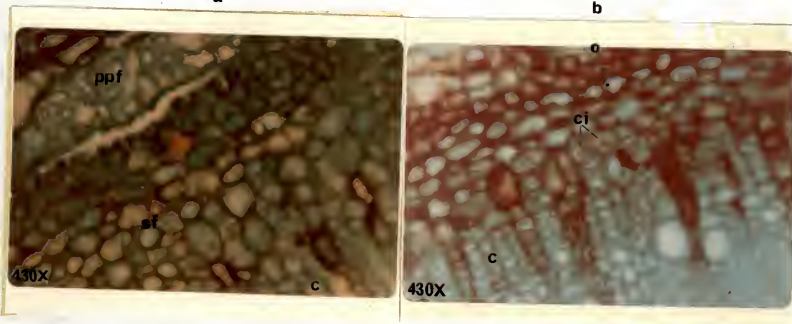

c d

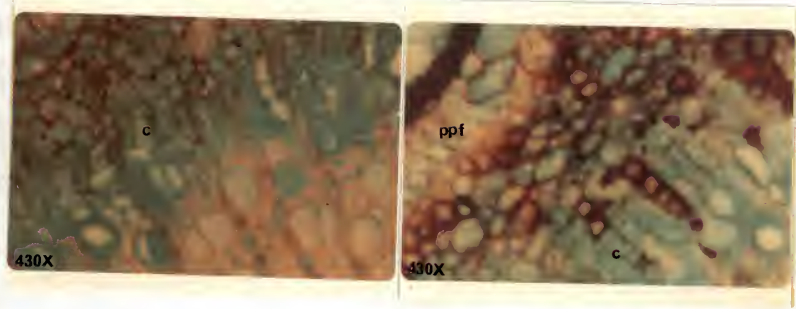

Fig. 7. Portions of cross-sectional ( $\mathrm{C}_{\mathrm{S}}$ ) views from the rooting zone at the base of stem cuttings of tea: a) Portion of a $\mathrm{C}$ view of a normal stem, showing the position of the primary phloem fibers (ppf) which appears as a non-continuous colony of cells; secondary phloem (sp) and the cambial zone (c); b) A C view of the stem 5 days after treatment with NAA $(10,000 \mathrm{ppm})$. $^{\mathbf{S}}$ Note the two cambial initial cells (ci) at prophase state of mitosis; c) and d) $\mathrm{C}_{\mathrm{S}}$ views of the stem 6 and 7 days after treatment with NAA, respectively, note different events of cell division, particularly the cambial zone and vicinities. 
a

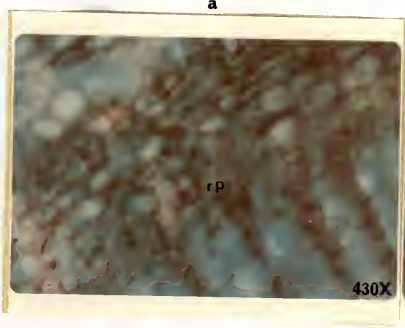

b

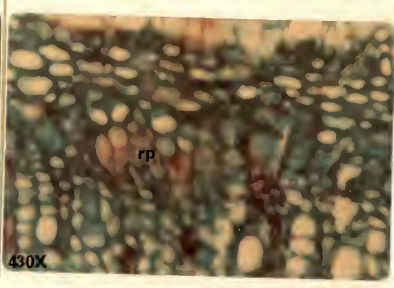

d

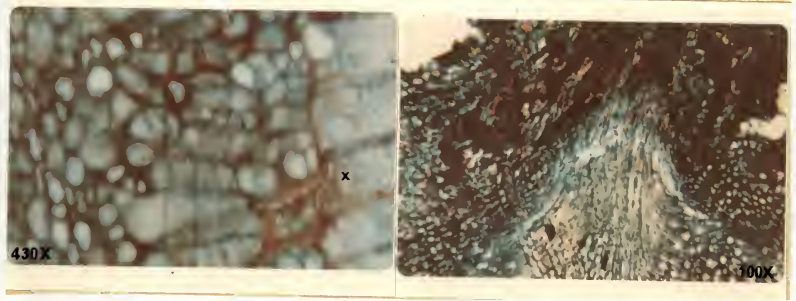

Fig. 8. Portions of cross-sectional $\left(\mathrm{C}_{\mathrm{S}}\right)$ views from the rooting zone at the base of stem cuttings of têa: a) A C view of the stem 12 days after NAA treatment. Note the formation of the root primordium ( $\mathrm{rp}$ ); b) A C of the stem 14 days after treatment with NAA. Note the development of the primordium with the apparent dissolution of the primary phloem fibers; c) A C of the stem 16 days after treatment with NAA. The adventitious root has already formed with connection with the $x y l e m(x)$; d) A C of the stem 20 days after treatment with NAA. Note the emergence pattern of the new root. 
vicinity of the fibers were almost completely dissolved. The vascular cylinder of the adventitious root developed to a very noticeable extent by the time the root reached the middle of the cortex (Fig. 8-d). By this time, some differentiation of the root had taken place and near the cambial region of the stem differentiating tracheids could be found. After a root had been initiated, secondary xylem and phloem that did not take part in the early formation of the root proper developed into connecting cells. By the time the root was about to emerge through the epidermis, the three primary regions were definitely established and maturation was taking place in the older portions of the root., The emergence of the root, i.e., the actual rupture of the mother tissue, took place in the Chinese type of tea about three weeks after treatment with NAA, and in the Assam type about four weeks after treatment.

\section{Uptake, Translocation and Accumulation of $N A A=1-\mathrm{C}^{14}$}

When cuttings were treated with NAA-1-C 14 for ten seconds, and utilized for cross $\left(C_{s}\right)$ or longitudinal-sections $\left(L_{s}\right)$ and for autoradiography after the cuttings were placed under greenhouse conditions for rooting for periods of $1,2,4$, and 8 days, it was found that $\mathrm{c}^{14}$ was present in all treated cuttings. Close observation of the autoradiographs of Figures 9 and 10 shows a significant amount of radioactivity in the stem-section corresponding to the treated basal third. The autoradiographs of the Chinese type of stem cuttings showed more translocation of the $\mathrm{C}^{14}$ than did the Assam type; on the other hand, the radioactivity at the base of the Chinese tea cuttings persisted at a higher level than in the Assam type of tea. 


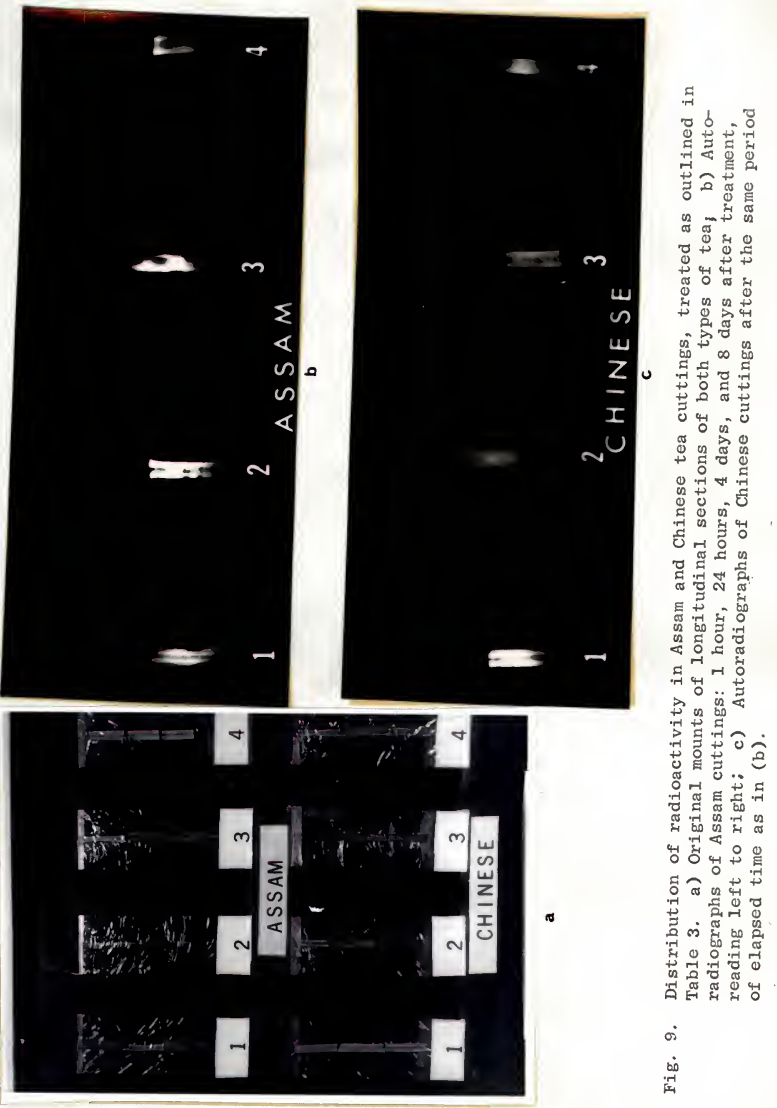




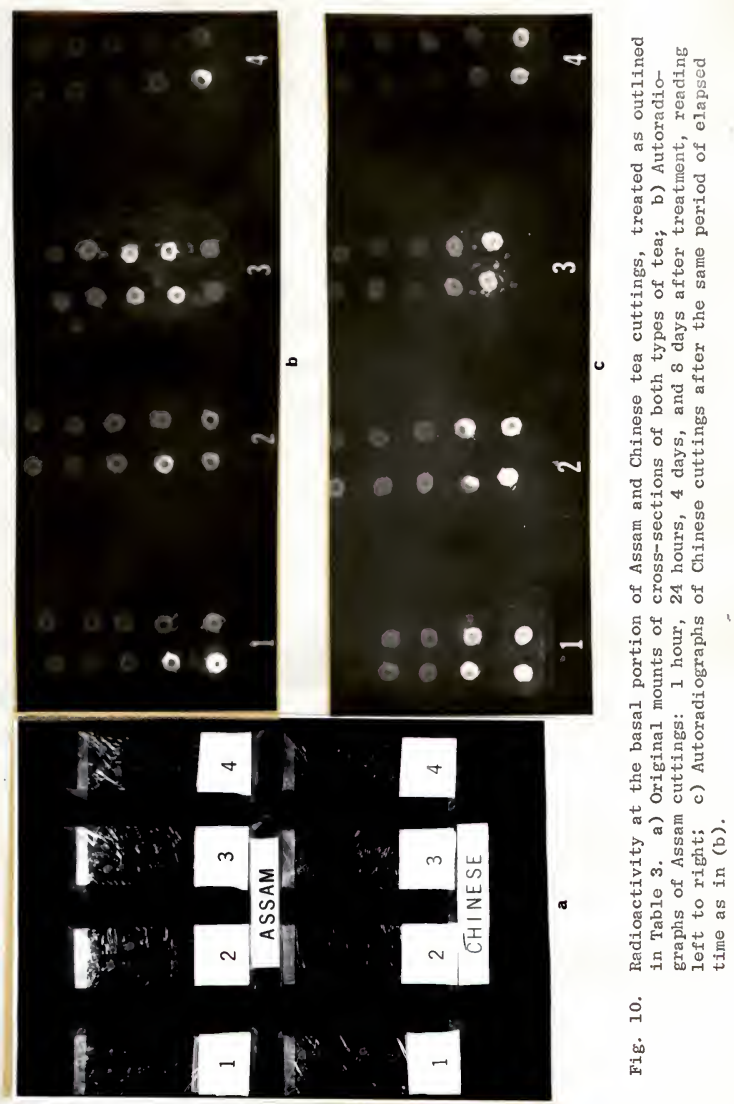


As corroboration of the autoradiographic data, the distribution of $\mathrm{C}^{14}$ in treated cuttings was determined by extracting the tissue with 80 per cent ethanol and determining the radioactivity by scintillation counting techniques. These data appear in Table 3. Each number represents the average net $\mathrm{cpm}$ of eight cuttings per time-interval treatment. After eight days, the base of the cuttings still contained approximately 36 per cent (Assam) and 44 per cent (Chinese) of the $c^{14}$ activity noted at one hour after treatment.

In addition to determining the radioactivity in the ethanol extract, an aliquot was subjected to thin-layer chromatography. TLC showed, besides the presence of $N A A-1-C^{14}$, another radioactive spot close to the front of the solvent system, as shown by the data in Table 4 and Figure 11 .

To determine in a gross way the tissue system that accumulated NAA $-1-C^{14}$, stem pieces treated with the labeled auxin were subdivided as outlined in Table 5. As illustrated, the accumulation of the NAA-1-C 14 in the outermost layers of the stem portions was considerable, as would be expected.

According to Table 5, in which each figure represents the average net cpm from six cuttings, the amount of auxin absorbed in the outer tissue system by the Chinese cuttings was greater than that absorbed by the Assam type of tea.

\section{Determination of the Translocation of $N A A-1-C^{14}$}

The study of auxin translocation by tracing the movement of $c^{14}$ added to the stem pieces as NAA-1-C 14 showed a relationship of 2 to 1 for the apex-toward-base diffusion vs the base-toward-apex diffusion in 
Table 3,- Distribution of $\mathrm{C}^{14}$ from alpha-labeled

NAA in tea cuttings ${ }^{a}$

\begin{tabular}{|c|c|c|c|c|c|c|}
\hline \multirow{3}{*}{$\begin{array}{l}\text { Time after } \\
\text { treatment }\end{array}$} & \multicolumn{3}{|c|}{ ASSAM } & \multicolumn{3}{|c|}{ CHINESE } \\
\hline & \multicolumn{3}{|c|}{ Portion of Cutting } & \multicolumn{3}{|c|}{ Portion of Cutting } \\
\hline & $\begin{array}{c}\text { Basal } \\
\text { cpm }\end{array}$ & $\begin{array}{l}\text { Middle } \\
\text { cpm }\end{array}$ & $\begin{array}{l}\text { Apical } \\
\text { cpm }\end{array}$ & $\begin{array}{c}\text { Basal } \\
\text { cpm }\end{array}$ & $\begin{array}{l}\text { Middle } \\
\text { cpm }\end{array}$ & $\begin{array}{l}\text { Apical } \\
\text { cpm }\end{array}$ \\
\hline 1 hour & 1,747 & 25 & 8 & 1,834 & 36 & 14 \\
\hline $4 \quad$ & 1,412 & 22 & 7 & 1,206 & 28 & 9 \\
\hline $8 \quad$ & 1,322 & 22 & 6 & 1,100 & 26 & 7 \\
\hline $16 "$ & 1,277 & 19 & 5 & 1,056 & 20 & 7 \\
\hline $24 "$ & 1,198 & 18 & 5 & 1,029 & 17 & 6 \\
\hline 4 days & 1,038 & 16 & 4 & 970 & 14 & 5 \\
\hline $8 "$ & 626 & 15 & 3 & 821 & 12 & 5 \\
\hline
\end{tabular}

${ }^{a}$ NAA-1- $C^{14}$ applied to the futtings by ${ }_{4}$ dipping the basal 1 inch of the stem in a solution of $10^{-3} \mathrm{M}$ NAA- $-\mathrm{C}^{14}$ of approximately $132,400 \mathrm{cpm} / \mathrm{ml}$.

${ }^{b}$ After treatment, cuttings were placed in a greenhouse under conditions for rooting until utilized.

${ }^{c}$ Cuttings divided into $1 / 3$ portions for extraction and analysis. 


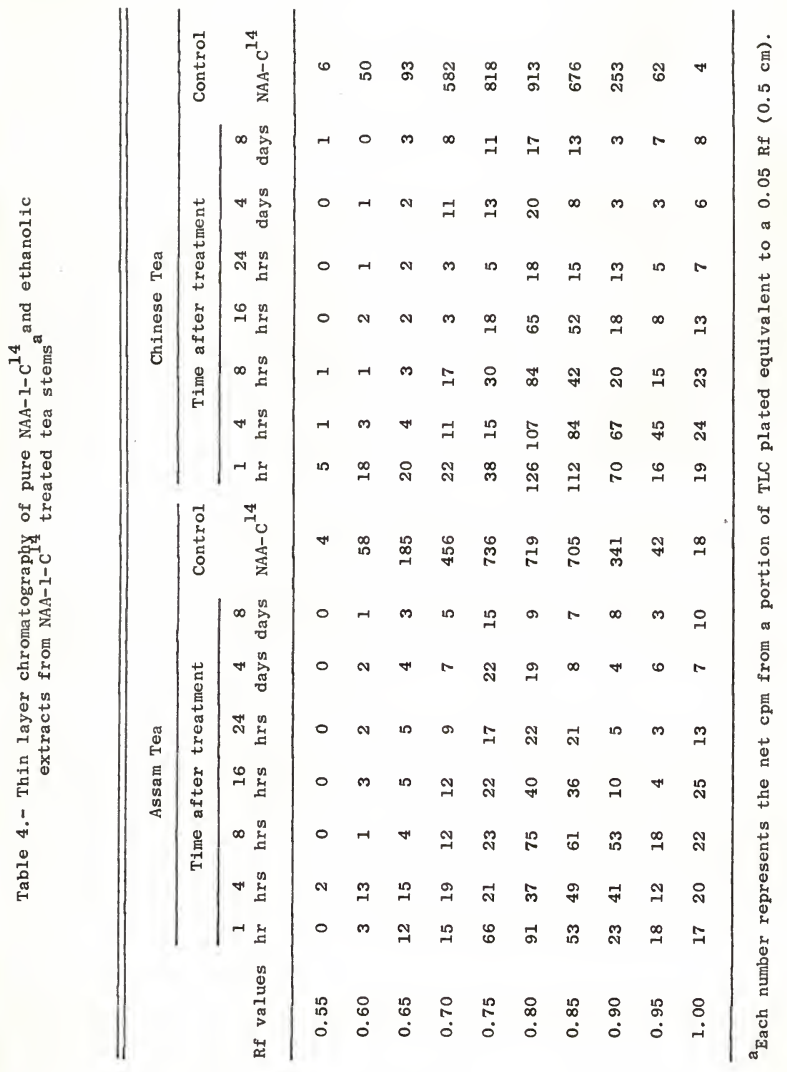




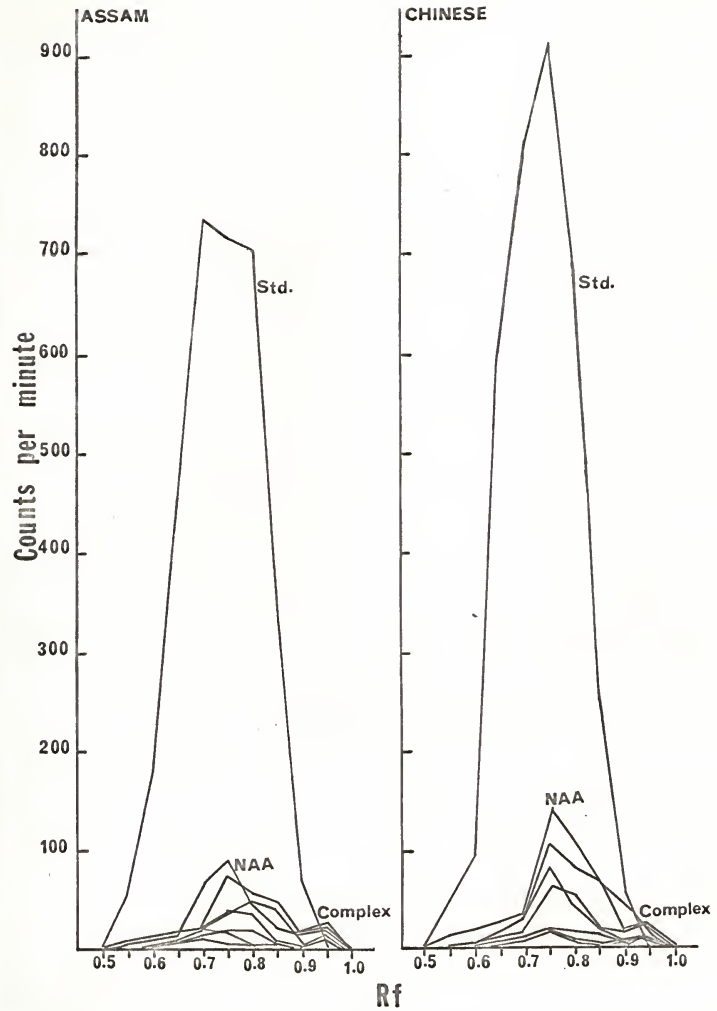

Fig. 11. Thin-layer chromatography of NAA-1-C $\mathrm{C}^{14}$ and ethanolic extracts from NAA-1-C $\mathrm{C}^{14}$ treated tea stems. (Note that only the upper one-half of the chromatogram was portrayed.) 
Table 5.- Radioactivity located in various tissuessstems of tea 1 hour after treatment with NAA-1-C

\begin{tabular}{lcr}
\hline Radioactivity in & $\begin{array}{c}\text { ASSAM } \\
\mathrm{cpm}\end{array}$ & $\begin{array}{c}\text { CHINESE } \\
\mathrm{cpm}\end{array}$ \\
\hline $\begin{array}{l}\text { 1. Epidermis and parenchymatous layer } \\
\text { of cells close to it }\end{array}$ & 1,082 & 1,370 \\
2. Vascular system, except primary xylem & 324 & 336 \\
3. Primary xylem and pith & 230 & 235 \\
\hline
\end{tabular}


stem pieces of both types of tea. Hence, there was possibility of a polarity of translocation of NAA and it was basipetal. This can be seen by comparing the data of tables 6 and 7 , and Figures 1 , and 13 .

\section{Determination of Decarboxylation of NAA \\ by Tissues of Tea}

Since it had been noticed in the autoradiographic test with NAA$1-C^{14}$ that there was an apparent loss of radioactivity from the tissues with time, an attempt was made to determine the route of this destruction of $N A A-1-C^{14}$. In the initial test, small pieces of stems were incubated in $10^{-3} \mathrm{M} N A A-1-\mathrm{C}^{14}$ for 24 hours and the $\mathrm{CO}_{2}$ evolving from the $t$ issue was trapped periodically and checked for $\mathrm{C}^{14} 0_{2}$. As can be seen in Table 8 and Figure 14 , there was $\mathrm{C}^{14} 0_{2}$ in the respiratory $\mathrm{CO}_{2}$ and there was a relationship between the length of time in the solution of $N A A-1-C^{14}$ and the amount of $\mathrm{C}^{14} \mathrm{O}_{2}$ evolved. The peak evolution time was eight hours. Note the greater amount of $\mathrm{C}^{14} \mathrm{O}_{2}$ evolving from the Assam type of tea at each of the samplings.

After this initial test, it was obvious that the amount of $\mathrm{c}^{14} \mathrm{O}_{2}$ evolved from the tissues treated with $N A A-1-C^{14}$ was Iow for a short sampling period so an efficient trapping and detecting system for $\mathrm{C}^{14} \mathrm{O}_{2}$ was needed for further study. Thus, Table 9 summarizes the data from a test to compare various agents for $\mathrm{C}^{14} \mathrm{O}_{2}$ trapping, and the detection of activity by scintillation techniques. As can be seen, there was a more efficient trapping and detection of $\mathrm{C}^{14} \mathrm{O}_{2}$ by the potassium hydroxide method, with the sodium hydroxide method the next best.

The next logical step seemed to be to determine the relation between uptake of NAA-1-C 14 , the amount decarboxylated and the amount retained in 
Table 6.- Acropetal movement of $\mathrm{C}^{7}$ aucled to
tea stems as NAA-1-C

\begin{tabular}{lccccc}
\hline & \multicolumn{2}{c}{ ASSAM } & \multicolumn{2}{c}{ CHINESE } \\
\cline { 2 - 5 } Radioactivity in & cpm & $\begin{array}{r}\text { cpm/mg } \\
\text { dry wt }\end{array}$ & & $\begin{array}{r}\text { cpm/mg } \\
\text { dry wt }\end{array}$ \\
\hline Receiver block & 0 & 0.0 & 0 & 0.0 \\
Apical third & 3 & 0.4 & 4 & 0.3 \\
Middle third & 32 & 0.6 & 35 & 0.6 \\
Basal third & 889 & 16.2 & 960 & 17.5 \\
Donor block & 4,464 & 446.4 & 4,727 & 472.8 \\
\hline
\end{tabular}

adffusion time 4 hours. Radioactivity was recorded in net $\mathrm{cpm}$, and each result was the average of 3 replications. 
Table 7.- Basipetal movement of $\mathrm{C}^{14}$ added to
tea stems as NAA-1-C

\begin{tabular}{|c|c|c|c|c|}
\hline \multirow[b]{2}{*}{ Radioactivity in } & \multicolumn{2}{|c|}{ ASSAM } & \multicolumn{2}{|c|}{ CH INESE } \\
\hline & cpm & $\begin{array}{l}\mathrm{cpm} / \mathrm{mg} \\
\mathrm{dry} w t\end{array}$ & cpm & $\begin{array}{l}\text { cpm/mg } \\
\text { dry wt }\end{array}$ \\
\hline Donor block & 4,049 & 404.9 & 4,278 & 427.8 \\
\hline Apical third & 1,694 & 30.8 & 1,783 & 32.4 \\
\hline Middle third & 123 & 2.2 & 130 & 2.4 \\
\hline Basal third & 32 & 0.6 & 66 & 1.2 \\
\hline Receiver block & 6 & 0.1 & 11 & 0.2 \\
\hline
\end{tabular}

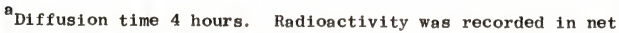
$\mathrm{cpm}$ and each result was the average of 3 replications. 


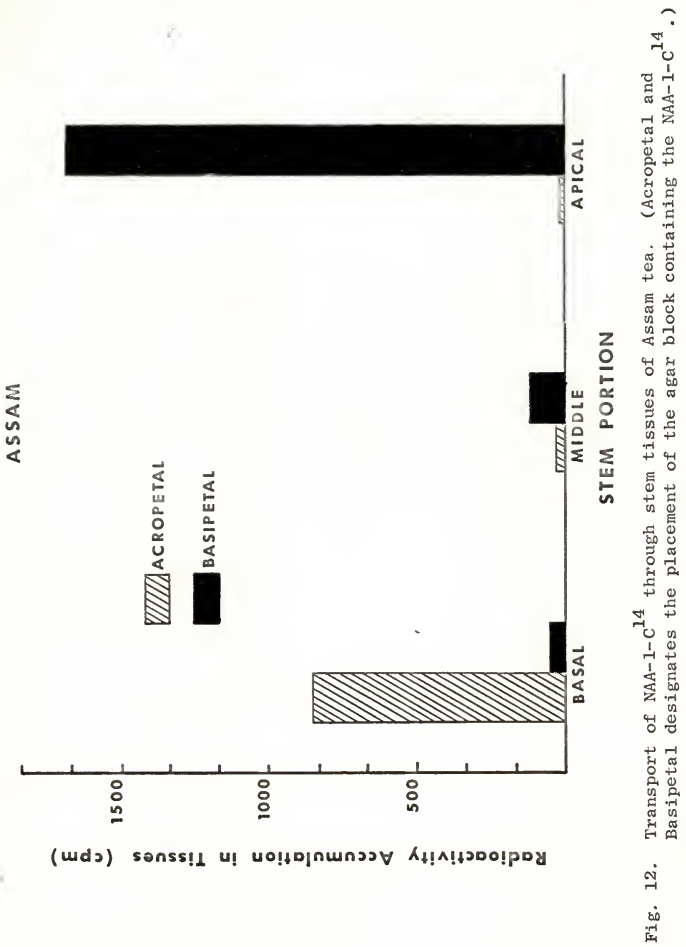




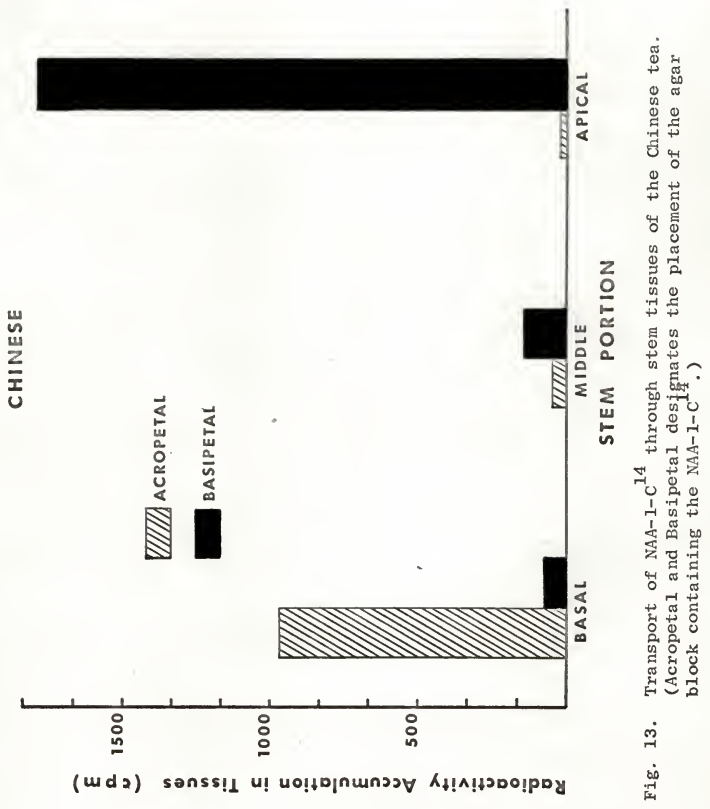


Table 8.- Radioactivity in the respiratory $\mathrm{CO}_{2}$ from stem cuttings after treatment with NAA-1-C ${ }^{14}$

\begin{tabular}{ccc}
\hline & $\mathrm{C}^{14} 0_{2}$ activity detected $(\mathrm{cpm})^{\mathrm{a}, \mathrm{b}}$ \\
\cline { 2 - 3 } Time (Hrs) & ASSAM & CHINESE \\
\hline 1 & 49 & 22 \\
16 & 337 & 299 \\
24 & 105 & 172 \\
& 95 & 74 \\
\hline
\end{tabular}

${ }^{B_{1}}$ The values listed are the means of net cpm from 6 replications.

$b_{\text {The trapping agent was Hydroxide of Hyamine and }}$ trapping was for $1 \mathrm{hr}$ at each time of sampling. 


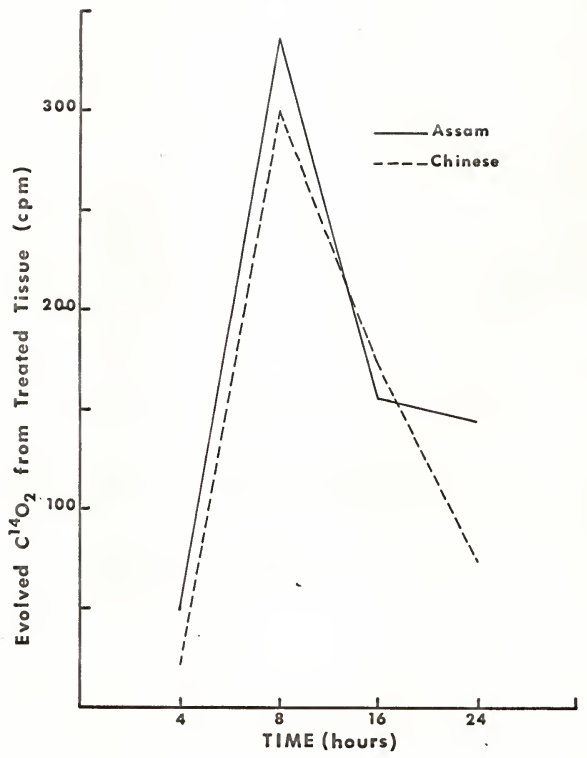

Fig. 14. Radioactivity in respiratory $\mathrm{CO}_{2} \mathrm{frgm}_{\mathrm{m}}$ tea stem cuttings treated with NAA- I- $\mathrm{C}^{4}$. 
Table $9 .-$ A comparison of trapping systems for respirgtory
$\mathrm{C}^{14} \mathrm{O}_{2}$ from cuttings after treatment with NAA-1-C

\begin{tabular}{lcc}
\hline & & \\
& & $\mathrm{C}^{14} 0_{2}$ detected $(\mathrm{cpm})^{\mathrm{a}, \mathrm{b}}$ \\
\cline { 2 - 3 } & ASSAM & CHINESE \\
\hline 1. Hydroxide of Hyamine 10-X & 49 & 22 \\
3. Sodium hydroxide & 104 & 88 \\
4. Paper, KOH, strip counting & 114 & 102 \\
\hline
\end{tabular}

\footnotetext{
${ }^{a}$ Each number represents the average net cpm from 3 replications. ${ }_{\mathrm{C}} \mathrm{C}^{14} \mathrm{O}_{2}$ sampling time was $1 \mathrm{hr}$.
} 
the tissue. This was attempted by treating tea stems with NAA-I $-C^{14}$ and determining the quantity taken up from the solution, the amount of $\mathrm{C}^{14^{4}} \mathrm{O}_{2}$ evolved, and the activity that could be extracted from the tissue with 80 per cent ethanol. As illustrated by Table 10, after three hours incubation 96.27 per cent of the $c^{14}$ activity could be recovered in these three fractions. The remaining 3.73 per cent not accounted for may have been in the ethanol-insoluble fractions in the tissue and/or errors in the analytical procedures. This does demonstrate that a large portion of the NAA-I-C 14 entering the tea tissue was either decarboxylated or could be extracted with 80 per cent ethanol.

To determine the nature of the system which gave rise to $\mathrm{C}^{14} 0_{2}$ from $N A A-1-C^{14}$, a preliminary step was to investigate the possibility of getting the system to operate free of the intact tissue. First, a comparison was made between the activity of intact tissue and a brei of the tissue without any addendum except NAA-1-C ${ }^{14}$. This comparison can be seen in Table 11. Note the slightly decreased activity with the breis and also the ratio of $\mathrm{C}^{14} \mathrm{O}_{2}$ between the Assam and Chinese types of tea with both intact tissues and breis. The main observation at this point was that the breis did have activity and there was a similarity to that found in intact tissues.

\section{Influence of Heat on Decarboxylation}

To determine if the apparent decarboxylation of NAA-1-C 14 was enzymatic, breis and intact stem pieces, and autoclaved stem pieces of tea were treated with NAA-1-C $C^{14}$. Table 12 shows the $C^{14} 0_{2}$ trapped during the first hour. Here again, one can compare the activity of 
Table 10,- Recovery of $\mathrm{C}^{14}$ after the jncubation
of tea stem tissues in NAA-1-C

Fraction

$\%$ Recovery by $\mathrm{C}^{14}$ ana 1 ysis ${ }^{\mathrm{a}, \mathrm{b}}$

Tissue (Ethanol extractable)

12.66

$\mathrm{CO}_{2}$ evolved ${ }^{\mathrm{c}}$

0.11

Incubation solution

83.50

Tota1 recovery

96.27

${ }^{a}$ Incubation period 3 hours.

$b_{\text {The values }}$ listed are the means of 2 replications.

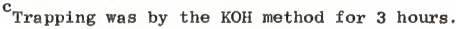


Table 11.- Radioactivity in the respiratory $\mathrm{CO}_{2}$ from $4^{\text {intact }}$ tissues and breis of tea treated with NAA-1- $\mathrm{C}^{14}$

\begin{tabular}{|c|c|c|}
\hline \multirow{3}{*}{ Type of material } & \multicolumn{2}{|c|}{ Radioactivity in the $\mathrm{CO}_{2}$ fraction $(\mathrm{cpm})^{\mathrm{a}, \mathrm{b}}$} \\
\hline & \multirow{2}{*}{ Intact tissue } & \multirow{2}{*}{$\frac{\text { Brei }}{\text { Intact tissue }}$} \\
\hline & & \\
\hline Assam & 104 & .84 \\
\hline Chinese & 82 & .77 \\
\hline \multicolumn{3}{|c|}{ 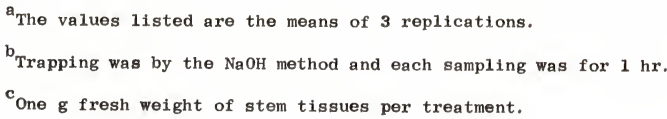 } \\
\hline
\end{tabular}


Table 12.- Radioactivity in the respiratory $\mathrm{CO}_{2}$ of tea tissues treated with NAA-1-C

\begin{tabular}{|c|c|c|c|}
\hline \multirow[b]{2}{*}{ Treatment } & \multicolumn{3}{|c|}{ Radioactivity in the $\mathrm{CO}_{2}$ Fraction $(\mathrm{cpm})^{\mathrm{B}, \mathrm{b}, \mathrm{c}}$} \\
\hline & Assam & Chinese & $\frac{\text { Chinese }}{\text { Assam }}$ \\
\hline Intact stem pieces & 112 & 99 & 88 \\
\hline Autoclaved stem pieces & 0 & 0 & 0 \\
\hline Breis & 114 & 102 & 89 \\
\hline
\end{tabular}

${ }^{a}$ The values listed are the means of 3 replications.

${ }^{b}$ One $g$ fresh weight of stem tissues per treatment.

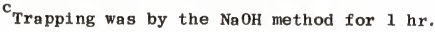


the intact tissue and breis. Nevertheless, the striking observation from this test was that the autoclaved samples did not evolve $\mathrm{CO}_{2}$ with any measurable radioactivity.

In a further test, when the breis prepared from $1 \mathrm{~g}$ of stem tissues were compared with the same preparation treated on a boiling water bath for ten minutes, the $\mathrm{C}^{14} \mathrm{O}_{2}$ evolved in one hour for Assam was 108 and 2 net cpm, respectively; and for Chinese 96 and 0 net cpm, respectively. Apparently, heat destroyed the capacity of the tissue to yield $\mathrm{C}^{14} 0_{2}$ from $N A A=1-C^{14}$.

Influence of Tissue Age on Decarboxylation

When three different ages of tea stem pieces were treated with NAA-I $-C^{14}$, the $\mathrm{C}^{14} \mathrm{O}_{2}$ trapped decreased with age. These data are presented in Table 13. Here again, note the greater decarboxylating activity of the Assam type of tea.

Influence of $\mathrm{pH}$ on the Rate of Decarboxylation

The influence of $\mathrm{pH}$ on the rate of decarboxylation of NAA-1-C 14 by breis from the two types of tea can be seen in Figure 15. Apparently the optimal $\mathrm{pH}$ for enzymic action on the NAA-1-C 14 , as measured $\mathrm{C}^{14} \mathrm{O}_{2}$ evolution, was around 6.0. Subsequent work was done using media adjusted to this $\mathrm{pH}$.

\section{Influence of Buffers on the Rate of Decarboxylation}

In comparing the influence of various buffers on the enzymatic decarboxylation of NAA-1-C 14 by breis prepared from $1 \mathrm{~g}$ of stem tissues, Mcllvaine's. Phosphate, and Tris buffers gave average net cpm of 61 , 
Table 13. - Decarboxylation of NAA-1-C ${ }^{14}$ by tissues of tea of different ages

\begin{tabular}{lccc}
\hline & \multicolumn{2}{c}{ Radioactivity of $\mathrm{Co}_{2}$ evolved $(\mathrm{cpm})^{\mathrm{a}, \mathrm{b}}$} \\
\cline { 2 - 4 } & Assam & Chinese & $\frac{\text { Chinese }}{\text { Assam }}$ \\
\hline 3 months & 88 & 73 & .82 \\
6 months & 61 & 54 & .88 \\
9 months & 52 & 45 & .86 \\
\hline
\end{tabular}

${ }^{a}$ The values listed are the means of 3 replications.

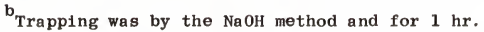

$c_{\text {One }} g$ fresh weight of stem tissues per treatment. 


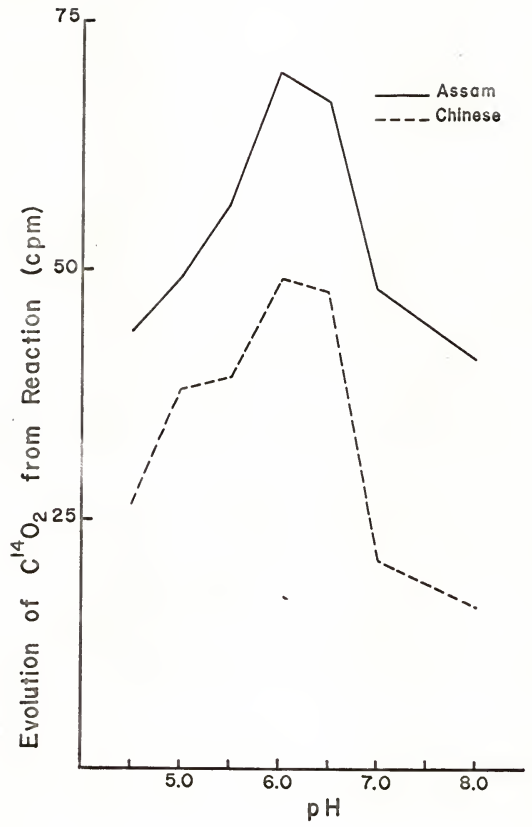

Fig. 15. The influence of $\mathrm{pH}$ on the activity of breis of Assam and Chinese tea cuttings as determined by the $\mathrm{C}^{14} \mathrm{O}_{2}$ evolved during the first 60 minutes after treatment with NAA-I-C ${ }^{14}$. (Breis prepared from one $g$ fresh weight of stem tissues. $\mathrm{C}^{14} \mathrm{O}_{2}$ trapped by the $\mathrm{NaOH}$ method.) 
52 , and 51 , respectively. In subsequent work, a phosphate buffer was used.

Influence of Substrates on Decarboxylation

A comparison of two different metabolites on the rate of decarboxylation of NAA-1-C 14 by breis from Assam type of tea appears in Table 14.

The decrease in radioactivity as related to the increase in the molar concentration of sucrose may be the result of an osmotic effect on the enzyme system. On the other hand, caseine hydrolyzate increased the enzymatic destruction of NAA as shown in the last column of Table 14; $10,000 \mathrm{ppm}$ of caseine hydrolyzate increased $\mathrm{C}^{14} 0$, production from $N A A-1-C^{14}$ by 122 per cent.

\section{Influence of Dialysis on Decarboxylation}

It was determined that centrifugating the breis at $10,000 \times \mathrm{xg}$ for 30 minutes resulted in a supernatant fraction and a pellet that decarboxylated $\mathrm{NAA}-\mathrm{I}-\mathrm{C}^{14}$ to $\mathrm{C}^{14} \mathrm{O}_{2}$ at the following rate: 119 and 99 net $\mathrm{cPm}$ for the Assam and Chinese supernatant fraction, and 136 and 70 net cpm for the Assam and Chinese pellet, respectively.

Dialysis of the supernatant fraction from the breis centrifuged at 10,000 xg appears in Table 15, in which the enzymatic activity during the first hour after NAA-I-C 14 treatment is expressed in net cpm.

From the data of Table $15 \mathrm{Mg}$ and $\mathrm{Mn}$ appear to have an influence on the enzymic decarboxylation of $N A A-1-C^{14}$, with Mg having the greater effect. 
Table 14.- Effect of various concentrations of sucrose and casein hydrolyzate on the enzymatic destruction of NAA-1- $\mathrm{C}^{14}$ by Assam tissue brei ${ }^{a, b, c}$

\begin{tabular}{cccc}
\hline $\begin{array}{c}\text { Sucrose } \\
\text { conc. (M) }\end{array}$ & $\begin{array}{l}\text { Radioactivity of } \\
\mathrm{CO}_{2} \text { evolved }(\mathrm{cpm})\end{array}$ & $\begin{array}{c}\text { Casein Hydrolyzate } \\
\text { conc. }(\mathrm{ppm})\end{array}$ & $\begin{array}{c}\text { Radioactivity of } \\
\mathrm{C0}{ }_{2} \text { labeled (cpm) }\end{array}$ \\
\hline 0.0 & 103 & 0 & 104 \\
0.1 & 106 & 1,000 & 181 \\
0.3 & 86 & 3,000 & 205 \\
0.7 & 63 & 7,000 & 224 \\
1.0 & 58 & 10,000 & 231 \\
2.0 & 52 & & \\
\hline
\end{tabular}

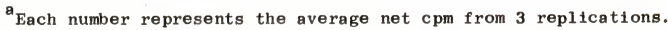

${ }^{b}$ Bret prepared from one $g$ of stem tissues per treatment.

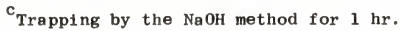


Table 15. - Effect of dialysis and divalent cations on

the evolution of $\mathrm{C}^{14}{ }_{2}$ from supernatant fraction of breis of tea treated with NAA-1-C

Treatment

Radioactivity of $\mathrm{CO}_{2}$ evolved $(\mathrm{cpm})^{\mathrm{a}}$

Assam Chinese

1. dialyzed supernatant

(after 36 hrs of dialysis)

539

86

2. dilalyzed supernatant + dialyzate

666

201

3. dialyzed supernatant $+\mathrm{Mg}^{++}$

710

224

4. dialyzed supernatant $+\mathrm{Mn}^{++}$

665

153

5. dialyzed supernatant $+\mathrm{Mg}^{++}$ $+\mathrm{Mn}^{++}$

a Trapping by the KOH method for $1 \mathrm{hr}$. 


\section{Influence of NAA Concentration on Upt ake of NAA-I $\mathrm{C}^{14}$}

Results of the study on auxin uptake showed that the amount of NAA which leached out of the tissue was approximately proportional to the concentration of NAA in which the sections had been previously incubated. The only exception was at very low NAA concentrations.

Auxin retention by tea tissue is illustrated by the data in Table 16 and Figure 16. The initial exchange was very rapid and was completed after about four hours. The second stage was slow and linear with time. Thus, this could indicate that the uptake of NAA, as measured by tissue retention, depends on two processes. The first was consumated in a short time and resembled diffusion since NAA taken up by this process would be readily leached to the external medium. The second component of NAA exchange that was slow could indicate that NAA $=1-C^{14}$ has been retained by the tissue and was not readily exchangeable. By 24 hours, the leaching of NAA-1-C 14 was approximately linear for $10^{-5}, 10^{-4}$, and $10^{-3} M$ NAA. An increased exchange of $10^{-6} M$ was observed.

In another experiment, an attempt was made to determine directly if the concentration of NAA has an influence on the amount of NAA penetrating the tissue; and also, to determine if the concentration of NAA external to the tissue played a role in the amount of NAA decarboxylated. To do this, stem explants were incubated in various concentrations of NAA, each containing a known, constant amount of NAA-I-C 14 . After three hours of incubation, the ethanol extractable components from the tissue and the amount of $\mathrm{C}^{14^{4}} \mathrm{O}_{2}$ from decarboxylated NAA-I-C 14 were significantly different for the various treatments. There was an 
Table 16.- Amount of radioactiyity leached from tea stems treated with NAA-1-C during, Soaking in
unlabeled NAA solution

\begin{tabular}{|c|c|c|c|c|}
\hline \multirow{2}{*}{$\begin{array}{c}\text { Time of } \\
\text { soaking } \\
\text { (Hrs) }\end{array}$} & \multicolumn{4}{|c|}{$\begin{array}{c}\text { Concentrations of NAA for pretreatment and for soaking } \\
\text { and activity leaching from tissues (cpm) }\end{array}$} \\
\hline & $10^{-6}$ & $10^{-5}$ & $10^{-4}$ & $10^{-3} \mathrm{M}$ \\
\hline 0.5 & 204 & 202 & 175 & 111 \\
\hline 1.0 & 226 & 222 & 188 & 166 \\
\hline 1.5 & 252 & 238 & 194 & 180 \\
\hline 2.0 & 269 & 256 & 231 & 240 \\
\hline 2.5 & 274 & 263 & 261 & 379 \\
\hline 3.0 & 342 & 272 & 309 & 419 \\
\hline 3.5 & 358 & 282 & 345 & 448 \\
\hline 4.0 & 362 & 286 & 363 & 464 \\
\hline 8.0 & 380 & 310 & 382 & 479 \\
\hline 16.0 & 403 & 325 & 392 & 487 \\
\hline 24.0 & 416 & 346 & 409 & 490 \\
\hline
\end{tabular}

a Tea-stem sections previously incubated for 3 hours in various concentrations of NAA isotopically diluted with a constant amount of NAA-1-C ${ }^{4}$.

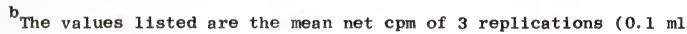
aliquots of each treatment). 

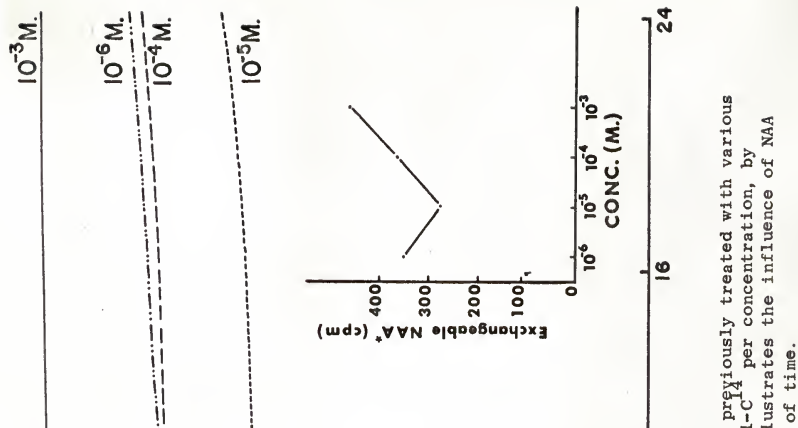

(1) nो

3 品岳

○ ले

$\therefore$ ब

4)

$\sum$ 吕

— $\underbrace{\prime}_{+\infty}$

ล

p. 0 .

$\infty$

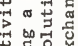

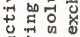

ه

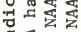

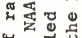

प्र० क्ष

0 ॠ

कृ

ऐ

出势

0 व

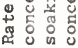

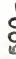

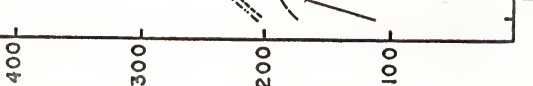

(udd) onss! $\perp$ wost $\forall \forall N$ to uo!sntf!

$\stackrel{\varphi}{\circ}$

is 
indication that the tissue content of ethanol-soluble components and the amount of $\mathrm{C}^{14} \mathrm{O}_{2}$ evolved was directly proportional to the concentration of NAA. These data can be found in Table 17.

Note the similarities in radioactivity obtained in the various ethanol extractable tissue fractions and in the various $\mathrm{C}^{14} \mathrm{O}_{2}$ fractions. For this to occur, since the amount of $N A A-1-C^{14}$ was constant in the treatments, the tissue in the presence of $10^{-3} \mathrm{M}$ NAA had to be accumulating and metabolizing NAA 1,000 times more rapidly than in the presence of $10^{-6} \sigma_{M}$ NAA.

$$
\begin{gathered}
\text { Decarboxylation of NAA-1-C } 14 \text { by Extracts } \\
\text { of Acetone Powders of Tea Stems }
\end{gathered}
$$

As a further step in delineating the nature of the decarboxylating system from tea tissues, an investigation was made of the possibility of extracting the decarboxylating system from acetone powders. The results of such an attempt are illustrated by the data on Table 18. Decarboxylating systems could be extracted from the acetone powders of both the Assam and the Chinese types of tea. The activity of the preparation from an equal amount of acetone powder was almost identical for the two types of tea for the first 60 minutes and after aging.

To determine if the decarboxylation system from acetone powders was heat sensitive, aliquots were subjected to autoclaving at 15 psi and to various periods of time at $90^{\circ} \mathrm{C}$. As shown in Table 19, the decarboxylating system from the acetone powders was heat sensitive. A ten-minute incubation period at $90^{\circ} \mathrm{C}$ destroyed the capacity of the system to decarboxylate NAA-1 - 14 . 
Table 17.- Influence of concentration of NAA ${ }^{a}$ on radipactivity in the ethanol extractable fraction and $\mathrm{C}^{14} \mathrm{O}_{2}$ fraction from tea-stems tncubated in the solutions for 3 hours

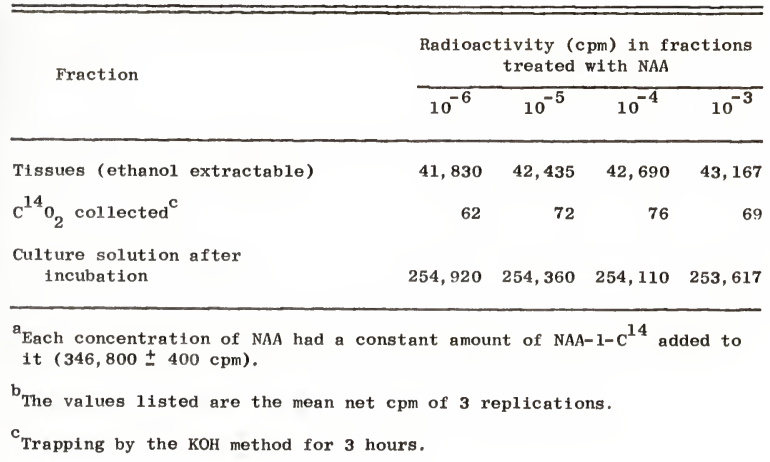


Tab1e 18. - Decarboxylating action on NAA-1- $\mathrm{C}^{14}$ of acetone-powder extract from tea tissues at various times after preparing the extract ${ }^{a}$

\begin{tabular}{ccc}
\hline \multirow{2}{*}{$\begin{array}{c}\text { Aging time } \\
\text { of extract } \\
\text { (Hrs) }\end{array}$} & Radioactivity of $\mathrm{Co}_{2}$ evolved $(\mathrm{cpm})^{\mathrm{b}, \mathrm{c}}$ \\
\cline { 2 - 3 } 1 & Assam & Chinese \\
\hline 4 & 546 & 535 \\
8 & 35 & 30 \\
16 & 28 & 26 \\
24 & 25 & 27 \\
\hline
\end{tabular}

${ }^{a}$ Each extract corresponds to $2 \mathrm{~g}$ fresh weight of stem tissues.

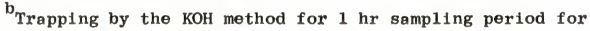
each time. 
Table 19.- Effect of high temperature treatments on the capacity of the acetone powder extracts to decarboxylate NAA-1-C

Treatment ${ }^{a}$

Radioactivity in the $\mathrm{CO}_{2}$ evolved (cpm)

1. Blank (Phosphate Buffer pH 6.0)

2. Room temperature

3. Autoclaved 15 psi for 1 hour

4. Water bath $\left(90^{\circ} \mathrm{C}\right)$ for 10 minutes

5. " " " 20 "

6. " " "

acetone powder extracts correspond to $2 \mathrm{~g}$ fresh weight of stem tissues.

${ }^{b}$ Reaction time was 60 minutes.

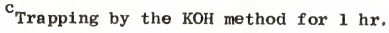


Similar to another test conducted on just the breis from tea, the acetone powder extracts were used for investigations of the influence of dialysis on the decarboxylating system. As can be seen from Table 20, neither dialysis in the cold nor the addition of magnesium or manganese to the dialyzed preparation had any appreciable influence on the decarboxylating system.

A final preliminary test was conducted to determine whether or not the NAA decarboxylating system could be precipitated by $\left(\mathrm{NH}_{4}\right)_{2} \mathrm{SO}_{4}$. As shown in Table $21\left(\mathrm{NH}_{4}\right)_{2} \mathrm{SO}_{4}$ concentrations up to $3.0 \mathrm{M}$ (near saturation) did not destroy nor completely precipitate the decarboxylating activity from the solution. However, partial precipitation was worthy of note.

$$
\text { Determination of NAA-1 - } \mathrm{C}^{14} \text { Metabolites }
$$

As has been repeatedly shown in the previous tests, a large portion of the radioactivity in tea tissue after treatment with $N A A-1-C^{14}$ can be extracted with 80 per cent ethanol. The following tests were conducted in an attempt to determine the nature of the radioactive components in this fraction. With a solvent system very similar to the one used by Zenk (186), fractions of the extract of tea treated wi th NAA-1-C 14 were subjected to thin-layer chromatography (TLC). Autoradiograms of the thin-layer chromatograms were prepared. An illustration of an autoradiogram of the fractions on TLC can be seen in Figure 17. The numbers at the point of application on the TLC radiogram refers to the NAA (No. 1) standard and the fractions (No. 2 through 5) from an ethanolic extract from tea treated with $N A A-1-C^{14}$. Briefly, the fractions for TLC were obtained by dissolving the residue of the ethanolic 
Table 20.- Effect of temperature and divalent cations on the evolution of $\mathrm{C}^{14} 0_{2}$ from dialyzed acetone 14

Treatment ${ }^{a}$

\begin{tabular}{lccccc}
\multicolumn{4}{c}{ Time } & in hours \\
\hline 1 & 4 & 8 & 16 & 24 \\
c pm & $\mathrm{cpm}$ & $\mathrm{cpm}$ & $\mathrm{cpm}$ & $\mathrm{cpm}$
\end{tabular}

1. Acetone powder extract solution (after $36 \mathrm{hrs}$ of dialysis) 495 242

80 52 28

2. Dialyzed acetone powder extract + dialyzate 403 214 70 43

3. Dialyzed acetone powder extract $+\mathrm{Mg}^{++}$

508

258

78

33

22

4. Dialyzed acetone powder extract $+\mathrm{Mn}^{++}$

488

236

47

31

21

5. Dialyzed acetone powder extract $+\mathrm{Mg}^{++}+\mathrm{Mn}^{++}$ 430 228 50 32 23

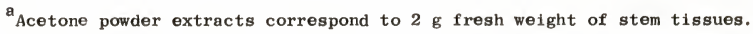
brapping by the KOH method for $1 \mathrm{hr}$ sampling period. 
Table 21.- Decarboxylating activity on NAA-1- $\mathrm{C}^{14}$ of the ammonium sulfate precipitable and non-precipitable fractions of acetone powder extracts of tea

\begin{tabular}{|c|c|c|}
\hline $\begin{array}{l}\text { Treatment of } \\
\text { acetone powder extract }\end{array}$ & $\begin{array}{l}\text { Radioactivity of } \mathrm{CO}_{2} \text { evolved } \\
\text { Supernatant fraction }\end{array}$ & $\begin{array}{l}(\mathrm{cpm})^{\mathrm{b}} \\
\text { Pellet }\end{array}$ \\
\hline 0 & 389 & -- \\
\hline $2.0 \mathrm{M}\left(\mathrm{NH}_{4}\right)_{2} \mathrm{SO} 4$ & 281 & 415 \\
\hline 3. $0 \mathrm{M}\left(\mathrm{NH}_{4}\right)_{2} \mathrm{SO}$ & 332 & 444 \\
\hline
\end{tabular}

${ }^{a}$ Acetone powder extract corresponds to $2 \mathrm{~g}$ fresh weight of stem pieces.

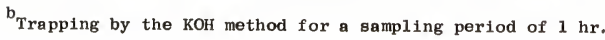




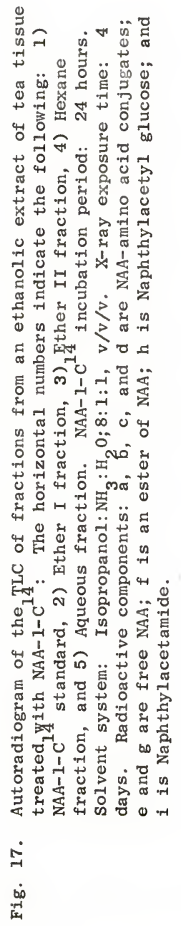




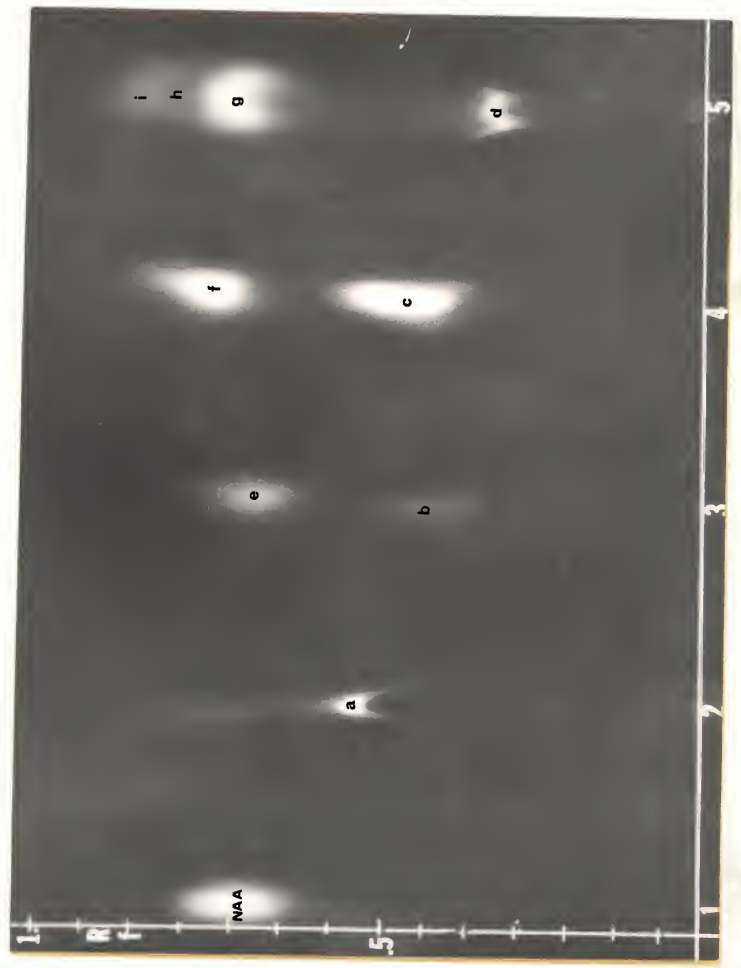


extract in an aqueous solution of $\mathrm{NaHCO}_{3}(\mathrm{pH} 8)$ then partitioning against wet ethyl ether. The residue in the ether phase (ether 1), presumably ether-soluble neutral compound, is spot No. 2 of Figure 17. Then, the aqueous phase was made acidic with tartaric acid ( $\mathrm{pH}$ 2.8) and partitioned with ethyl ether again (spot No. 3 of Figure 17). This presumably was the ether-soluble acidic compounds. After this second partitioning with ether, the remaining aqueous phase was thoroughly washed with n-hexane and the hexane (spot No. 4) and water (spot No. 5) fractions retained.

Referring again to Figure 17, it can be seen that the standard NAA had an Rf similar to that of components in fractions 3, 4, and 5 . However, free NAA should only be present in 3 and 5 . The component in fraction 4 with an Rf similar to NAA could be ethyl-naphthylene acetate. In addition to NAA, it was obvious that a number of radioactive components were present in the extract and that these were formed within 24 hours in tea tissue.

In comparing the radioactive components of the TLC to those identified by Zenk (186), it would seem that the radioactive components can be characterized as follows: components a, b, c, and $d$ are conjugates with amino acids; components $e$ and $g$ are free NAA; component $f$ is an ester of NAA; component $h$ is naphthylacetyl glucose; and component i is naphthylacetamide.

The next experiment was conducted to obtain some indication of the time required for the conversion in tea tissue of the NAA to other components. The data of Figure 18 gave some answers to this question. When the ethanolic fractions alone were subjected to TLC, it became 


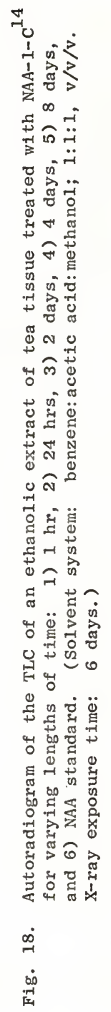




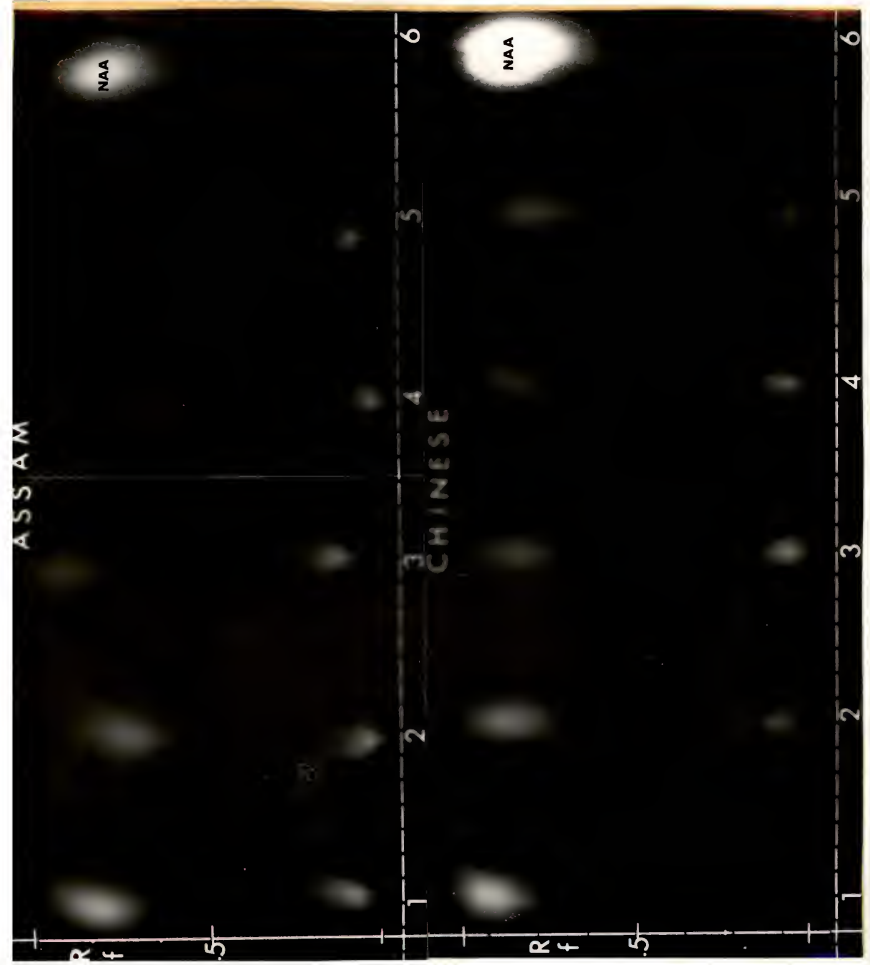


apparent that complexes were forming in less than one hour with the Assam type of tea and in less than two hours with the Chinese type of tea. After eight days there was apparently more free NAA in the Chinese type of tea than in the Assam type.

Since it was determined that tea tissue metabolized NAA to various components in less than two hours and that probably some of the components were conjugational products between NAA and amino acids, an experiment was conducted to determine if tea tissue incubated with either certain $C^{14}$ labeled amino acids or NAA-1-C 14 , or with both, would yield similarly labeled products. The amino acids chosen were alanine, aspartic acid and glutamic acid. The incubation time was three hours. Figure 19 is an autoradiogram of radioactive fractions from tea incubated with just NAA-1-C 14 . Note the similarity between this TLC and the one illustrated in Figure 17.

When alanine $-c^{14}$ and unlabeled NAA were incubated with tea tissue, a prominent labeled product appeared in Ether I on the TLC autoradiograms, as can be seen in Figure 20. Free alanine should not be present in this fraction. When both alanine $-C^{14}$ and $N A A-1-C^{14}$ were added to the incubation solution, extracted, partitioned for fractions, thinlayer chromatographed, and autoradiogramed (Figure 21), there was an indication that a complex did form between alanine and NAA. This can be seen by comparing Figures 19, 20, and 21 .

With aspartic-c 14 acid, a very weak radioactive component was found in the other I fraction, as shown in Figure 22. Free aspartic acid should not be in this fraction and there was no indication of radioactive components in the other fractions; however, the activity 


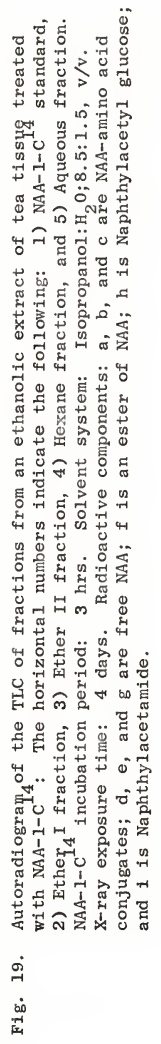




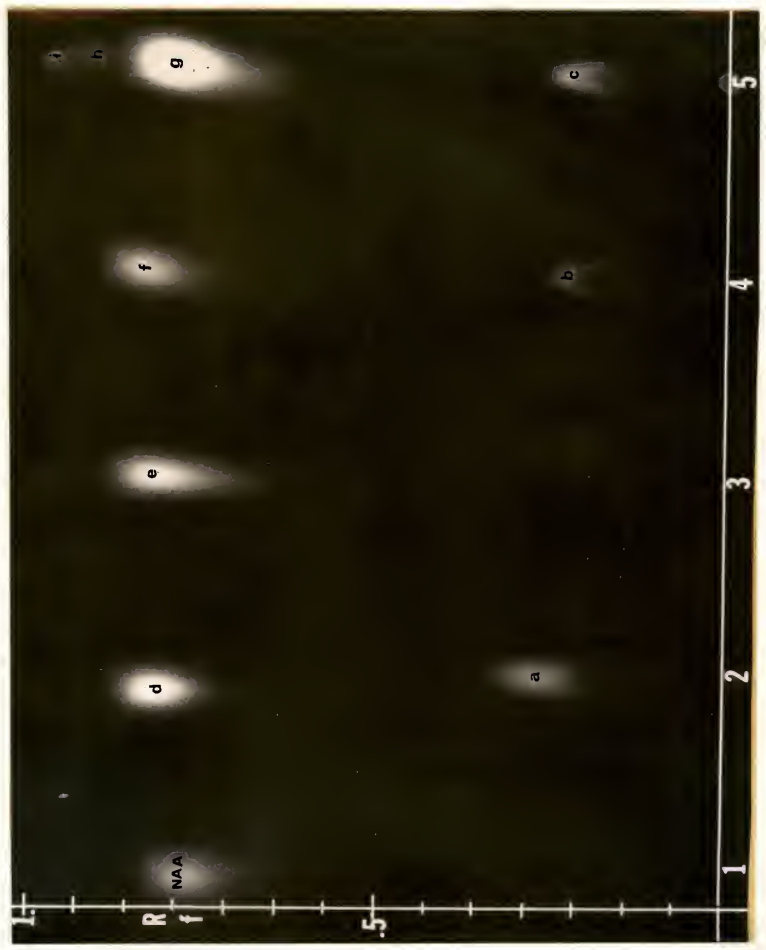




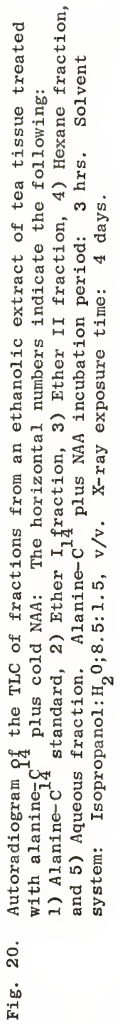




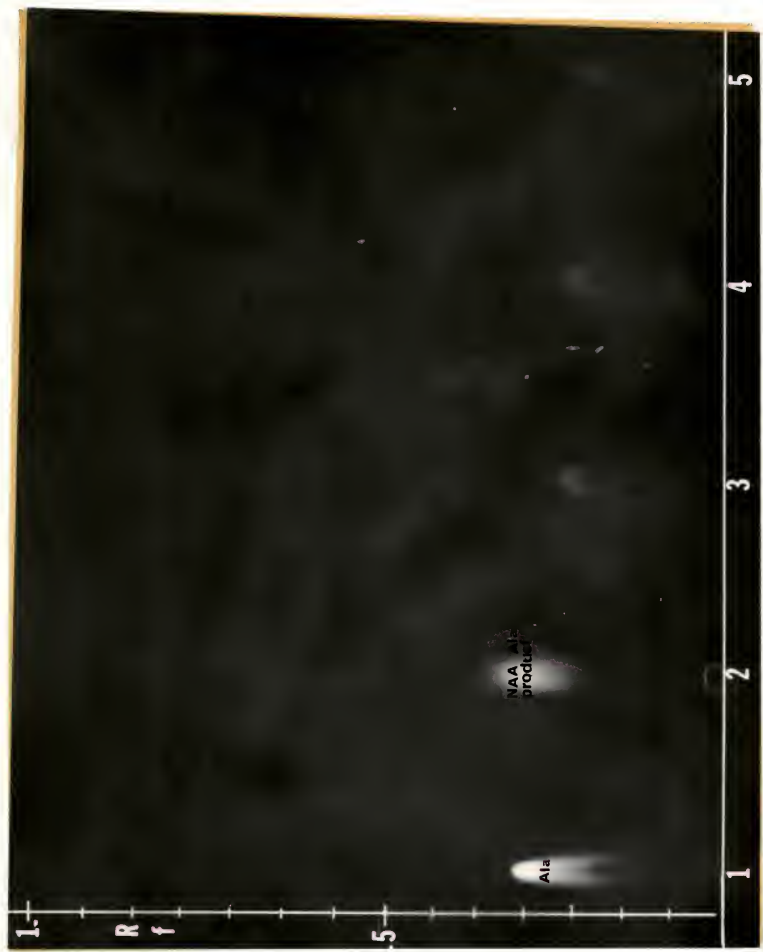




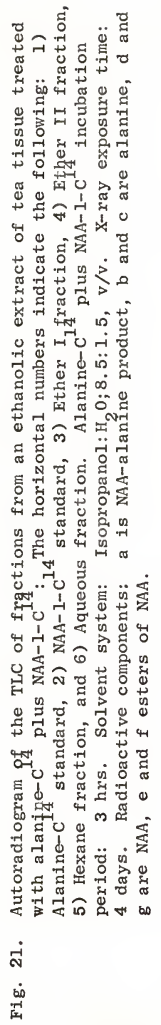




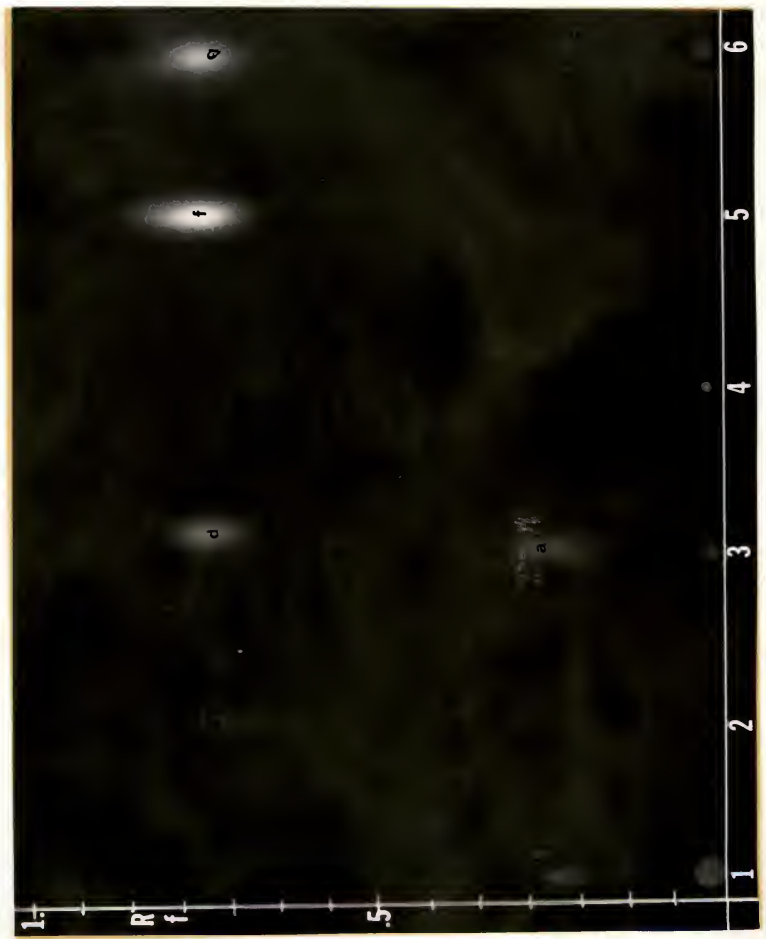




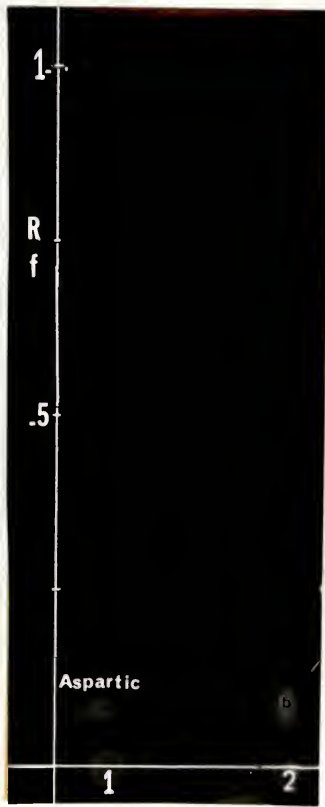

Fig. 22. Autoradiogram of the TLC of fractions from an ethanolic extract of tea tissue treated with aspartic- $\mathrm{C}^{14}$ plus cold NAA: The hgrizontal numbers indicate the following: 1) Aspartic-C ${ }^{14}$ standard, and 2) Ether I fraction. Aspartic$\mathrm{C}^{14}$ plus NAA incubation period: 3 hrs. Solvent system: Isopropanol: $\mathrm{H}_{2} 0 ; 8.5: 1.5, \mathrm{v} / \mathrm{v}$. X-ray exposure time: 14 days. Radioactive components: a is aspartic- $\mathrm{C}^{14}$ standard and $b$ is an unknown. 


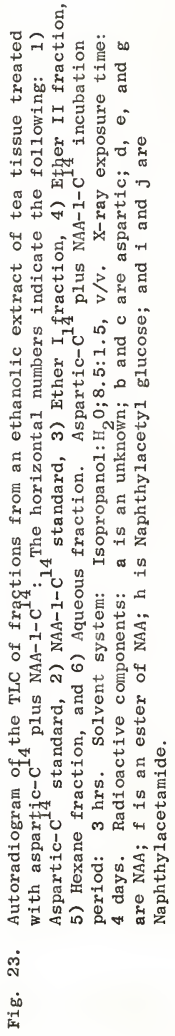




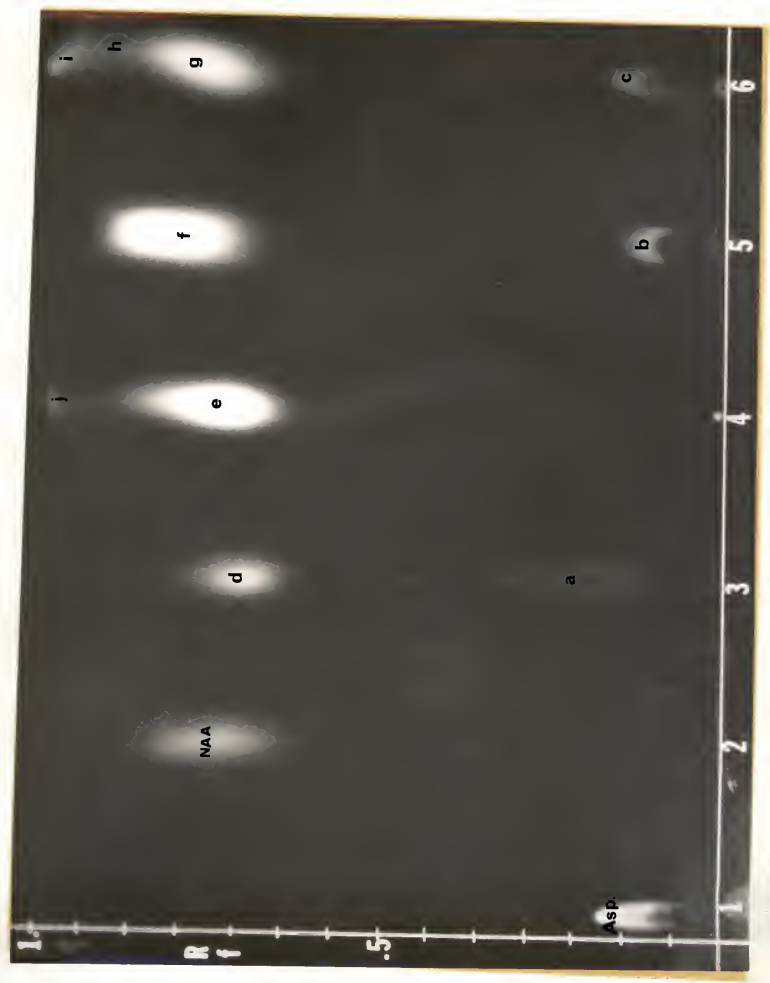




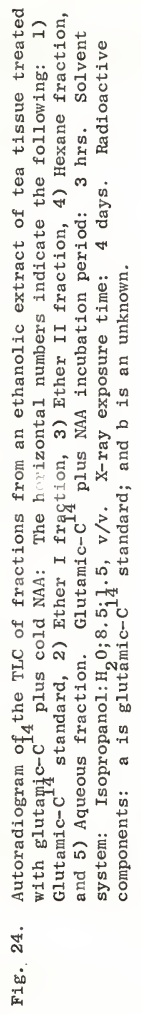




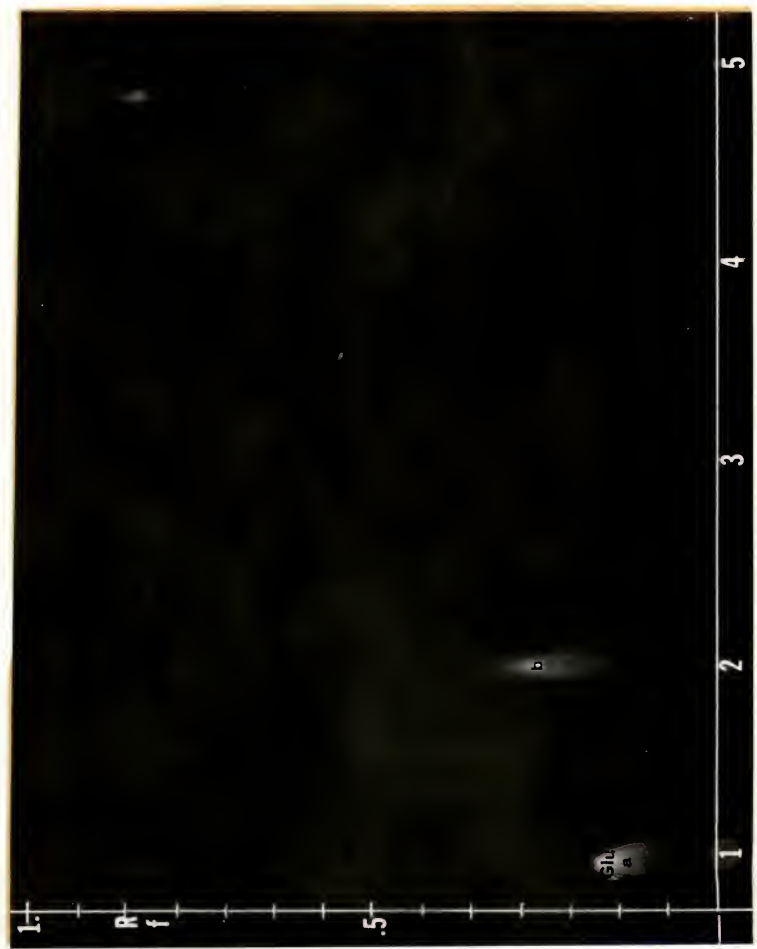




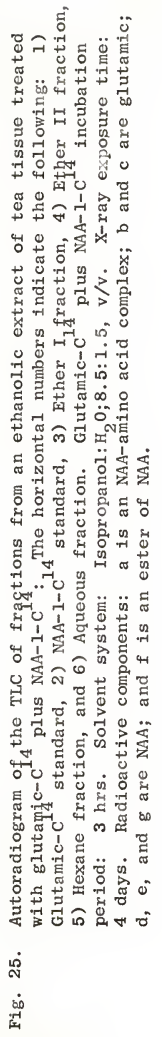




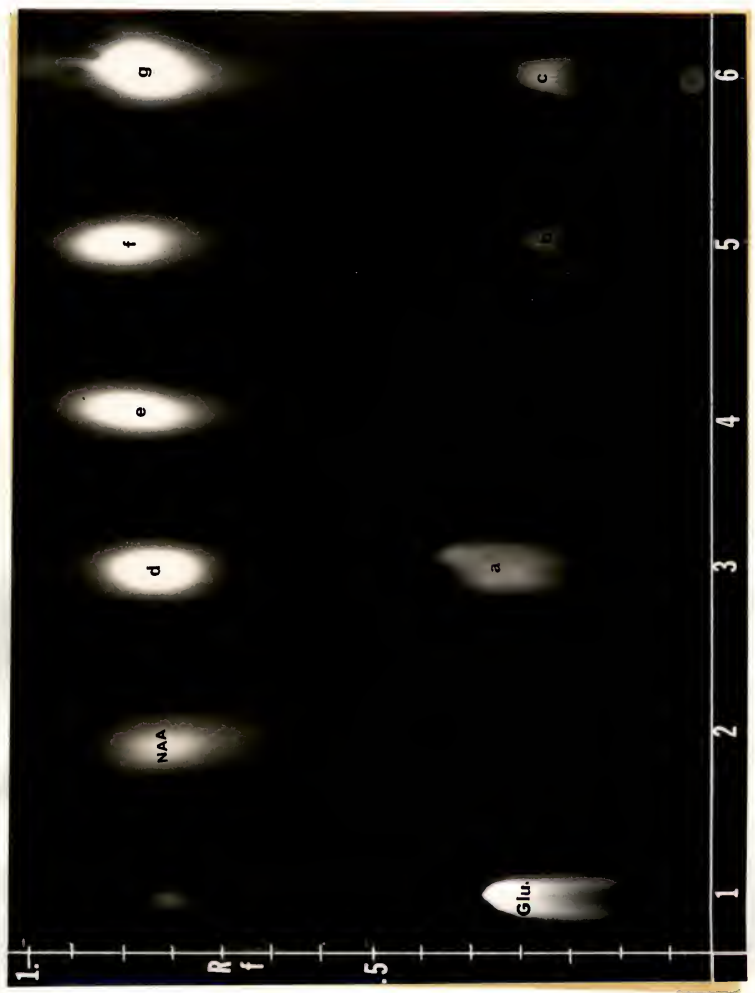


of the added sample was somewhat weak. However, when both aspartate$\mathrm{C}^{14}$ and $N A A-1-C^{14}$ were added to the incubating solution, autoradiograms (Figure 23) were obtained that had the labeled component again in the Ether I fraction and possibly some free aspartic acid in fractions 5 and 6. Although there was a radioactive product from aspartic acid in Ether 1 of Figures 22 and 23 , it did not correspond to a component when just NAA-I $-C^{14}$ was incubated with the tissue (Figure 19). The main point to be made from this experiment is that a conjugation does not seem to occur or if it does, it is weak between NAA and aspartic acid in tea tissues.

The results with glutamic acid appeared to be similar to those of aspartic acid. With glutamate-c ${ }^{14}$, there was a major radioactive product in the Ether I fraction on the autoradiograms as can be seen in Figure 24 , and this was also present when NAA-1-C 14 and glutamate $-c^{14}$ were incubated with the tissue, as shown in Figure 25 . However, as with aspartic acid, the radioactive product was not evident on the autoradiograms of fractions from tissues treated with only NAA-1-C 14 .

Thus, of the three amino acids tested, only alanine seemed to conjugate with NAA in tea tissue in a three-hour period of time. 


\section{DISCUSSION}

Auxin (NAA) enhanced the rooting of tea cuttings. Under the conditions of these tests, NAA at 10,000 ppm appeared to be approximately the optimal concentration and higher concentrations were somewhat inhibitory. Chinese tea cuttings responded to added NAA by producing more roots per cutting and by a more rapid rate of rooting than the Assam type of tea.

Since the application of NAA to tea cuttings stimulated adventitious root production, but inhibited shoot development, it therefore seems that the initial cell differentiation was determined, at least in part, by the local concentration of the auxin, shoots developing at lower and roots at higher concentrations. In fact, it has been shown by Skoog (137) that in segments of tobacco stems, when the auxin concentration was relatively high, formation of adventitious root primordia was favored and bud formation prevented.

The origin of adventitious roots took place in the phloem initials (phloem "mother" cells). More than a layer of cells, rather than a single cell, became meristematic, and gave rise to root primordia. These results are similar to those of Siegler and Bowman (130), Smith (138), Sudds (150), and Wilcox (181), who stated that the adventitious roots arose in the phloem region of apple stem pieces, Begonia maculata and B. semperflorens stem segments, several types of red and black raspberry stems, and 'Noble' fir stems, respectively.

Good agreement was obtained between the autoradiographic and extraction techniques for measuring the absorption and translocation of labeled NAA. 
Both techniques indicated that the site of auxin accumulation was the basal portion of the explants. Furthermore, it was shown that the active cellular regions accumulated the NAA-I-C 14 , particularly the area around the cambium.

Fractionating the extract by chromatography showed the presence of a considerable amount of free NAA and of a number of NAA products. Most of the radioactivity remained in the basal portion of the cuttings, with only slight amounts distributed throughout the other portions. This situation persisted from one day after treatment until eight days. By the eighth day, meristematic activity leading to formation of adventitious roots has been initiated. Since during this interval the amount of free NAA was still high, it was possible that either the free auxin molecule, or some activated form of it, was responsible for root initiation. As further support for this suggestion, it was found that the amount of free NAA was greater in the Chinese type of tea than in the more difficult to root Assam type.

The accumulation of radioactivity at the base of the cutting is of significance in connection with root initiation, since free NAA was found in these tissues during rooting and it does initiate rooting (53). 0ther similar studies by Andreae and Good (3), and Fang et al. (51) with IAA showed that applied IAA was present in tissues both as free IAA and as conjugated products with aspartic acid and ammonia. Also, Zenk (186) and Sudi (151) found that the formation of complexes between aspartic acid and NAA or IAA was adaptive and could be induced by preincubation with NAA, IAA, 2, 4-D and other carboxylic acids. Some of these conjugated products had auxin activity that varied from very weak to weak when compared to IAA, depending on the assay method used. 
From the data obtained in this study, it was not possible to determine the nature of the action of NAA on rooting. Therefore, these data do not substantiate or repudiate that NAA changed the rooting behavior of the cuttings by the mobilization of some factor(s) in the leaf for transport to the root, as has been suggested as a mode of action of auxin in rooting $(96,176)$. However, auxin (NAA) was present in the tissue at the site of rooting in a higher concentration than in surrounding tissues and this could have had an influence on mobilization.

From the data it was evident that the total amount of radioactivity in the cuttings decreased with time. The decrease that occurred during the four days following initial treatment was probably due primarily to leaching of the labeled solution from the cuttings placed under intermittent mist, although there was some decarboxylation of the NAA. As was shown, the subsequent disappearance of radioactivity was due to enzymatic conversion of NAA to other compounds. This was supported by the presence of $\mathrm{C}^{14}$ in the respiratory carbon dioxide from tissues treated with NAA-I$\mathrm{c}^{14}$ and by the demonstration of other metabolites in the tissue that arose from NAA-I-C $\mathrm{C}^{14}$. (Figure 14.) Strydom and Hartmann (146), working with plum stem cuttings treated with IAA also observed that the total amount of radioactivity in the cuttings decreased with time. The sharp decrease that they found within the first day after treatment was reported to result from non-enzymatic destruction of IAA. With tea tissue, we found no evidence for non-enzymatic destruction of NAA.

In the stem sections of tea, there was a predominantly basipetal movement of radioactivity, as was demonstrated by application of NAA$1-c^{14}$ to basal or apical stem pieces for short periods of time. This 
was in accordance with the findings of others for various tissues $(70,81,97,98)$. Only 0.06 and 0.1 per cent of the radioactivity lost from the NAA-1-C 14 donor block when it was at the apical end of stem pieces reached the receiver block for Assam and Chinese cuttings, respectively; a large percentage remained in the tissues and was immobilized there. But in both types of stem pieces the gradient of acropetally moving NAA declined so steeply that one may conclude that NAA is not transported acropetally; if it is, it is in very small amounts.

Here, as noted by McCready (104), a discussion of the means of auxin movement seems profitless until its physiology is better understood. However, it was demonstrated that NAA can be polarly transported by tea tissues and that it does accumulate in the basal portion of the cutting where rooting normally takes place.

The experiments dealing with decarboxylation and thin-layer chromatography of the ethanolic extracts suggested at least two possible mechanisms of auxin destruction in cuttings of tea. One was clearly enzymatic as indicated by evolution of $\mathrm{C}^{14} \mathrm{O}_{2}$ by $1 \mathrm{iving}$ tissues. The other was the formation of retained additional tissue-products from NAA-1-C ${ }^{14}$. Also, no liberation occurred when the labeled auxin was incubated with autoclaved tissues as was the case with extracted decarboxylating systems when exposed to $90^{\circ} \mathrm{C}$ for ten minutes.

In some reported instances, both conjugation and degradation of auxin occurred with intact tissues but only degradation occurred in breis (4) and this was the case with tea stems. With a reported case in pea (4), conjugation appeared to occur primarily in the undisturbed cortical areas. When a brei of tea was treated with $N A A-1-C^{14}$, 
apparently there was only degradative activity by decarboxylation. Andreae et al. (7) found similar results using carboxyl-labeled IAA with breis of pea roots and epicotyls. No attempt was made in the present study to locate the tissues involved in the conjugational reactions. The increased destruction of NAA that occurred by eight hours after treatment probably was the result of substantial amounts of auxin having reached the secondary phloem and the cambial zone, where it came in contact with a large number of living cells capable of metabolizing it. This explanation seems reasonable since measurements of the radioactivity of respiratory $\mathrm{CO}_{2}$ showed that short stem pieces floating in an NAA solution had an initial lag period for the production of $\mathrm{C}^{14} \mathrm{O}_{2}$, that was not present with breis of similar materials.

Previous work on the uptake of auxin by plant tissues has been reported by others $(2,84,125)$. In the case of the work by Albaum et al. (2), they concluded that IAA tended to attain only a diffusion equilibrium between external solution and plant tissue. This was not confirmed in the present work, and it was clearly shown that auxin (NAA) was actively accumulated. The present tests are in agreement with the conclusions of Reinhold (125) and Johnson and Bonner (84) that the uptake of auxin by plant tissue consists of at least two separate components. An initial rapid absorption that was completed in the case of tea stem sections in four hours or less. This could be diffusion into the free space of the tissue. NAA taken up by the tissue in this way was free to diffuse out or to be exchanged by unlabeled NAA. A second component was apparently metabolic uptake for there was a fraction of NAA that was not readily available for diffusion or exchange by 
unlabeled NAA. This accumulation took place steadily over a period of hours. Apparently, this was a fraction that was in the cytoplasm in a free or metabolized form.

The differences in the 1 iberation of $C^{14} 0_{2}$ from NAA-1- $c^{14}$ by the tea system with variations in $\mathrm{pH}$ showed the characteristics of an enzymatic reaction. For this particular enzyme system from tea tissues, $\mathrm{pH} 6.0$ appeared to be optimal. However, a comparison of three buffer systems indicated that the nature of the buffer had an influence on the relation of the enzyme systems and $\mathrm{pH}$. Thus, the type of buffer may influence the optimal $\mathrm{pH}$, as occurred with the Assam brei preparations. This apparently is rather common with enzyme systems (123).

As reported by $\mathrm{Klambt}(87)$, who studied the formation of metabolic products from labeled IAA and benzoic acid supplied to wheat coleoptile tissue, and the present work, at least five reaction products were formed when tea stem pieces were treated with NAA. With Isopropanol: $\mathrm{NH}_{3}: \mathrm{H}_{2} \mathrm{O}$ $(8: 1: 1, v / v / v)$ as the solvent system for TLC (186), products were found at $\mathrm{Rf}^{\text {is }}$ corresponding to NAA-amino acids conjugates of NAA, an ester of NAA, naphthylacetyl glucose and naphthylacetamide. Later with Isopropanol: $\mathrm{H}_{2} \mathrm{O}(8.5: 1.5, v / v)$ as the solvent system (15), a conjugated product of NAA with alanine, probably by means of a peptide link established between the carboxyl group of the auxin and the amino group of alanine, was found. Products of NAA-aspartic acid and NAA-glutamic acid have been reported for other plant species $(87,186)$. However, with tea stem pieces there did not seem to be present conjugates between NAA and aspartic acid, and NAA and glutamic acid, at least after a three-hour incubation period of tea tissue in NAA-I-C 14 . 
1. A study was made to determine the influence of $\alpha$-naphthaleneacetic acid (NAA) on the rooting of Assam and Chinese types of tea (Camellia sinensis, (L.) 0. Kuntze). Using clonal material from both. types, it was established that NAA stimulated rooting of Chinese types of tea cuttings to a greater extent than it did the Assam type of tea. This included a greater number of roots and a faster rate of rooting. A significant characteristic of the NAA treatments was the relatively strong concentration $(10,000 \mathrm{ppm})$ needed for the optimal rooting of both types of tea. This indicated a problem with either uptake, translocation, detoxification, or tissue sensitivity to NAA or a combination of these factors.

2. The origin of adventitious roots in stem cuttings of both types of tea originated in the phloem initials (phloem "mother" cells). The first cell divisions, leading to root primordia, took place between five to six days after NAA treatment.

3. The absorption, translocation, distribution, and destruction of carboxyl-labeled NAA (NAA-1-C $\mathrm{C}^{14}$ ) in Assam and Chinese tea cuttings, were determined by using autoradiographic, chromatographic and liquid scintillation techniques.

4. The amount of NAA-I-C $\mathrm{C}^{14}$ taken-up by Chinese cuttings was greater than that of Assam cuttings.

5. The basal part of both types of cuttings still showed appreciable amounts of radioactivity eight days after treatment. 
6. The polarity of transport of NAA-1-C 14 in tea-stem pieces was basipetal.

7. The uptake of NAA depended apparently on two processes. The first, consumated in about four hours or less, resembled a diffusion into the tissue because the NAA taken up by this process was readily leached from the tissue. The second component of NAA uptake was a continuing absorption, maintained at a steady rate for the duration of the treatments ( 24 hours).

8. The decarboxylation of NAA by tea tissue was established. The amount of $\mathrm{C}^{14} \mathrm{O}_{2}$ evolved during a period of three hours of incubation was 0.11 per cent of the tissue fraction. However, over a period of several days the NAA destroyed in this manner could be considerable.

9. The cuttings treated with $N A A-1-C^{14}$ showed detectable amounts of radioactivity in the respiratory $\mathrm{CO}_{2}$ within one hour following treatment. Within eight hours the $\mathrm{C}^{14} 0_{2}$ evolved reached its peak, and after 24 hours, these values had decreased appreciably.

10. Both conjugation and degradation of NAA occurred in intact tissues, but in breis of tea tissues only degradative activity was observed.

11. The $N A A-I-C^{14}$ degradated by intact stem pieces varied with the type of tea and the age of the tissue treated with auxin. The Chinese type of tea yielded less $\mathrm{C}^{14} 0_{2}$ by decarboxylation than the Assam type. In both types of tea, the older stem tissues decarboxylated NAA to a lesser extent.

12. When intact tissues from both types of tea were treated with $N A A-1-C^{14}$, there was a difference in the lag period for production of 
the auxin complexes. Within three hours after the start of incubation of stem tissues in $N A A-1-C^{14}$, the Assam type showed greater amounts of conjugated products than the Chinese type.

13. Intact tea-stems treated with $N A A-1-C^{14}$ yielded at least five reaction products after three hours of incubation.

14. Of the three amino acids (alanine-c $c^{14}$, aspartate- $c^{14}$ and glutamate $-c^{14}$ ) tested for possible conjugation with NAA only alanine seemed to conjugate with NAA in tea tissues in a three-hour period of time.

15. The formation of the NAA-alanine derivative could have a role in the detoxification of NAA.

From the results of the comparative studies between the two types of tea, Assam and Chinese, it was established that the greater rooting response to NAA obtained with the Chinese in relation to Assam was due to: 1) a greater amount of auxin taken up by the Chinese type of tea, and 2) the NAA taken up remained unaltered for a longer period of time, undergoing less degradation and conjugation at the site where the adventitious root differentiation takes place with Chinese type. However, with both teas, the high concentration of NAA required for rooting was probably due to metabolism of the applied synthetic auxin. 


\section{LITERATURE CITED}

1. Aberg, B. 1952. On the growth-regulating effects of some 1-Naphthyl and 2,4-Dichlorophenoxyl derivatives without carboxyl groups. Physiol. Plantarum. 5:567-574.

2. Albaum, H. G., S. Kaiser, and H. A. Nestler. 1937. The relation of hydrogen-ion concentration to the penetration of indoleacetic acid into Nitella cells. Amer. J. Bot. 24:513-518.

3. Andreae, W. A., and N. E. Good. 1957. Studies on 3-indoleacetic acid metabolism. IV. Conjugation with aspartic acid and ammonia as processes in the metabolism of carboxylic acids. Plant Physiol. $32: 566-572$.

4. and M. W. H. van Ysselstein. 1956. Studies on 3-indoleacetic acid metabolism. III. The uptake of 3-indoleacetic acid by pea epicotyls and its conversion to 3-indoleacetyl aspartic acid. Plant Physiol. 31.235-240.

5. and 1960. Studies of 3-indoleacetic acid metabolism. V. Effect of calcium ions on 3-indoleacetic acid uptake and metabolism of pea roots. Plant Physiol. 35:220-224.

6. and 1960. Studies on 3-indoleacetic acid metabolism. VI. Indoleacetic acid uptake and metabolism by pea roots and epicotyls. Plant Physiol. 35:225-232.

7. J. R. Robinson, and M. W. H. van Ysselstein. 1961. Studies on 3-indoleacetic acid metabolism. VII. Metabolism of radioactive 3 -indoleacetic acid by pea roots. Plant Physiol. $36: 783-787$.

8. Bach, M. K. and J. Fellig. 1961. Correlation between inactivation of 2,4-Dichlorophenoxyacetic acid and cessation of callus growth in bean stem sections. Plant Physiol. 36:89-91.

9. Bannan, M. W. 1941. Vascular rays and adventitious root formation in Thuia accidentalis L. Amer. J. Bot. 28:457-463.

10. 1942. Notes on the origin of adventitious roots in the native Ontario conifers. Amer. J. Bot. 29:593-598.

11. Barrier, G. E. and W. E. Loomis. 1957. Absorption and translocation of 2,4-Dichlorophenoxyacetic acid. Plant Physiol. 32:225231 . 
12. Beakbane, A. B. 1961. Structure of the plant stem in relation to adventitious rooting. Nature. 192:954-955.

13. Bentley, J. A. and S. Housley. 1953. Growth of Avena coleoptile sections in solutions of 3-indoleacetic acid and 3-indolylacetinitrile. Physiol. Plantarum. 6:480-484.

14. and 1954. Bio-assay of plant growth hormones. Physiol. Plantarum. 7:405-419.

15. Biggs, R. H. 1959. Investigations on growth substances in peach buds. Proc. Fla. State Hort. Soc. 72:341-346.

16. Black, C. C. and T. E. Humphreys. 1962. Effects of 2,4-Dichlorophenoxyacetic acid on enzymes of glycolysis and pentose phosphate cycle. Plant Physiol. 37:66-73.

17. Blackman, G.E. and J.A. Sargent. 1959. The uptake of growth substances. 11. Jour. Exp. Bot. 10:480-503.

18. Bonner, J. and R. S. Bandurski. 1952. Studies of the physiology, pharmacology, and biochemistry of the auxins. Ann. Rev. Plant Physiol. 3:59-86.

19. Bray, G. A. 1960. A simple efficient liquid scintillator for counting aqueous solutions in a liquid scintillator counter. Anal. Biochem. 1:279-285.

20. Brian, P. W., H. G. Hemming and M. Radley. 1955. A physiological comparison of gibberellic acid with some auxins. Physiol.

$\mathrm{Plantarum.} \mathrm{8:899-912.}$

21. Briggs, W. R., T. A. Steeves, 1. M. Sussex and R. H. Wetmore. 1955. A comparison of auxin destruction by tissue extracts and intact tissues of the fern 0smunda cinnamonea. Plant Physiol. 30:148-155.

22. Brown, C. L. and R. H. Wetmore. 1959. Auxin transport in the long shoots of pine. Amer. J. Bot. 46:585-590.

23. Burstron, H. 1950. Studies on growth and metabolism of roots. IV. Positive and negative auxin effects on cell elongation. Physiol. Plantarum. 3:277-292.

24. 1951. Studies on growth and metabolism of roots. VII. The growth action of $\beta$-(Phenoxy) propionic acids. Physiol. Plantarum. 4:641-651.

25. Physiol. 1953. Physiology of root growth. Ann. Rev. Plant

26. 1955. Evaluation on the growth activity of naphthalene derivatives. Physiol. Plantarum. 8:174-188. 
27. Cajlahjan, M. R., R. H. Tureckaja and N. S. Kljuskina. 1961. The interaction of physiologically active substances in plant cuttings during the formation and growth of roots and stems. Plant Physiol. (Fiziologiya Rastenii). 8:601-12.

28. Carlson, M. C. 1930. Origin of adventitious roots in coleus cuttings. Contr. Boyce Thomp. Inst. 2:39-46.

29. 1933. Comparative anatomical studies of Dorothy Perkins and American Pillar Roses. I. Anatomy of canes. II. Origin and development of adventitious roots in cuttings. Contr. Boyce Thomp. Inst. 5:313-330.

30.

1938. The formation of nodal adventitious roots in Salix cordata. Amer. J. Bot. 25:721-725.

31. 1950. Nodal adventitious roots in Willow stems of different ages. Amer. J. Bot. 37:555-561.

32. Carlton, W. 1944. Histological and cytological responses of roots to growth-regulating substances. Bot. Gaz. 105:268-281.

33. Chailakhyan, M. Kh., R. H. Turetskaya and N. S. Klyushkina. 1961. Interaction of physiologically active substances in plant cuttings during the formation and growth of roots and stems. Plant Physiol. (Fiziologiya Rastenii). 8:479-489.

34. Cochran, W. G. and G. M. Cox. 1964. Experimental Design. 2nd ed. John Wiley and Sons, Inc., New York.

35. Connard, M. H. and P. W. Zimmerman. 1931. The origin of adventitious roots in cuttings of Portulaca oleracea, L. Contr. Boyce Thomp. Inst. $3: 337-346$.

36. Cooper, W. C. 1935. Hormones in relation to root formation on stem cuttings. Plant Physiol. 10:789-794.

37. 614. 1938. Hormones and root formation. Bot. Gaz. 99:599-

38. Crafts, A. S. 1956 . The mechanism of translocation: Methods of study with $\mathrm{C}^{14}$ labeled 2,4-D. Hilgardia. ?6: $87-334$.

39. 1959. Further studies on comparative mobility of labeled herbicides. Plant Physiol. 34:613-620.

40. and S. Yamaguchi. 1958. Comparative tests on the uptake and distribution of labeled herbicides by Zebrina pendula and Iradescantia fluminensis. Hilgardia. 27:421-454. 41. Amer. J. Bot. $47: 248-255$. 1960 . Absorption of herbicides by roots. 
42. Crane, J. C. and T. S. Mallah. 1952. Varietal root and top regeneration of fig cuttings as influenced by application of indole butyric acid. Plant Physiol. 27:309-319.

43. Dannenburg, W. $N_{4}$ and J. L. Liverman. 1957. Conversion of tryptophan $2-\mathrm{C}^{\mathrm{i}}$ to indoleacetic acid by watermelon tissue slices. Plant Physiol. 32:263-269.

44. Dhillon, B. S. 1963. Effect of winter storage on rooting of black currant cuttings. Indian J. Hort. 20:200-203.

45. du Buy, H. G. and R. A. 01son. 1940. The relation between respiration, protoplasmic streaming, and auxin transport in the Avena coleoptile. Amer. J. Bot. 27:401-414.

46. Dugger, W. M. 1957. Autoradiography with plant tissue. Bot. Rev. $23: 351-388$.

47. Eliasson, L. 1963. Response of aspen roots to auxin-type growth substances applied to the leaves. Physiol. Plantarum. 16:201214.

48. Easu, K. 1962. Anatomy of Seed Plants. John Wiley and Sons, Inc. New York.

49. 1965. Plant anatomy. John Wiley and Sons, Inc. New York.

50. Fang, S. C. and J. S. Butts. 1957. Studies of carboxyl-c $14-1$ abeled 3-indoleacetic acid in plants. Plant Physiol. 32:253-259.

51. P. Theisen, and J. S. Butts. 1959. Metabolic studies of applied indoleacetic acid in plants. Plant Physiol. 34:26-32.

52. Fawcett, C. H. 1961. Indole auxins. Ann. Rev. Plant Physiol. $12: 345-368$.

53. Figueroa, R. H. 1964. Response of tea leaf-bud cuttings to different concentrations of alpha-naphthaleneacetic acid. Unpublished data. University of Florida, Gainesville, Fla.

54. Foster, R. E. 1963. Aereation, light and type of cuttings for vegetative propagation of muskmelon (Cucumis melo L.), Proc. Amer. Soc. Hort. Sci. 83:596-598.

55. Fransson, P. 1953. Studies on auxin in young stem parts of Pinus silvestris. Physiol. Plantarum. 6:533-537.

56. Galston, A. W. 1955. Some metabolic consequences of the administration of indoleacetic acid to plant cells. In: The chemistry and mode of action of plant growth substances. Wain, R. L. and F. Wightman, eds. Butterworths Scientific Publications, London. 
57. and L. Y. Dalberg. 1954. The adaptive formation and physiological significance of indoleacetic acid oxidase. Amer. J. Bot. $41: 373-380$.

58. and W. K. Purves. 1960. The mechanism of action of auxin. Ann. Rev. Plant Physiol. 11:239-276.

59. Gautheret, R. J. 1955. The nutrition of plant tissue cultures. Ann. Rev. Plant Physiol. 6:433-484.

60. Geronimo, J., P. B. Caţin and E. C. Maxie. 1964. Metabolism of indoleacetic acid-2-C 14 in plum stem cuttings. Physiol.

Plantarum. 17:644-653.

61. Gillespie, B, and K. V. Thimann. 1963. Transport and distribution of auxin during tropistic response. 1. The lateral migration of auxin in geotropism. Plant Physiol. 38:214-225.

62. Goldberg, E. 1939. Histological responses of cabbage plants grown at different levels of nitrogen nutrition to indole-3acetic acid. Bot. Gaz. 100:347-369.

63. Goldsmith, M. H. 1966. Movement of indoleacetic acid in coleoptiles of Avena sativa, L. II. Suspension of polarity by total inhibition of the basipetal transport. Plant Physiol. 41:15-27.

64. Good, N. E., W. A. Andreae, and M. W. H. van Ysselstein. 1956. Studies on 3 -indoleacetic acid metabolism. 11. Some products of metabolism of exogenous indoleacetic acid in plant tissues. Plant Physiol. 34:26-32.

65. Gordon, S. A. 1954. Occurrence, formation and inactivation of auxins. Ann. Rev. Plant. Physiol. 5:341-378.

66. and L. G. Paleg. 1957. Observations on the quantitative determination of indoleacetic acid. Physiol. Plantarum. 10:39-47.

67. and 1961. Formation of auxin from tryptophan through action of polyphenols. Plant Physiol. 36:838-845.

68. Gorter, C. J. 1958. Synergism of indole and indole-3-acetic acid in the root production of Phaseolus cuttings. Physiol. Plantarum. $11: 1-9$.

69. 1962. Further experiments on auxin-synergists. Physiol. Plantarum. 15:88-95.

70. and H. Veen. 1966. Auxin transport in explants of Coleus. Plant Physiol. 41:83-86. 
71. Gregory, L. E. and J. Van Overbeek. 1945. Analysis of the process of root formation on cuttings of a difficult-to-root hibiscus variety. Proc. Amer. Soc. Hort. Sci. 46:427-433.

72. Gregory, F. G. and C. R. Hancock. 1955. The rate of transport of natural auxin in woody shoots. Annals Bot. 19:451-465.

73. Hamner, K. C. and E. J. Kraus. 1937. Histological reactions of bean plants to growth-promoting substances. Bot. Gaz. 98:735-807.

74. Hartmann, H. T. and D. E. Kester. 1964. Plant Propagation: Principles and Practices. Prentice-Hall. Englewood Cliffs, N.J.

75. Hausen, S. 1948. On the role of growth substances in higher plants. Physiol. Plantarum. 1:85-94.

76. Hemberg, T. 1951. Rooting experiments with hypocotyles of Phaseolus vulgaris L. Physiol. Plantarum. 4:358-369.

77. 1953. The effect of Vitamin $K$ and Vitamin $H^{\prime}$ on the root formation in cuttings of Phaseolus vulgaris, L. Physiol. PIantarum. 6:17-20.

78. 1954. The relation between the occurrence of auxin and the rooting of hypocotyles in Phaseelus vulgaris, L. Physiol. Plantarum. 7:323-331.

79. Higdon, R. J. and M. N. Westwood. 1963. Some factors affecting the rooting of hardwood pear cuttings. Proc. Amer. Soc. Hort. Sci. 83:193-198.

80. Hitchcock, A. E. and P. W. Zimmerman. 1935. Absorption and movement of synthetic growth substances from soils as indicated by the responses of aerial parts. Contr. Boyce Thomp. Inst. 7: $447-476$.

81. Jacobs, W. P. 1950a. Auxin transport in the hypocotyl of Phaseolus vulgaris, L. Amer. J. Bot. 37:248-254.

82. 1950b. Control of elongation in the bean hypocotyl by the ability of the tip to transport auxin. Amer. J. Bot. 37: $551-555$.

83. Johansen, D. A. 1940. Plant Microtechnique. McGraw-Hill. New York.

84. Johnson, M. P. and J. Bonner. 1956. The uptake of auxin by plant tissue. Physiol. Plantarum. 9:102-118.

85. Kato, J. 1958. Studies on the physiological effect of gibberellin. Il. On the interaction of gibberellin with auxins and growth inhibitors. Physiol. Plantarum. 11:10-15. 
86.

1959. Studies on the relation between auxin activity and chemical structure. II. Optically active 1,2-Dihydronaphthoic acids-(1) and the hydrogenated derivatives of naphthoic acids-(2). Physiol. Plantarum. 11:200-206.

87. Klambt, H. D. 1961. Wachstumsinduktion und Wuchsstof fmetabo1 ismus im Weizenkoleoptilzylinder. Stoffwechselprodukte der Indol-3-Essigsaure und der Benzoesaure. Planta. 56:618-631.

88. Kefeli, V. I. and R. Kh. Turetskaya. 1964. A method for determination of free auxins and inhibitors in woody plant tissues. Plant Physiol. (Fiziologiya Rastenii). 10:414-417.

89. Keitt, G. W. and F. Skoog. 1959. Effect of some substituted benzojc acids and related compounds on the distribution of callus growth in tobacco explants. Plant Physiol. 34:177-212.

90. Knight, R. C. and A. W. Witt. 1926. The propagation of fruit tree stocks by stem cuttings. Observations on the factors governing the rooting of hardwood cuttings. J. Pomol. Hort. Sci. 5:248266.

91. Kraus, E. J., N. A. Brown and K. C. Hamner. 1937. Histological reactions of bean plants to indoleacetic acid. Bot. Gaz. 98: $370-419$.

92. Lanphear, F. O. and P. R. Meah1. 1963. Influence of endogenous rooting cofactors and environment on the seasonal fluctuation in root initiation of selected evergreen cuttings. Proc. Amer. Soc. Hort. Sci. 83:811-818.

93. Larsen, P. 1951. Formation, occurrence and inactivation of growth substances. Ann. Rev. Plant Physiol. 2:169-198.

94. 1955. On the separation of acidic and non-acidic auxins. Physiol. Plantarum. 8:343-357.

95. Lefanu, B. 1936. Auxin and correlative inhibition. New Phytol. $35: 205-220$.

96. Leopold, A. C. 1964. Plant Growth and Development. McGraw Hill. New York.

97. and F. S. Guernsey. 1953. Auxin polarity in the coleus plant. Bot. Gaz. 115:147-154.

98. and S. L. Lam. 1961. Polar transport of three auxins. In R. M. Klein (ed.), Plant Growth Regulation. Iowa State University Press, Ames, lowa.

99. Plantarum. $15: 631-638$.

1962. The auxin transport gradient. Physiol. 
100. Lindner, R. C. 1939. Effects of indoleacetic acid and naphthylacetic acid on development of buds and roots in horseradish. Bot. Gaz, $100.500-527$.

101. Loewenberg, J. R. 1965. Promotion of indoleacetic acid destruction by citric acid and L-alanine. Physiol. Plantarum. 18:31-40.

102. Manning, D. T. and A. W. Galston. 1955. On the nature of the enzymatically catalyzed oxidation products of indoleacetic acid. Plant Physiol. 30:225-231.

103. McCready, C. C. 1963. Movement of growth regulators in plants. I. Polar transport of 2,4-D. New Phytol. 62:3-18.

104. 1966. Translocation of growth regulators. Ann. Rev. Plant Physiol. 17:283-294.

105. Mitchell, J.W. and W. E. Martin. 1938. Effect of indoleacetic acid on growth and chemical composition of etiolated bean plants. Bot. Gaz. 99:171-183.

106. and N. W. Stuart. 1939. Growth and metabolism of bean cuttings subsequent to rooting with indoleacetic acid. Bot. Gaz. $100: 627-649$.

107. and P. C. Marth. 1950. Growth-regulating substances in Horticulture. Ann. Rev. Plant Physiol. 1:125-140.

108. Muir, R. M. and C. Hansch. 1955. Chemical constitution as related to growth-regulator action. Ann. Rev. Plant. Physiol. 6:157-176.

109. Niedergang-Kamien, E. and F. Skoog. 1956. Studies on polarity and auxin transport in plants. Physiol. Plantarum. 9:60-73.

110. and A. C. Leopold. 1957. Inhibitors of polar auxin transport. Physiol. Plantarum. 10:29-38.

111. 1959. The inhibition of transport of indoleacetic acid by phenoxyacetic acids. Physiol. Plantarum. $12: 776-785$.

112. Nitsch, J. P. 1955. Free auxins and free tryptophane in the strawberry. Plant Physiol. 30:33-39.

113. Pearse, H. L. 1948. Growth substances and their practical importance in Horticulture. Commonwealth Bur. Hort. and Plant Crops. Tech. Comm. No. 20.

114. Perlis, I. B. and J. F. Nance. 1956. Indoleacetic acid and the utilization of radioactive pyruvate and acetate by wheat roots. Plant Physiol. 31:451-455. 
115. Pijet, P. E. 1960. In Vitro: Destruction of auxin labeled with

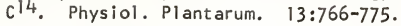

116. 1961. Kinetics of the auxin catabolism. Physiol. Plantarum. 14:787-802.

117. and A. W. Galston. 1955. Auxin destruction, peroxidase activity, and peroxidase genesis in the roots of Lens culinaria. Physiol. Plantarum. 8:888-898.

118. and K. V. Thimann. 1956. The destruction of indoleacetic acid. 1. Action of an enzyme from 0mphalia flavida. Arch. Biochem. Biophys. 64:175-192.

119. Plant, W. 1940. The role of growth substances in the regeneration of root cuttings. Annals Bot. 4:607-616.

120. Pridman, J. B. 1965. Low molecular weight phenols in higher Plants. Ann. Rev. Plant Physiol. 16:12-36.

121. Priestley, J. H. and C. F. Swingle. 1929. Vegetative propagation from the standpoint of plant anatomy. U.S. Dept. Agr. Tech. Bul. 151 .

122. Purves, W. K. and W. S. Hillman. 1958. Response of pea stem sections to indoleacetic acid, gibberellic acid, and sucrose as affected by length and distance from apex. Physiol. Plantarum. $11: 29-35$.

123. Ray, P. M. 1958. Destruction of auxin. Ann. Rev. Plant Physiol. 9:81-118.

124. and K. V. Thimann. 1955. Steps in the oxidation of indoleacetic acid. Science. 122:187-188.

125. Reinhold, L. 1954. The uptake of indole-3-acetic acid by pea epicotyl segments and carrot disks. New Phytol. 53:217-239.

126. Sass, J. E. 1951. Botanical Microtechnique. lowa State College Press. Ames, lowa.

127. Sen, S. P. and A. C. Leopold. 1954. Paper chromatography of plant growth regulators and allied compounds. Physiol. Plantarum. 7:98-108.

128. Shantz, E. M. 1966. Chemistry of naturally occurring growthregulating substances. Ann. Rev. Plant Physiol. 17:409-438.

129. Siegel, S. M. and R. L. Weintraub. 1952. Inactivation of 3indoleacetic acid by peroxides. Physiol. Plantarum. 5:241-247. 
130. Siegler, E. A. and J. J. Bowman. 1939. Anatomical studies of root and shoot primordia in 1-year apple roots. J. Agr. Research. 58: 795-803.

131. Simon, E. W. and H. Beevers. 1952. The effect of pH on the biological activities of weak acids and bases. 1. The most unusual relationship between $\mathrm{pH}$ and acidity. New Phytol. 51: 163-190.

132. Sinkukhim, A. M. 1958. Physiological peculiarities of callus formation by secondary meristems. Plant Physiol. (Fiziologiya Rasteni i). 5:491-499.

133. Skoog, F. 1938. Absorption and translocation of auxin. Amer. J. Bot. 25:361-372.

134. 1944. Growth and organ formation in tobacco tissue cultures. Amer. J. Bot. 31:19-24.

135. 1951. Growth substances and the formation of buds in plant tissue. Plant Growth Substances. University of Wisconsin Press, Madison.

136. C. L. Schneider and P. Malan. 1942. Interactions of auxin in growth and inhibition. Amer. J. Bot. 29:568-576.

137. and C. Tsui. 1948. Chemical control of growth and bud formation in tobacco stem and callus. Amer. J. Bot. 35:782-787.

138. Smith, A. 1. 1936. Adventitious roots in stem cuttings of Beqonia maculata and B. semperflorens. Amer. J. Bot. 23:511515.

139. Snow, R. 1936. Upward effects of auxin in coleoptiles and stems. New Phytol. 35:292-304.

140. Steeves, T. A., G. Morel and R. H. Wetmore, 1953. A technique for preventing inactivation at the cut surface in auxin diffusion studies. Amer. J. Bot. 40:534-538.

141. Stevens, V. L., J. S. Butts and C. Fang. 1962. Effects of plant growth regulators and herbicides on metabolism of $C^{14}$ labeled acetate in pea root tissues. Plant Physiol. 37:215-222.

142. Steward, F. C. and E. M. Shantz. 1959. The chemical regulation of growth (some substances and extracts which induce growth and morphogenesis). Ann. Rev. Plant Physiol. 10:379-404.

143. Straus, J. and R. K. Gerding. 1963. Auxin oxidase and growth control in tissue culture of ephedra. Plant Physiol. 38:621-627. 
144. Strydom, D. K. 1959. Physiological and biochemical aspects of root initiation in detached woody stem tissue. Ph.D. dissertation. University of California. Davis.

145. 1962. The effect of leaves on root initiation in Marianna-2624 pl um cuttings. S. Afr. Jour. Agr. Sci. 5:147-148.

146. and H. T. Hartmann. 1960. Absorption, distribution and destruction of indoleacetic acid in plum stem cuttings. Plant Physiol. 35:435-442.

147. Stuart, N. W. 1939. Nitrogen and carbohydrate metabolism of kidney bean cuttings as affected by treatment with indoleacetic acid. Bot. Gaz. 100:298-311.

148. Stutz, R. E. 1957. The indole-3-acetic acid oxidase of Lupinus albus, L. Plant Physiol. 32:31-39.

149. 1958. Enzymatic formation of indole-3-carboxaldehyde from indole-3-acetic acid. Plant Physiol. 33:207-212.

150. Sudds, R. H. 1935. The origin of roots in several types of red and black raspberry stem cuttings. Proc. Amer. Soc. Hort. Sci. $33: 380-388$.

151. Sudi, J. 1964. Induction of the formation of complexes between aspartic acid and indolyl-3-acetic acid or 1-naphthaleneacetic acid by other carboxylic acids. Nature. 201:1009-1010.

152. Swanson, C. A. and J. B. Whitnay. 1953. Studies on the translocation of foliar applied $\mathrm{p}^{32}$ and other radioisotopes in bean plants. Amer. J. Bot. 40:816-832.

153. Swingle, C. F. 1940. Regeneric and vegetative propagation. Bot. Rev. 6:301-355.

154. Tang, Y. U. and J. Bonner. 1947. The enzymatic inactivation of indoleacetic acid. I. Some characteristics of the enzyme contained in pea seedlings. Arch. Biochem. 13:11-25.

155. Thimann, K. V. 1935. On the plant growth hormone produced by Rhizopus suinus. Jour. Biol. Chem. 109:279-291.

156. 1948. Use of 2,4-D herbicides on some woody tropical plants. Bot. Gaz. 109:334-340.

157. 1963. Plant growth substances: past, present and future. Ann. Rev. Plant Physiol. 14:1-18.

158. and J. B. Koepfli. 1935. Identity of the growthpromoting and root-promoting substances of plants. Nature. 135:101-102. 
159. and J. Behnke. 1947. The use of auxins in the rooting

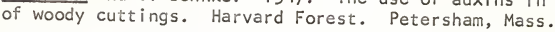

160. and I. F. Wardlaw. 1963. The effect of light on the uptake and transport of indoleacetic acid in the green stem of the pea. Physiol. Plantarum. 16:368-377.

161. Troxler, R. F. and R. H. Hamilton. 1965. The metabolism of indole-3-acetic acid by geranium stem callus cultures. Plant Physiol. 40:400-405.

162. Tukey, H. B. and J. V. Morgan. 1963. Injury to foliage and its effects upon the leaching of nutrients from above-ground plant parts. Physiol. Plantarum. 16:557-564.

163. Turetskaya, R. Kh. 1957. Radioactive carbon investigation of the uptake and distribution of growth regulators in plant cuttings. Plant Physiol. (Fiziologiya Rastenii). 4:42-51.

164. Umbreit, W. W., R. H. Burris and J. F. Stauffer. 1964. Manometric Techniques. 4th ed. Burgess Publishing Company, Minneapolis.

165. Van Overbeek, J. 1952. Agricultural application of growth regulators and their physiological bases. Ann. Rev. Plant Physiol. $3: 87-108$.

166. 1956. Absorption and translocation of plant regulators.
Ann. Rev. Plant Physiol. 7:355-372.

167. and L. E. Gregory. 1945. A physiological separation of two factors necessary for the formation of roots on cuttings. Amer. J. Bot. 32:336-341.

168. S. A. Gordon and L. E. Gregory. 1946. An analysis of the function of the leaf in the process of root formation in cuttings. Amer. J. Bot. 33:100-107.

169. Veldstra, H. 1953. The relation of chemical structure to biological activity in growth substances. Ann. Rev. Plant Physiol. 4:151-198.

170. Wagenknecht, A. C. and R. H. Burris. 1950. IAA inactivating enzymes from bean roots and pea seedlings. Arch. Biochem. Biophys. 25:30-53.

171. Warmke, H. E. and G. L. Warmke. 1950. The role of auxin in the differentiation of root and shoot primordia from root cuttings of Taraxacum and Cichorium. Amer. J. Bot. 37:272-280. 
172. Weaver, R. J. and H. R. de Rose. 1946. Absorption and translocation of 2,4-D. Bot. Gaz. 107:509-521.

173. Weintraub, R. C. and J. W. Brown. 1950. Translocation of exogenous growth regulators in the bean seedling. Plant Physiol. 25:140-149.

174. J. W. Brown, M. Fields and J. Rohan. 1952. Metabolism of 2,4-Dichlorophenoxyacetic acid. 1. $\mathrm{C}^{14} \mathrm{O}_{2}$ production by bean plants treated with labeled 2,4-Dichlorophenoxyacetic acid. Plant Physiol. 27:293-301.

175. Went, F. W. 1935. Hormones involved in root formation. Proc. 6th Int. Bot. Cong. 2:267-269.

176. 1938. Specific factors other than auxin affecting growth and root formation. Plant Physiol. 13:55-80.

177. 1941. Polarity of auxin transport in inverted tagetes cuttings. Bot. Gaz. 103:386-390.

178. and R. White. 1939. Experiments on the transport of auxin. Bot. Gaz. 100:465-484.

179. and K. V. Thimann. 1949. Phytohormones. 2nd ed. Macmillan, New York.

180. White, P. R. 1939. Potentially unlimited growth of excised plant callus in an artificial nutrient. Amer. J. Bot. 26: 59-64.

181. Wilcox, H. 1954. Regeneration of injured root systems in Noble Fir. Bot. Gaz. 116:221-234.

182. Wolfe, F. 1934. Origin of adventitious roots in Cotoneaster Dammeri. Bot. Gaz. 95:686-694.

183. Yamaguchi, S. and A. S. Crafts. 1958. Autoradiographic method, of studying absorption and translocation of herbicides using $\mathrm{C}^{14}$ labeled compounds. Hilgardia. 28:161-191.

184. and 1959. Comparative studies with labeled herbicides on woody plants. Hilgardia. 29:171-204.

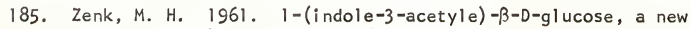
compound in the metabolism of indole-3-acetic acid in plants. Nature. 191:493-494.

186. 1962. Aufnahme und Stoffwechsel von $\alpha$-NaphthylEssigsaure durch Erbsenepicotyle. Planta. 58:75-94. 
187. Zimmerman, P. W. 1943. Present status of "Plant Hormones." Indus. \& Eng. Chem. 35:596-601.

188. , W. Crocker and A. E. Hitchcock. 1933. Initiation and stimulation of roots from exposure of plants to carbon monoxide gas. Contr. Boyce Thomp. Inst. 5:1-17.

189.
adventitious roots caused by unsaturated hydrocarbon stimulation of Boyce Thomp. Inst. 5:351-369.

190.

and $F$. Wilcoxon. 1935. Several chemical growth substances which cause initiation of roots and other response in plants. Contr. Boyce Thomp. Inst. 7:209-229.

191. and A. E. Hitchcock. 1940. Adventitious shoots and roots induced by natural influences and synthetic growth substances. Contr. Boyce Thomp. Inst. 11:127-141. 


\section{BIOGRAPHICAL SKETCH}

Raal H. Figueroa was born September 19, 1933, in Huánuco, Perá. In December, 1951, he was graduated from Leoncio Prado High School in his hometown, Huánuco. In December, 1956, he received the degree of Agriculture Engineer from "La Molina" Agriculture University, Lima, Pera.

In March, 1957, he entered the Agricultural Experiment Station at Tingo María, Pera, serving as Assistant of the Horticulture Department until July, 1958. In August, 1958, he was admitted at the Interamerican Institute of Agricultural Sciences Graduate School, Turrialba, Costa Rica and earned the Master of Agriculture degree in November, 1959, with a major in Plant Physiology. After six months of training under the Nuclear Energy Program at Turrialba Institute, he returned to Tingo Maria, where he served as Head of the Horticulture Department until December, 1963.

In January, 1964, he entered the University of Florida Graduate School and completed requirements toward the Doctor of Philosophy degree in December, 1966.

He is member of the American Association for the Advancement of Science, the American Society for Horticultural Science, Colegio de Ingenieros del Perá, Asociación Peruana de Ingenieros Agrónomos, Phi Sigma Society (Honorary). He is married to the former Miss Flor de María Toullier. They have one child, Fernando. 
This dissertation was prepared under the direction of the Chairman of the candidate's Supervisory Committee. It was submitted to the Dean of the College of Agriculture and to the Graduate Council, and was approved as partial fulfillment of the requirements for the degree of Doctor of Philosophy.

December 17,1966

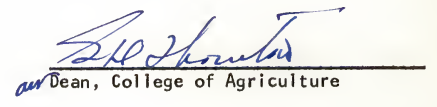

Dean, Graduate School

Supervisory Committee:

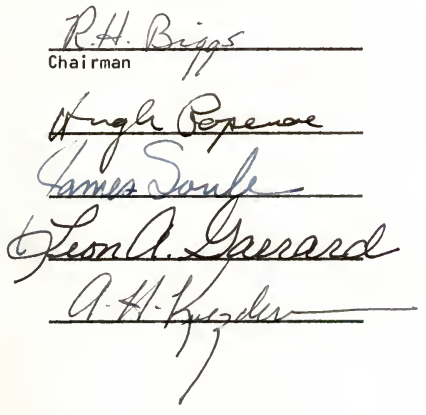

